\title{
Final Technical Report Advanced Anchoring Technology \\ DOE Award Number DE-EE0003632 \\ Project Period 09/10 - 09/12
}

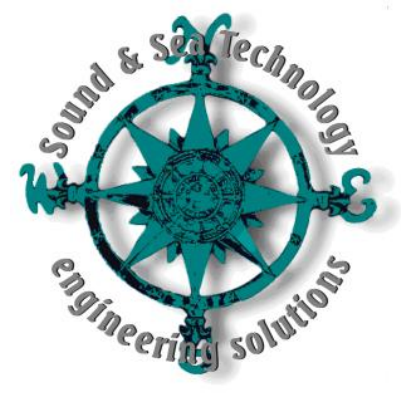

Principal Investigator:

Dallas J. Meggitt

(425) 743-1282

dmeggitt@soundandsea.com

Sound \& Sea Technology, Inc.

3507 Shelby Road

Lynnwood, WA 98097-5524

Project Team Members:

Cellula Robotics Ltd.

Geomarine Ltd.

SST Report 2012-035

09 November 2012 
Acknowledgment: "This report is based upon work supported by the U. S. Department of Energy under Award No. DE-EE0003632.“

Disclaimer: "Any findings, opinions, and conclusions or recommendations expressed in this report are those of the author(s) and do not necessarily reflect the views of the Department of Energy"

\section{LIST OF ACRONYMS}

MHK Marine Hydro-Kinetic

ROV Remotely Operated Vehicle

TBD To Be Determined

TRL Technology Readiness Level

NEPA National Environmental Policy Act

CWA Clean Water Act

USACE US Army Corps of Engineers

EPA Environmental Protection Agency

OTEC Ocean Thermal Energy Conversion

MMA Grouted Marine Micropile Anchor

LCOE Levelized cost of electricity

OPT Ocean Power Technology

CPT Columbia Power Technology

DWW Deep Water Wind

FPSO Floating Production Storage Offloading

ROV Remotely Operated Vehicle 


\section{TABLE OF CONTENTS}

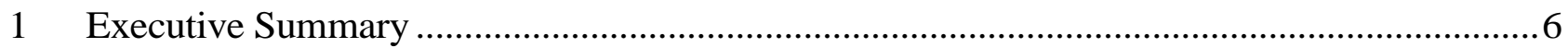

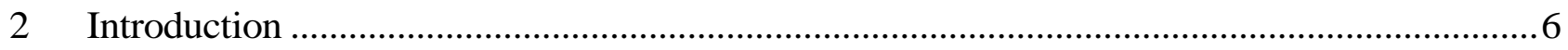

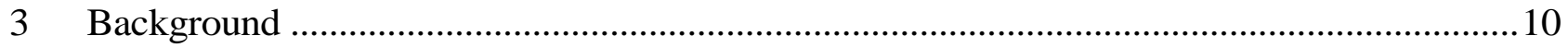

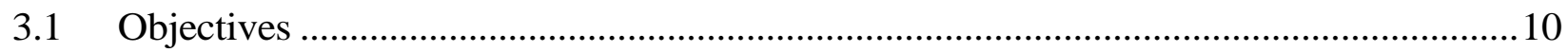

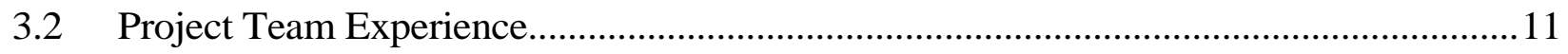

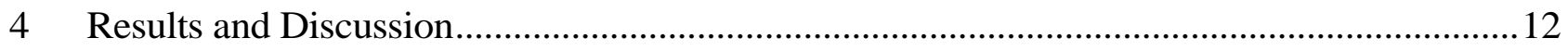

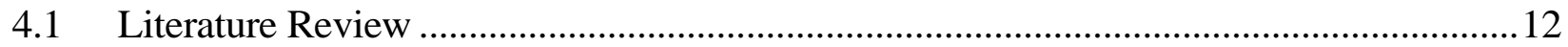

4.1.1 Design Codes and Practice................................................................................... 12

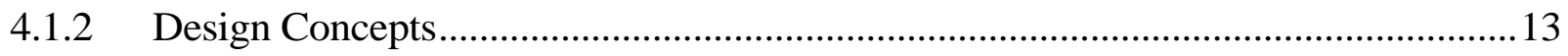

4.1.3 The Load Resistance Mechanism ..........................................................................13

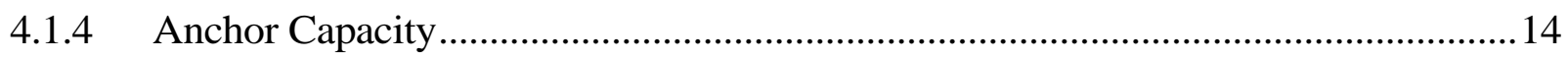

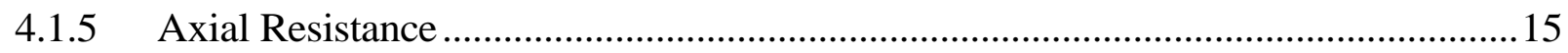

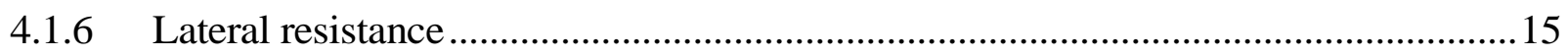

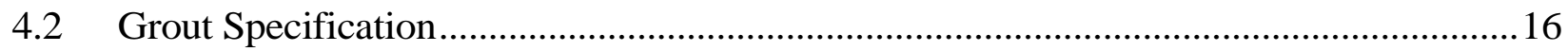

4.3 Drilled Grouted Anchor Testing ………………...................................................... 16

4.3.1 Purpose and Objectives ..................................................................................... 16

4.3.2 Initial Installation Concept ……………………................................................. 17

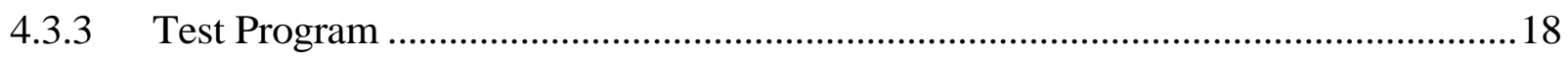

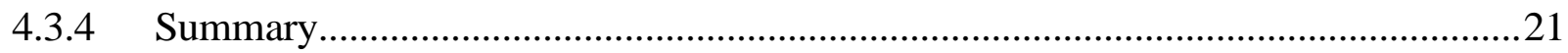

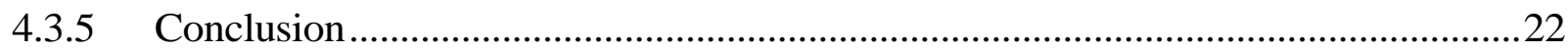

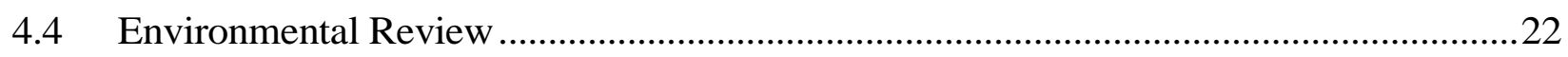

4.4.1 Scope

4.4.2 Systems Engineering Requirements ....................................................................22

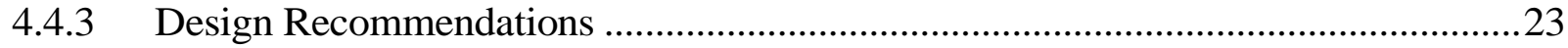

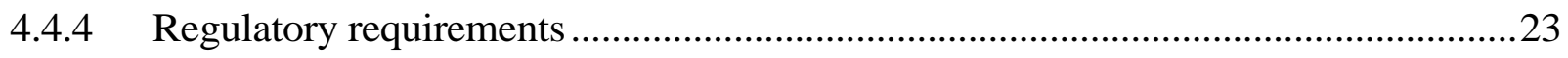

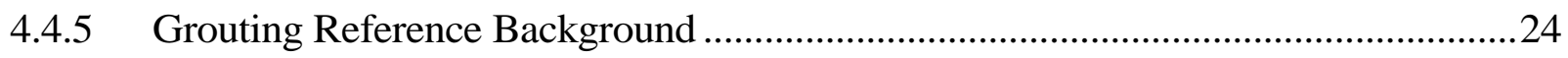

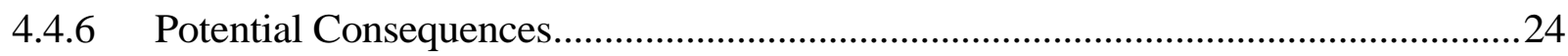

4.4.7 System Engineering Guidance for Complying with The Clean Water Act, Section

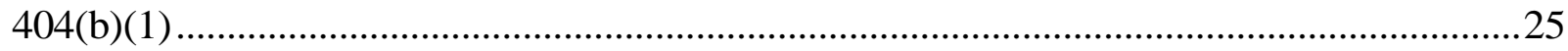


4.5 Drilled Grouted Anchor Conceptual Designs......................................................25

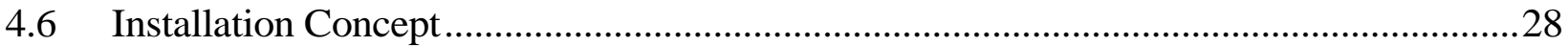

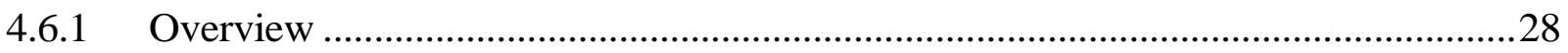

4.6.2 Availability of Sea Floor Drilling Rigs .........................................................29

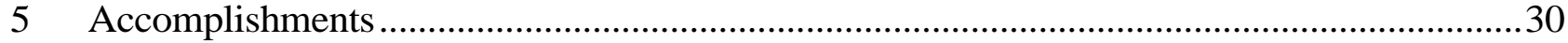

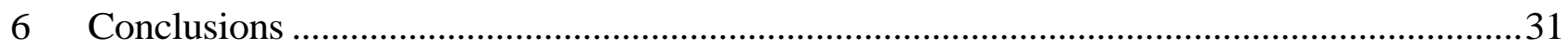

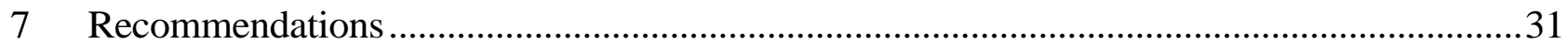

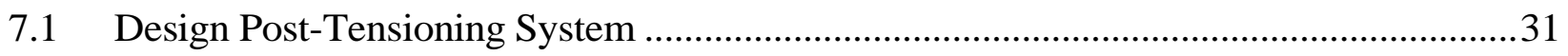

7.2 Design, Fabricate and Test/Demonstrate Single Micropile Prototype That Incorporates Grout Injection and Instrumentation and Post-Tensioning. Test Terrestrially, Pierside, In-Situ,

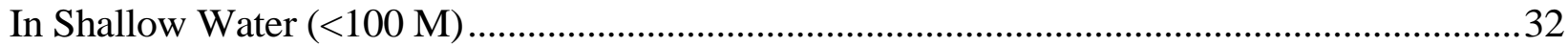

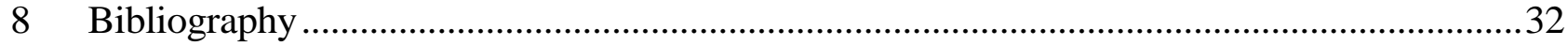

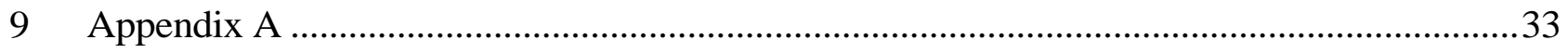

\section{TABLE OF FIGURES}

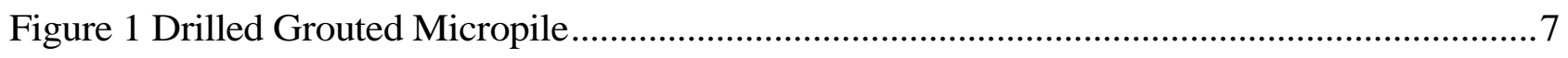

Figure 2 Conceptual Drilled Grouted Micropile for Directional Loading (courtesy

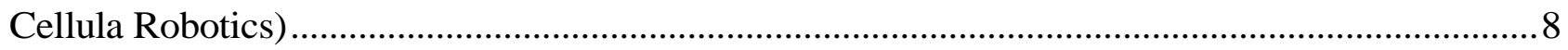

Figure 3 Rectangular Template Eight-Micropile System ～(courtesy Cellula Robotics)8

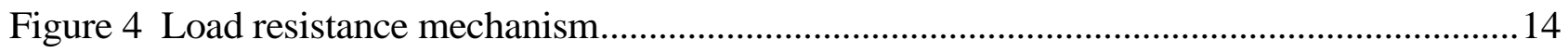

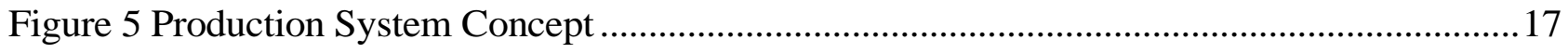

Figure 6 Overall Experimental/Investigative Program .......................................................20

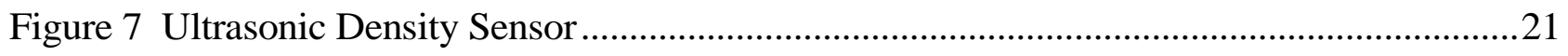

Figure 8 Template designs suitable for angled micropile installations (courtesy Cellula Robotics)26

Figure 9 Template designs suitable for vertical micropile installations (courtesy Cellula Robotics)26

Figure 10 Template design with rails for production line micropile installation, showing drilling

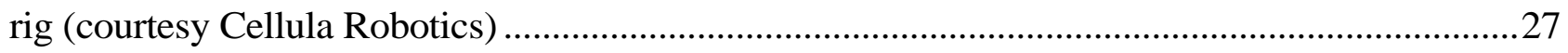

Figure 11 Images of Canyon Offshore Rovdrill2 sea floor drilling rig .....................................30 


\section{TABLE OF TABLES}

Table 1 Project Team Experience Related to Subsea Systems ................................................ 12

Table 2 Ischebeck "Titan” micropile no. 103/51 NB: maximum working load includes FoS 2.0 on

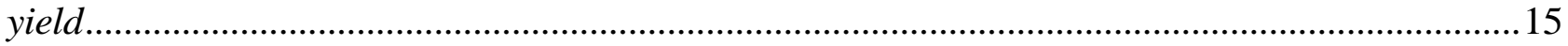

Table 3 General micropile system installation sequence ...................................................28

Table 4 List of Robotic Seabed Drilling Rigs .....................................................................29 


\section{Executive Summary}

It is generally conceded that the costs associated with current practices for the mooring, anchoring, or foundation systems of Marine HydroKinetic (MHK) and Deepwater Floating Wind systems are a disproportionate portion of the total cost of an installed system. Reducing the cost of the mooring and anchoring components for MHK systems can contribute substantially to reducing the levelized cost of electricity (LCOE). Micropile anchors can reduce the LCOE both directly, because the anchors, associated mooring hardware and installation costs are less than conventional anchor and mooring systems, but also because micropile anchors require less extensive geotechnical surveys for confident design and proper implementation of an anchor or foundation system.

This report presents the results of the development of critical elements of grouted marine micropile anchor (MMA) technology for application to MHK energy conversion systems and other ocean engineering applications that require fixing equipment to the seafloor. Specifically, this project identified grout formulations and developed designs for grout dispensing systems suitable for use in a seawater environment as a critical development need for successful implementation of practical MMA systems.

The project conducted a thorough review of available information on the use of cement-based grouts in seawater. Based on this review and data available from commercial sources, the project selected a range of grout formulations for testing as part of a micropile system. The project also reviewed instrumentation for measuring grout density, pressure and flow rate, and integrated an instrumentation system suitable for use with micropile installation.

The grout formulations and instrumentation system were tested successfully and demonstrated the suitability of MMA technology for implementation into anchor systems for MHK and other marine renewable energy systems.

In addition, this project developed conceptual designs for micropile anchor systems and the associated drilling and grouting systems to demonstrate the feasibility and practicality of micropile anchors. This report presents several conceptual system designs for different applications.

This project has concluded that grouted marine micropile anchor technology is practical and very attractive technically and financially for marine renewable energy applications. This technology is considered to be at a Technology Readiness Level 5.

\section{Introduction}

This research project is based on the concept of using a remotely operated subsea drill rig, to drill, install and grout small-diameter drilled grouted micropile anchors, which, when considered in group response, would be capable of withstanding the loadings associated with Marine Hydrokinetic (MHK) devices. 
A schematic of a drilled grouted micropile is shown in Figure 1. The micropile is hollow to allow grout to be dispensed at the sacrificial drill bit. Pile segments are connected via couplings to achieve the desired pile length, which can vary from 6 to $20 \mathrm{~m}$ depending on soil/rock type and strength. The grout body adheres to the pile and to the anchoring medium and pile capacity typically depends on the bond strength between the grout and soil/rock interface.

The most common use of drilled grouted micro-pile anchors in terrestrial applications is for slope stabilization. In this application, post-process, post-cure, pull testing typically is used to verify the quality of the installation. The consequences of failure are low, the installation costs are comparatively low, and there is a human in the loop to correct any problems that occur during the installation process. In subsea applications, the process and quality assurance methodologies must be much different because the environment is much different. The overhead cost of the at-sea installation process is much higher. It is dominated by the cost of a vessel that is expected to be dedicated to the installation.

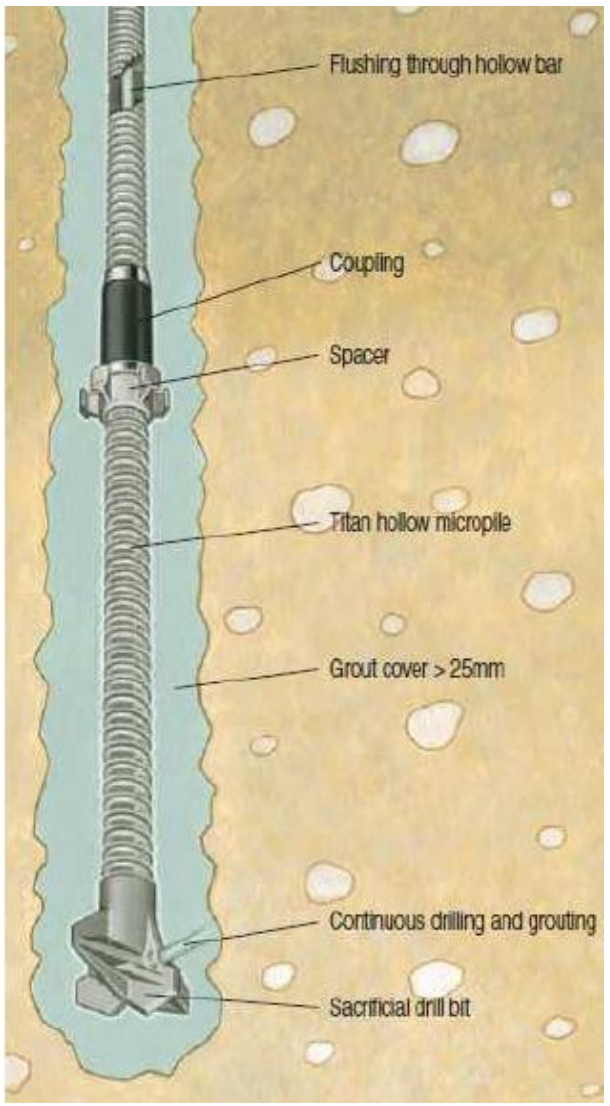

Figure 1 Drilled Grouted Micropile It is much more expensive (and not practical in many applications) to have a human at the installation site (underwater) where visibility can be extremely poor, currents and wave action can be high, and other challenging conditions can be present.

Installation sites typically are chosen in high energy environments, leading to large hydrodynamic forces on the tools and tooling during installation. While drilled, grouted piles are installed underwater today, the large diameter monopiles typically used to anchor or support tidal, in-river hydro and offshore wind energy generation systems are very different from the micropile technology that is the subject of this development. A key difference between large diameter monopile installations and Drilled Grouted Micropiles is the number of piles installed (and therefore grouting operations to be completed). Typically there is just one monopile, with no joints, and only one grouting operation. With drilled grouted micropiles, we expect to install many smaller piles, assembled together in groups of 3 or 4 piles, with typically 8-16 bore holes per anchor assembly. Figure 2 shows a conceptual drilled grouted micropile anchor system with piles oriented to resist primarily tensile loading at the top. Figure 3 shows an isometric view of a dual drilling system with an eight micropile template at bottom. 


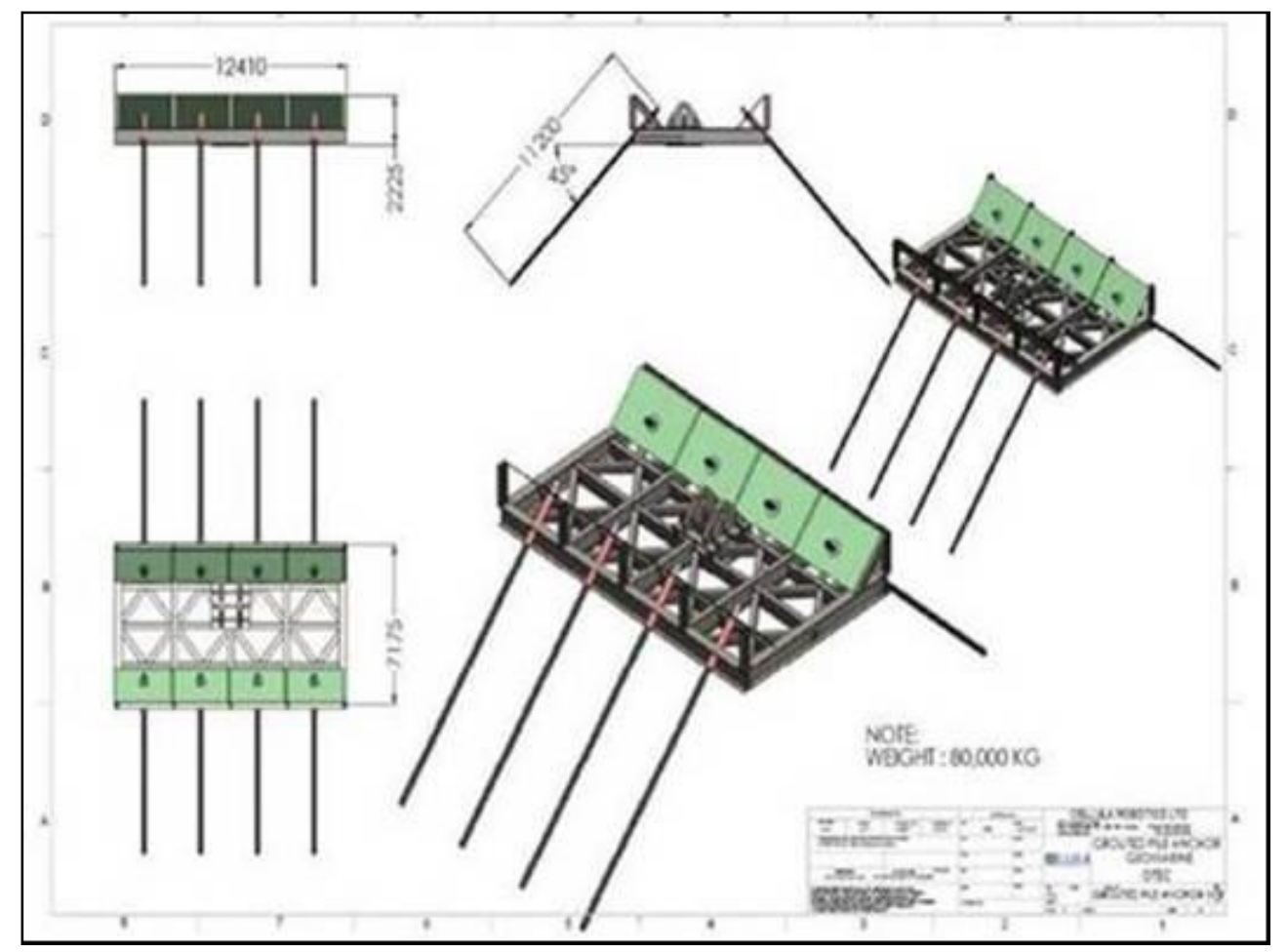

Figure 2 Conceptual Drilled Grouted Micropile for Directional Loading (courtesy Cellula Robotics)

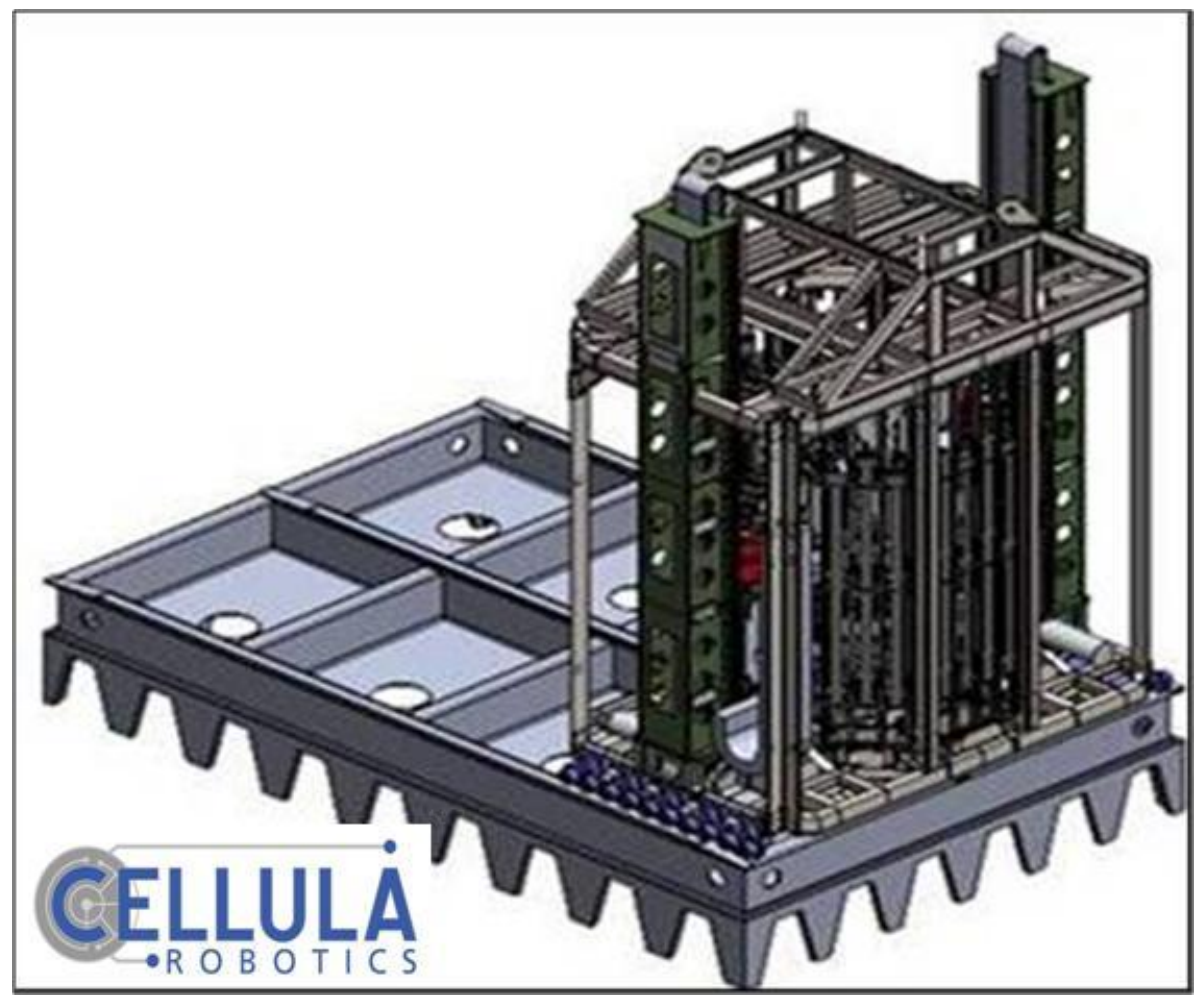

Figure 3 Rectangular Template Eight-Micropile System (courtesy Cellula Robotics) 
It is generally conceded that the costs associated with current practices for the mooring, anchoring, or foundation systems of Offshore Wind (especially floating) and Marine HydroKinetic (MHK) systems are a disproportionate portion of the total cost of an installed system. Reducing the cost of the mooring and anchoring components for MHK systems can contribute substantially to reducing the levelized cost of electricity (LCOE). Micropile anchors can reduce the LCOE both directly, because the anchors, associated mooring hardware and installation costs are less than conventional anchor and mooring systems, but also because micropile anchors require less extensive geotechnical surveys for confident design and proper implementation of an anchor or foundation system. Current conventional survey practices for offshore wind and MHK geotechnical surveys generally include a drill ship coring into the seabed, and subsequently taking cone penetrometer measurements, often with a separate vessel, to characterize the strength and composition of the seabed. In particular, these surveys identify the seabed layers and the engineering properties of each. Cone penetrometer measurements cannot be done in rock or other hard bottoms, and are probably unusable for MHK systems that are likely to be located at hard-bottom sites (e.g., tidal systems). The survey information is used to identify and design an appropriate anchoring or foundation system appropriate for that site. Clearly, this process is both time-consuming and expensive.

Micropile systems require less geotechnical information because the drilling process itself provides information on the formation being drilled through. This results in a significant cost saving for MHK systems.

Marine micropile systems can be utilized in a broad range of bottom-fixing applications. In addition to MHK anchors and moorings, other applications include deep-water floating wind, wind and wave resource assessment systems (e.g., WindSentinel), pipeline stabilization, OTEC, and floating production, storage and offloading (FPSO) platforms. The initial target markets for the micropile anchor and foundation technology are:

- Marine renewable energy projects, specifically including wave, tidal and offshore floating wind (this is the initial market). The customers in this market are the individual device developers (e.g., Wavebob, OPT, CPT, Atlantis, Clipper Wind) and developers of wave, tidal and deepwater wind projects (i.e., "farms"). In addition, system designers and integrators, and installers are target customers.

- Ocean engineering and oilfield applications, specifically including pipeline stabilization and anchoring offshore structures. Target customers for these applications include all of the major offshore project developers (e.g., Woodside, BHP Billeton, Chevron, others).

According to the European Union's published data, the foundation costs represent $21 \%$ of the costs of an offshore wind development. Other EU studies suggest that for future Deepwater (floating) Wind (DWW) and MHK projects, the percentage of the anchoring or foundation will be even greater as water depths increase, up to $40 \%$ of the total cost of the system. MMA systems have the potential to reduce these costs substantially. We have conducted cost trade studies that indicate MMA system costs should be about $10 \%$ of the overall cost of a MHK or DWW system. 
The UK and other marine-energy rich countries such as Ireland and Portugal plan to increase the proportion of their energy from marine renewable sources to approximately $10 \%$ of their total energy requirements by 2020-2030. The total investment is estimated to be in excess of $\$ 500$ bn over a 20 -year period, based on published data. Similar data for DWW estimate an investment of about $\$ 275 \mathrm{bn}$ over a similar period. The total investment in MMA target markets is about $\$ 775 \mathrm{bn}$ over 20 years. We have estimated an initial market penetration of about $10 \%$, increasing by about $5 \%$ per year, to $50 \%$ over the first ten years. This results in an estimated potential revenue of $\$ 12.6 \mathrm{bn}$ total over ten years.

The adoption of MMA technology will be paced by acceptance by the MHK/DWW developers and the offshore installation industry. Historically, both of these industries have been relatively fast to adopt new technologies where it can be shown that the technology offers substantial cost benefits. We believe that to be the case with MMA. We have estimated gradual market penetration beginning at about $10 \%$, and increasing by $5 \%$ per year over the first ten years.

\section{Background}

\subsection{Objectives}

Currently, anchoring and mooring systems are a substantial and disproportionate share of the installed cost of MHK devices. These devices will tend to be most favorably located in dynamic and high energy marine environments. Industry expectations are that such environments will frequently coincide with the presence of more severe seafloor conditions, e.g. harder outcrops of soil sediments, rocky reefs, steeper slopes and the like. There will be a clear driver from industry to innovate and improve anchoring and anchoring technologies available for use in such conditions, both to improve survivability and to reduce costs.

Specifically MHK Energy Systems might have to be moored in the following areas:

- Where traditional anchoring systems are impractical, e.g. rocky bottoms such as lava flows or areas of high currents, steep slopes

- Where remotely operated technologies are mandated or desirable, such as in deep water or areas of high currents and low visibility

Today, the anchoring solution typically employed is based on a gravity anchor. Typically this involves filling a large underwater structure with high-density ore. This solution is limited in its application, particularly in cases of rugged and/or steep seabeds. The mass and volume involved also require the use of costly installation vessels and equipment.

An alternative and novel solution for an anchor system relies on secure attachment to the seabed instead of a friction force for anchor holding capacity. It uses Grouted Pile Anchor technology, which is commonly used in terrestrial construction projects. The system consists of multiple Grouted Pile Anchors secured to the seabed and joined together by a Pile Cap to form a secure, highly competent anchor. 
A grouted pile anchor solution shows potential to reduce both the capital and installation costs for MHK systems. Due to its increased flexibility of configuration, this approach also expands the site choices for an offshore energy system, likely increasing the efficiency and/or decreasing fixed and operating costs.

The objectives of this project were to:

- Reduce the capital and installation costs of Marine Hydrokinetic (MHK) Systems by developing a lower cost and more flexible anchoring technology to at least Technology Readiness Level (TRL) 4, Proof of Concept

- Perform critical research and development activities that will significantly decrease the costs of anchoring MHK systems in shallower water depths (to 100 meters) and in areas with rocky bottoms

- Expand MHK site selection possibilities, leading to a greater number of available and more optimal locations

- Advance the technology required to remotely attach MHK anchoring systems to the ocean floor in situations where traditional anchoring technologies are impractical

- Develop a remotely controlled grouting procedure that can be applied to deepwater Grouted Pile Anchor installations with emphasis on a grout delivery control system

- Assess requirements and technologies for a Quality Control and Certification Procedure to validate deep underwater grouted pile anchor installations and conformance with identified environmental concerns

The grouting procedure and the qualification pull test procedure were identified as key technology areas that required development to advance the concept to TRL 4 . We conducted an extensive technology review of currently available grouting methodologies, both terrestrial and marine, to identify promising grout chemistries and grouting procedures. For the pull test, our plan was to use the concept validation tests as an opportunity to develop and prove a pull test apparatus and procedure scalable to the production application.

\subsection{Project Team Experience}

The project team has broad experience related to the analysis, design and testing of systems capable of operating in the subsea environment. Team members have developed unique remotely operated vehicles, drill systems, mooring design procedures, geotechnical design processes and designed foundation and anchoring systems for the military and offshore industry. Table 1 identifies key project personnel. 
Table 1 Project Team Experience Related to Subsea Systems

\begin{tabular}{|c|c|c|c|}
\hline Team Member & Qualifications & Experience & Education \\
\hline $\begin{array}{l}\text { Dallas Meggitt } \\
\text { Technical Director } \\
\text { Sound \& Sea } \\
\text { Technology, Inc. }\end{array}$ & $\begin{array}{l}\text { Professional } \\
\text { Engineer }\end{array}$ & $\begin{array}{l}40+\text { years of experience in } \\
\text { development and installation } \\
\text { of subsea systems }\end{array}$ & $\begin{array}{l}\text { BS Engineering, MS } \\
\text { Aeronautical and MS } \\
\text { Environmental Engineering, }\end{array}$ \\
\hline $\begin{array}{l}\text { Robert Taylor } \\
\text { Sound \& Sea } \\
\text { Technology, Inc. }\end{array}$ & $\begin{array}{l}\text { Professional } \\
\text { Engineer }\end{array}$ & $\begin{array}{l}40+\text { years of experience in } \\
\text { subsea geotechnical } \\
\text { engineering and anchoring } \\
\text { systems }\end{array}$ & $\begin{array}{l}\text { BS Civil and MS } \\
\text { Civil/Ocean Engineering }\end{array}$ \\
\hline $\begin{array}{l}\text { Jon Machin } \\
\text { Senior Consultant } \\
\text { Geomarine Limited }\end{array}$ & $\begin{array}{l}\text { Strong } \\
\text { background in } \\
\text { subsea drilling } \\
\text { techniques }\end{array}$ & $\begin{array}{l}\text { Over } 20 \text { years experience in } \\
\text { subsea geotechnical } \\
\text { endeavors }\end{array}$ & $\begin{array}{l}\text { MA Engineering Science, } \\
\text { University of Oxford }\end{array}$ \\
\hline $\begin{array}{l}\text { Scott Anderson } \\
\text { Project Engineer } \\
\text { Cellula Robotics Ltd. }\end{array}$ & $\begin{array}{l}\text { System } \\
\text { Engineering of } \\
\text { Subsea and } \\
\text { Space robotics }\end{array}$ & $\begin{array}{l}10+\text { years experience in } \\
\text { subsea robotics applications }\end{array}$ & $\begin{array}{l}\text { BA Sc Mechanical } \\
\text { Engineering and } \\
\text { MS Manufacturing Systems } \\
\text { Engineering }\end{array}$ \\
\hline $\begin{array}{l}\text { Eric Jackson } \\
\text { Cellula Robotics Ltd. }\end{array}$ & $\begin{array}{l}\text { Professional } \\
\text { Engineer }\end{array}$ & $\begin{array}{l}32 \text { years of project experience } \\
\text { in advanced subsea and } \\
\text { terrestrial robotic systems }\end{array}$ & $\begin{array}{l}\text { BS Engineering and Master } \\
\text { of Engineering, Mechanical } \\
\text { Engineering }\end{array}$ \\
\hline $\begin{array}{l}\text { Fred Arnold } \\
\text { Sound \& Sea } \\
\text { Technology, Inc. }\end{array}$ & $\begin{array}{l}\text { Registered } \\
\text { Geologist, State } \\
\text { of California }\end{array}$ & $\begin{array}{l}20 \text { years experience in } \\
\text { geology related projects }\end{array}$ & BS Geology \\
\hline
\end{tabular}

\section{Results and Discussion}

Summary results are described below with detailed results and discussion provided in Appendix A.

\subsection{Literature Review}

This project began with a thorough review of the literature to identify codes, standards and industry practice for grouting procedures, micropile design and testing methods, compliance requirements for use of cement grout and environmental concerns, and an industry survey to determine equipment suited to remote installation, testing and certification of grouted micropiles.

The bibliography provided in Section 9 represents many of the documents reviewed. These also provide dozens of additional references.

\subsubsection{Design Codes and Practice}

Small diameter ground anchors have been used onshore for over thirty years, with various countries developing their own codes or standards. In the USA there has been no national standard or code for rock and soil anchors, although ASTM standards cover material testing. 
The U.S. Department of Transportation has also produced a comprehensive Geotechnical Engineering Circular on Ground Anchors and Anchored Systems. In the UK, BS8081 "Code of Practice for Ground Anchorages" was published in 1989 and was for a time adopted worldwide although it has recently been superseded by the Eurocodes.

While currently there are no applicable design codes for marine micropiles, designs based on British Standard BS8081 are probably among the most relevant to the technology. However this standard is primarily concerned with onshore applications and is not directly applicable to marine designs. During the course of the project, briefings have also been conducted with marine certification authorities (American Bureau of Shipping, DNV) who, while highly supportive, have advised that the micropile anchorages shall be considered "novel" and certified accordingly.

The application of pre-tensioning may therefore require load testing both immediately following installation and also at regular intervals during the life of the anchor. Alternatively a conservative approach to fatigue loading with enhanced factors of safety may be required. Detailed consideration will also duly need to be given to design for corrosion. There is a risk of some design uncertainty here, with a resultant requirement to increase the effective factor of safety.

\subsubsection{Design Concepts}

It is anticipated that typical anchor solution concepts will typically comprise an array (group) of multiple subsea micropiles, each of diameter about 100 to $150 \mathrm{~mm}$, that are drilled into the seafloor from a seabed drilling rig, and then grouted in place, through a template that forms the anchor assembly. The number of micropiles per group would depend on the application loading.

The micropiles consist of threaded hollow rods drilled into the seafloor at an adjustable angle and at variable length, depending on the seafloor material and the required axial and lateral foundation fixation holding capacity. The micropiles can be pre-tensioned immediately following installation as a means of significantly enhancing the lateral resistance of the anchor assembly.

\subsubsection{The Load Resistance Mechanism}

The anchor system would be designed to resist applied loads by a combination of actions as shown below:

- Bearing reaction, including pre-stress, provided by the spread foundation of the structural steel frame of the seabed template.

- Uplift reaction resisted by the embedded anchor elements and submerged weight of the seabed template. 
- Lateral reaction resisted by interface friction at the seabed under the net pre-stress after allowance for complimentary uplift, loss of pre-stress and the submerged weight of the seabed template.
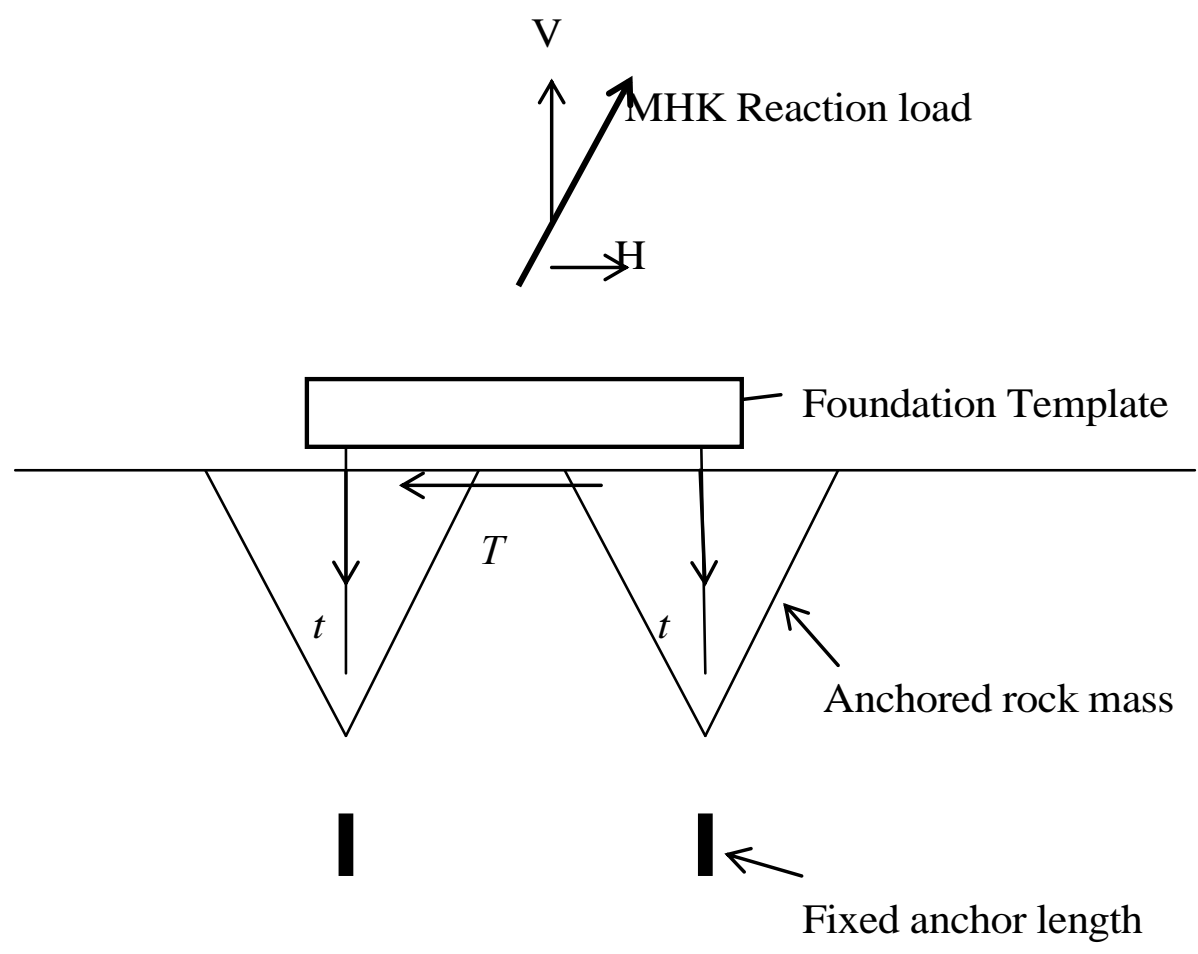

Figure 4 Load resistance mechanism

\subsubsection{Anchor Capacity}

Given the novel application, the anchor elements are in likely designed as "Type A" grouted straight shaft boreholes according to BS8081. The fixed anchor length is designed as embedded in intact (unweathered) rock, based upon the depth of the rock socket. The seabed template is considered to bear onto sediment or weathered rock at the surface of the seabed.

The Ischebeck Titan micropile has a rolled thread similar to a deformed bar, which also controls grout crack widths for durability. Details of a typical product are shown below in Table 2. 
Table 2 Ischebeck “Titan” micropile no. 103/51 NB: maximum working load includes FoS 2.0 on yield

\begin{tabular}{|l|c|c|c|c|c|c|}
\cline { 2 - 6 } \multicolumn{1}{c|}{} & \multicolumn{1}{c|}{$\begin{array}{c}\text { Effective } \\
\text { OD/ID } \\
(\mathbf{m m})\end{array}$} & $\begin{array}{c}\text { Cross } \\
\text { Section } \\
\text { Area } \\
\left(\mathbf{m m}^{2}\right)\end{array}$ & $\begin{array}{c}\text { Ultimate } \\
\text { Load }(\mathbf{k N})\end{array}$ & $\begin{array}{c}\text { Yield } \\
\text { Load } \\
(\mathbf{k N})\end{array}$ & $\begin{array}{c}\text { Max } \\
\text { Working } \\
\text { Load } \\
\mathbf{( T e )}\end{array}$ & $\begin{array}{c}\text { Nom hole } \\
\text { dia } \\
(\mathbf{m})\end{array}$ \\
\hline $\begin{array}{l}\text { Ischebeck } \\
\text { Titan }\end{array}$ & $103 / 51$ & 5680 & 3660 & 2670 & 136 & 185 \\
\hline
\end{tabular}

\subsubsection{Axial Resistance}

The pull out capacity (Tf) of a Type A anchorage is dependent upon the strength of the rock mass and is limited in BS8081 to a grout/rock bond stress of $4 \mathrm{~N} / \mathrm{mm}^{2}$ for strong rock. Similarly, the grout/tendon bond stress is limited in to $2 \mathrm{~N} / \mathrm{mm}^{2}$ for deformed bar.

Thus, the tendon/grout bond is critical. When stressed, the anchor theoretically mobilizes a cone of rock above the mid-point of the fixed length. The geometry of the rock cone depends on the degree of jointing, and the inclination of bedding planes. A $60^{\circ}$ cone angle represents a highly jointed or shattered rock, and a $90^{\circ}$ cone angle represents a competent blocky rock. Because shear at the interface between the surface of the cone and the surrounding rock is neglected, a safety factor of unity $(\mathrm{FoS}=1)$ can be taken on the weight of the rock cone, where the rock is horizontally (or sub-horizontally) bedded.

To limit interaction between fixed anchor lengths, a minimum spacing of $1.5 \mathrm{~m}$ to $2.0 \mathrm{~m}$ is recommended (BS 8081). Where anchors are spaced so closely, the individual cones overlap to partially cancel each other out, reducing the weight of rock mobilized. To increase the weight mobilized, either the spacing should be increased, or the depth of the cone increased, until the required uplift resistance is achieved.

\subsubsection{Lateral resistance}

Substantial lateral resistance of the anchor system can be mobilized via the friction resistance on the steel to soil/rock interface at the seabed and can be enhanced by a spiked or ridged bearing surface to partially penetrate the rock surface or take up irregularities.

The lateral resistance per anchor must be based upon the specific vertical/horizontal load combination. It will be necessary to include a nominal allowance for loss of pre-stress due to fatigue loading and settlement. 


\subsection{Grout Specification}

The literature review identified that certain key grout attributes would be needed for marine anchoring applications, namely:

- Non-shrinkage (expansive properties beneficial).

- Good pumpability.

- Good strength (minimum unconfined compressive strength of over 6,000psi / approx. $40 \mathrm{kN} / \mathrm{mm} 2$ at 28 days is specified in this application).

- Free of chlorides or other salts (high resistance to chemical attack when cured).

It was found that such grouts typically comprise a blend of Ordinary Portland Cement (OPC), selected fillers, plasticizers, expansion additives and waterproofing admixtures. For subsea placement, the addition of anti-washout properties was also suggested to be beneficial. Finally it was identified that manufacturers would have to be consulted to ensure that none of the chemicals or additives to be used would be harmful to the marine environment.

A detailed grout specification was prepared for the project, covering grout properties, chemical composition and also testing requirements.

Due to quality control issues and the relatively small volumes of grout required for each anchor it was recommended that pre-blended bagged grout be used, and mixed using potable water. This ensures that the QA/QC testing will correlate with manufacturer's recommendations and international design standards.

For mixing the grout, a high speed, high shear colloidal grout mixer was specified. The highspeed shearing action of a colloidal mixer achieves greater hydration of the cement by wetting each individual particle, and mixing time is significantly lower than conventional paddle

mixers. This type of mixer provides an extremely efficient and rapid means of producing high quality grout.

\subsection{Drilled Grouted Anchor Testing}

The overall experimental program is described in Appendix A. The following is an overview:

\subsubsection{Purpose and Objectives}

The objectives of these tests, as revised from the original project objectives, are as follows:

- To advance the application of renewable energy anchoring technology from TRL3 (Proof of Concept) to at least TRL4 (Component Validation in Lab Environment).

- Conduct tests to support the development of a remotely controlled grouting procedure and grout quality control system suitable for marine Grouted Pile Anchor installations. 


\subsubsection{Initial Installation Concept}

A concept for a full-scale production system is shown in Figure 7. The concept is described as follows:

- An anchor template with pre-located positions for the micropiles is placed over the target anchor location on the seafloor.

- A seafloor drill is situated over the target location of the pile. It holds one or more micro-piles, which it inserts by drilling them into the seafloor.

- The grout delivery system is connected to the drillhead at the top of the pile that is being inserted, allowing the grout to flow through the pile and out the bottom; grout is used as a flushing fluid during drilling.

- A collar is installed around the pile to capture flushing grout flow rising to the surface around the pile.

- $\quad$ Rich grout is prepared on surface and pumped to the subsea injection point via a subsea throttling valve.

- Fresh water is also supplied from the surface vessel.

- The grout mixture dilution occurs subsea with surface-supplied fresh water. Subsea (rather than surface-based) mixing reduces the time delay between a decision to change the grout/water mix (grout density) and the injection of the modified grout mixture into the hole.

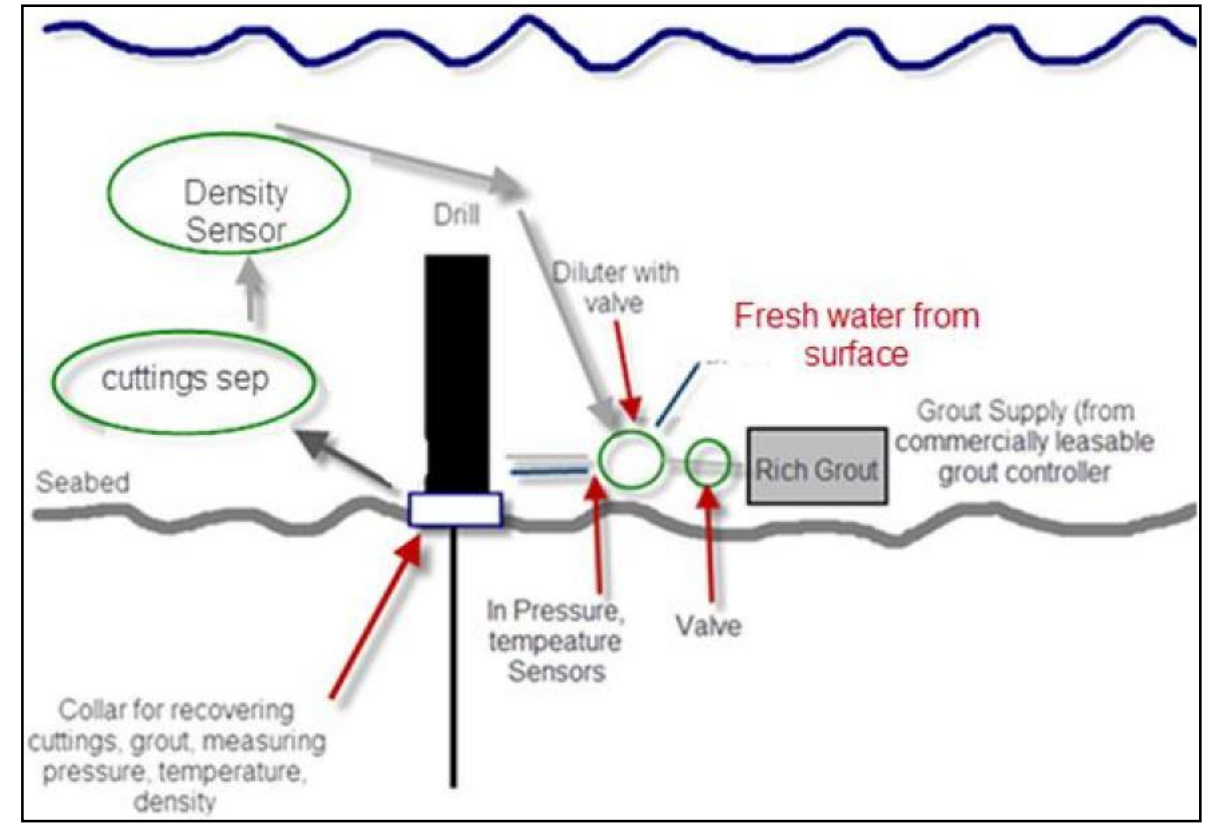

Figure 5 Production System Concept

- Some combination of water and grout is injected into the hole during insertion of the pile (i.e. drilling), controlled by a throttling valve. 
o Typically, a highly diluted grout is used during the pile insertion (drilling) stage in order to flush cuttings from the hole.

o Once pile insertion is complete, a rich grout solution (at the final water/cement ratio) is used to anchor the pile.

- The pressure of the grout entering the hole is controlled via a throttling valve situated at the connection between the grout supply hose and the drill assembly. This pressure control function is important in order to avoid over-pressuring the foundation or damaging/ disconnecting the collar.

- When flushing grout exits the hole, the cuttings are separated from the grout, e.g. through a filter.

- The density of the grout is measured as the grout exits the hole. By doing this, we expect to be able to see when all the weak, flushing grout has exited the hole and the hole is completely filled by the undiluted, rich grout.

- Due to environmental concerns in some jurisdictions, we expect to maintain a completely closed loop system, not allowing grout to mix with the ambient seawater until it is cured. This means that the weak flushing grout cannot be simply discharged into the environment, but instead will either be reused, returned to surface through a tube, or deposited into a sealed form at the anchor.

\subsubsection{Test Program}

The overall experimental/investigative program is illustrated in Figure 5. The figure is intended to illustrate the evolution of the test program as we have gained knowledge. The elements in hexagons indicate experiments or investigations; the rectangles indicate learnings.

The overall flow of the investigations, as shown in the diagram, is described briefly as follows:

- The concept for a production remotely operated subsea grouting procedure is described in the next section. The following results have been derived from evaluation of this concept:

○ understanding the effects of the marine environment (salinity, pressure, temperature) on grout setting times is critical

○ grout quality control is important, especially:

- the ability to perform real-time grout density measurement

- the ability to perform real-time grout pressure control

- We performed a literature review to learn what data exist on the influence of the subsea environment (temperature, pressure, salinity) on grout-setting time. We found that this issue has been well researched, and there is no need to perform any additional special experiments.

- We identified a candidate density sensor and defined a series of experiments to evaluate its practicality/suitability for subsea grout measurement application. 
- We identified a simple pressure control apparatus and included testing of this apparatus along with the grout density sensor experiment. To date, the following results derived from these investigations:

$\circ$ the off-the-shelf density sensor is easily marinizable to operating depths of $100 \mathrm{~m}$

$\circ$ the sensor readily detects changes in grout density over the range of interest

- We defined an integrated experiment that included a "gun-barrel" grout-setting test, combined with use of the grout density sensor and the grout pressure control apparatus. The experiment concluded with a pull test.

Based on the results of these experiments we believe that the drilled, grouted micropile anchor concept is suitable for further development for subsea applications. 


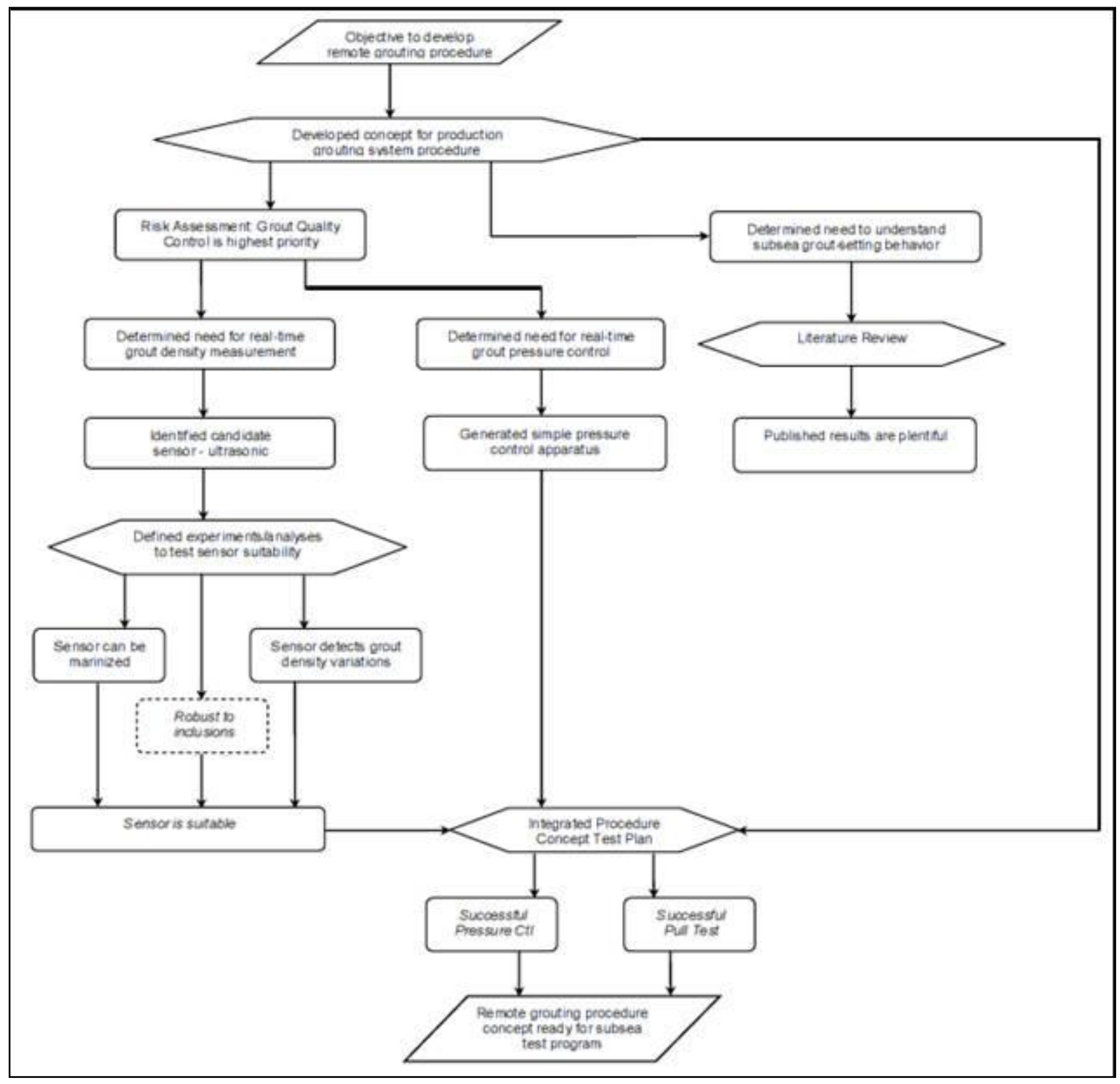

Figure 6 Overall Experimental/Investigative Program

We identified an ultrasonic density sensor, Figure 6, and performed a series of experiments to evaluate its practicality/suitability for subsea grout measurement application. The following results derived from these investigations:

- The off-the-shelf density sensor is easily marinizable to operating depths of $100 \mathrm{~m}$

- The sensor is suitable for use with grout

- The sensor readily detects changes in grout density over the range of interest 


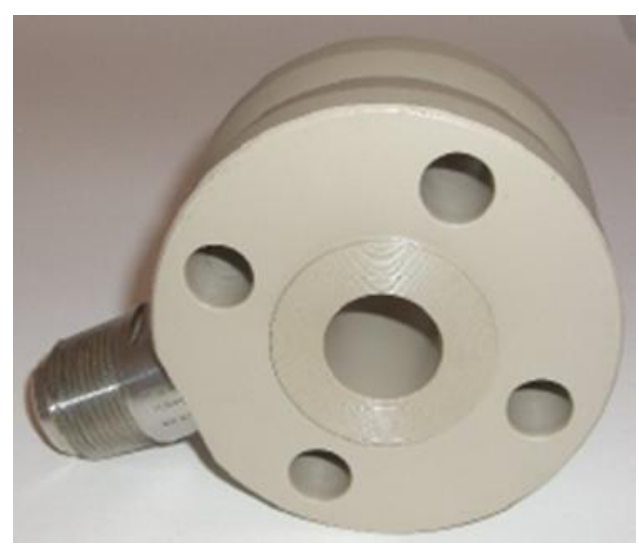

Figure 7 Ultrasonic Density Sensor

We identified a simple pressure control apparatus and tested this apparatus simultaneously with the grout density sensor. We were able to limit the injection pressure to reasonable values. If the input pressure were too high, it potentially could damage the seafloor matrix around the pile.

We performed an integrated experiment that included a "gun-barrel" grout-setting test, combined with use of the grout density sensor and the grout pressure control apparatus. The experiment concluded with a pull test.

\subsubsection{Summary}

The experimental results were intended to answer the following:

- Will the ultrasonic density sensor adequately signal the transition from the drilling (weak) grout mix to the full rich grout mix?

The ultrasonic density sensor performed very well for this purpose.

- Does the ultrasonic density sensor perform acceptably in the presence of pressure? Are there any predicted limits of pressure?

According to the manufacturer, the ultrasonic sensor is rated for shallow water depths, and from our inspection, it can be readily marinized for use in shallow sea water (less than $100 \mathrm{~m}$ ).

- Are the changes in grout density due to cuttings and inclusion of seabed materials discernible from changes in grout density due to different water/cement ratios?

This test was unsuccessful. However, the density sensor performed very well over the range of densities, and we see no reason why it would not properly measure the overall density of the combination of grout and particles. If the specific gravity of the seafloor material were significantly different from that of concrete, this mixing of seafloor material with grout could cause errors in measurement and thereby confuse the operator as to when the grout changes from a weak mixture to a rich mixture.

- Are there any significant issues regarding robustness with this sensor? 
Nothing noted. The sensor exhibited very little wear over the course of the tests. In operation, it will need to be inspected on a regular basis.

- Does the grout pressure control apparatus function? Does it show promise for automation?

The grout pressure control methodology appears to work well and will adapt readily to automation.

- Did the grout set properly?

Yes.

- Did the pull test reveal any irregularities in the experiment?

No. The Pull Test emulated a standard gun barrel test, and the results were within the normal range of behavior.

\subsubsection{Conclusion}

The experiments were successful, and we therefore believe that the drilled, grouted micropile anchor concept will be suitable for further development for subsea applications.

\subsection{Environmental Review}

\subsubsection{Scope}

A review was conducted of potential environmental consequences from, and compliance requirements for the use of Portland cement grout as a drilling mud (thinned) and as an adhesive and seal for the lower portion of a pile anchor into the ocean bottom. Grout provides an annular seal between drill bores and installed piling anchors. The grout reduces friction between the drilling equipment and the earth and offers some corrosion protection properties.

This review provides a generic view and systems engineering requirements based on this scope. As systems engineering develops and a project solidifies from concept to specification, additional specifics for environmental requirements can be raised, considered and applied as appropriate.

\subsubsection{Systems Engineering Requirements}

Installation of grouted anchors shall not cause a $\mathrm{pH}$ change of more than 0.2 units from the naturally occurring variation or any case outside the range of 6.5 to 8.5 within 1 meter of the sediment-water interface vertically and immediately outside the drill entry construction site horizontally.

Grouted anchor installation design shall comply with the Clean Water Act (US) or equivalent legislation of the host country. 


\subsubsection{Design Recommendations}

- Maintain a written environmental record of design trade studies and alternative analyses demonstrating the identification of the "least environmentally damaging practicable alternative."

- Employ a water quality modeling and decision support program such as CORMIX ${ }^{1}$ to predict and validate environmental consequences during system development and testing. This approach reduces uncertainty and improves the permitting outlook for project applications.

- Employ drilling mud recycling and isolate the bore entrance from surrounding waters. During drilling, the recycling system would avoid the release of cement grout into the surrounding water. The drill bore at the mudline would be isolated from the surrounding water and contain the release of cement grout.

- Use anti-washout admixtures to the grout to limit potential release of cement grout into surrounding waters.

- Use only bottom-up fill (aka Tremie) methods to inject the anchor grout.

\subsubsection{Regulatory requirements}

National Environmental Policy Act (NEPA) and State Environmental Policy Acts require a review of the environmental consequences of a proposed action that is available for public review before implementing the action. These laws are intended to raise the consideration of environmental consequences from afterthought to project development decision making. A well-executed NEPA process should identify all compliance requirements. The NEPA compliance process is typically a critical path work package for any project. The process is highly project and site-specific and must be planned, funded and initiated well in advance of the project installation date.

In the US, water quality impacts during construction are covered by the Clean Water Act (CWA). This law is one of few that downloads jurisdiction from the Federal government to the individual States. Each state establishes water quality standards (usually based on water uses), basically extending the reach of the law with greater specificity and applicability.

The CWA regulatory program is based on the US Army Corps of Engineers (USACE) permit program. Potential intended discharges of solid materials in quantity (cubic yards) must be approved through this program. CWA permitting is very project and site-specific. Compliance involves design decisions that are reported in the project scope documentation submitted to regulatory agencies. The regulatory permit process is typically under political pressure to be

\footnotetext{
${ }^{1}$ http://water.epa.gov/scitech/datait/models/cormix.cfm
} 
conducted without delay. Thus, one can expect a typical CWA 404/401 process to last from 6 months to a year.

Other environmental laws of importance include substantive and procedural compliance that is generally addressed in parallel with the NEPA impact assessment or the CWA permit process.

\subsubsection{Grouting Reference Background}

Background information from the Environmental Protection Agency (EPA) and US Army Corps of Engineers (USACE) was excerpted from reference materials. Other information was researched, but not included here as it tended to repeat these statements.

(EPA 1997)

- Grouting can prevent surface and cross-contamination of aquifers that have been intruded by the drill bore.

- There are differing views on the best grouting materials and placement methods. In general, full length grouting of the borehole using the Tremie method and a proper grout can help maximize thermal performance and environmental safety. See state regulations for drinking water wells.

- A popular installation method is the Tremie method.

- Because many types of grouts and placement methods exist, it is best to determine the specific cross-contamination requirements for acceptable types of grout and application methods in your state.

- Some states address well construction methods and require specific types of grouts for different geologic formations, and prescribe grouting methods that depend on whether or not the well penetrates an aquifer. Because of the relatively short length of marine micropiles, it is considered unlikely that an aquifer will be penetrated.

\section{$\underline{\text { (USACE 2006) }}$}

- Cement particles can be leached into (and contaminate) the water during underwater Tremie concrete placement.

- Jet grouting works as effectively below water as above.

- Tremie pipes can be used effectively to place underwater fills.

\subsubsection{Potential Consequences}

The following potential consequences associated with use of cement grout were described and assessed:

- Hazardous Materials and Safety

- Terrestrial surface runoff and sediment transport 
- Alkaline contamination with $\mathrm{pH}$ rise

- Cross-contamination (up/down, in/out) of underground aquifers

4.4.7 System Engineering Guidance for Complying with The Clean Water Act, Section 404(b)(1)

The following guidance is provided as a method to develop an environmental tradeoff analysis in support of design features that exceed environmental standards. Details are provided by Appendix A.

- Describe the alternatives that would meet project objectives.

- Address the practicability of the above alternatives.

- Assess the impact (adverse and beneficial) of each alternative on the aquatic ecosystem and the environment overall.

- If the alternative identified as the least environmentally damaging practicable alternative still has adverse impacts, identify how to further mitigate the effects.

\subsection{Drilled Grouted Anchor Conceptual Designs}

An element of this project has been to assess the feasibility and practicality of drilled, grouted marine micropile anchor systems for application to a broad variety of undersea systems, including specifically MHK and Deepwater Wind systems. To aid in the feasibility and practicality assessment, a range of potential conceptual designs has been developed. The general configuration concept for micropile anchors is:

- a template that provides the foundation for the anchor and is the base for the drilling system; the configuration of the template depends on the magnitude and direction of the anticipated design loads

- a number of locations on the template for the micropiles; the number and orientation of micropiles is determined by the design loads

- a means for post-tensioning the grouted micropiles

Some examples for specific applications are shown below in Figures 8 - 10. The optimum design configuration likely will depend on the overall sub-structural configuration of the MHK system. The micropile template and the sub-structure will be connected and it may be possible to fully integrate the two components into one as an attractive and potentially highly-beneficial design optimization. 


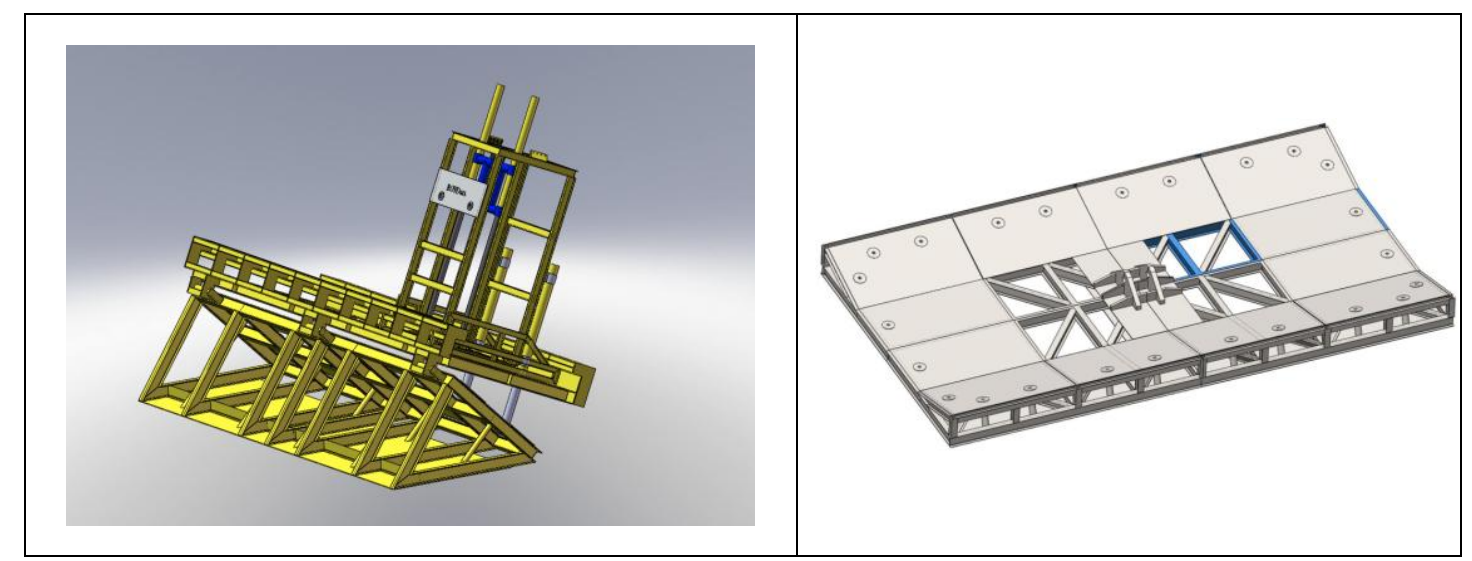

Figure 8 Template designs suitable for angled micropile installations (courtesy Cellula Robotics)

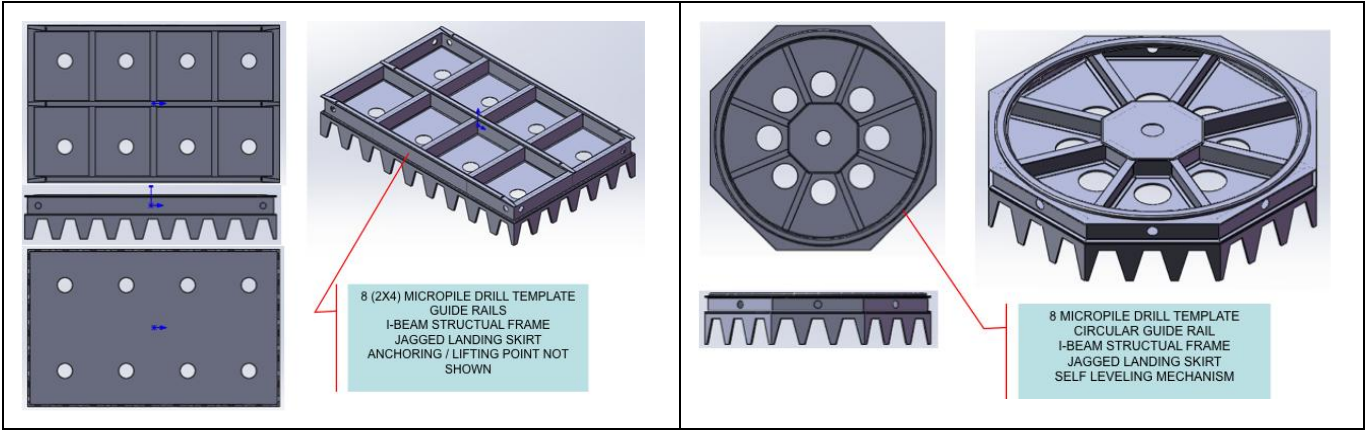

Figure 9 Template designs suitable for vertical micropile installations (courtesy Cellula Robotics)

Figure 10 shows a template design that incorporates an integrated rail system for the drilling/grouting system. This concept is for a production micropile installation system and has two drilling/grouting systems for rapid installation of the anchor. The drilling/grouting unit is indexed over the micropile locations in a manner that distributes the loads on the micropiles as they are installed. This system has the micropiles in a cassette on the drilling/grouting unit. The grout is supplied from the surface. 


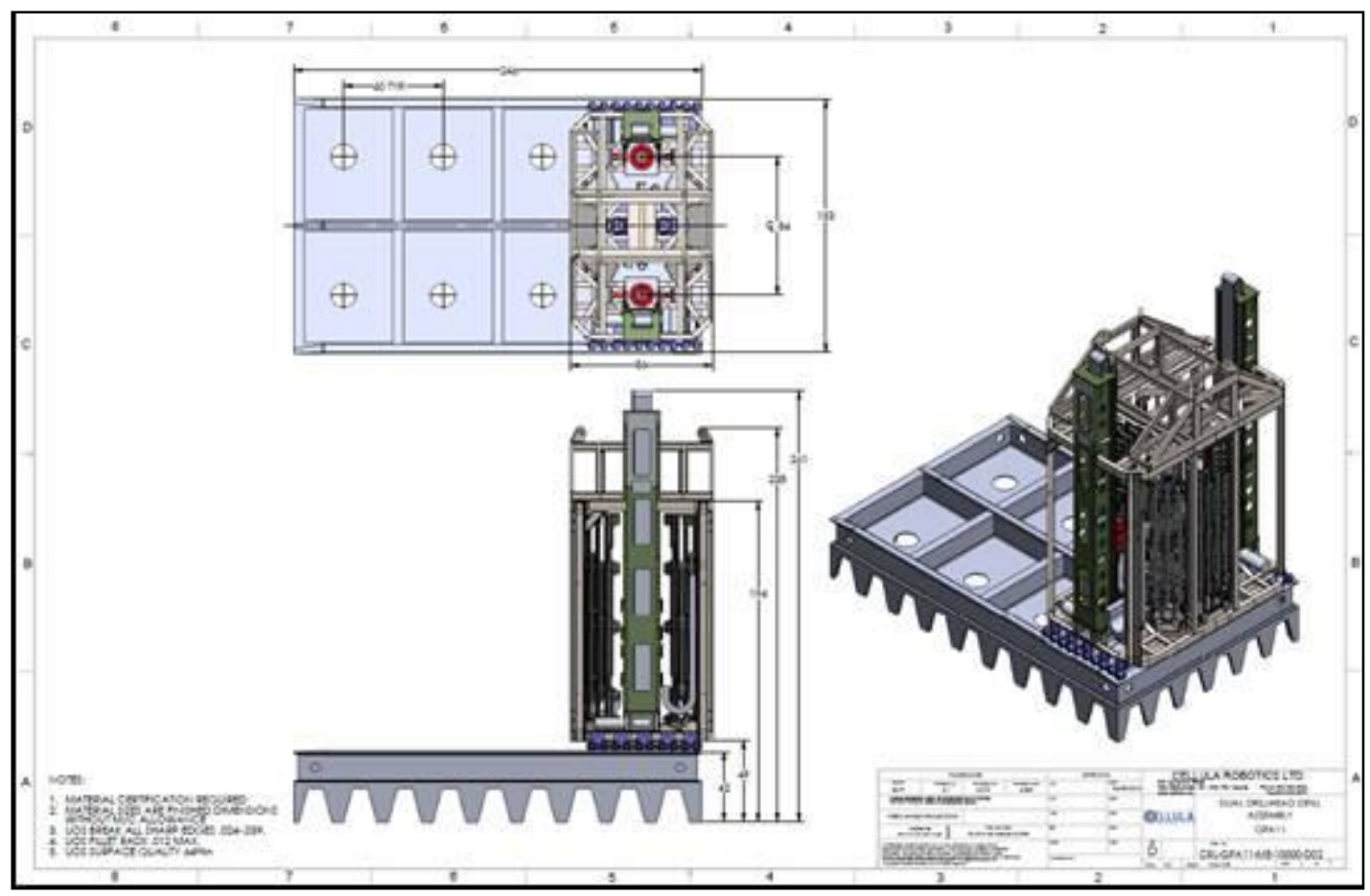

Figure 10 Template design with rails for production line micropile installation, showing drilling rig (courtesy Cellula Robotics) 


\subsection{Installation Concept}

\subsubsection{Overview}

A key advantage of marine micropile systems is that they can utilize smaller, less expensive installation vessels and likely can use existing or slightly modified subsea drilling rigs. We have included an overview of the general installation sequence and a list of existing subsea drilling rigs, below in table 3 .

Table 3 General micropile system installation sequence

1. A seafloor drill is situated over the target location of the pile. It holds one or more micropiles, which it inserts by drilling them into the seafloor.

2. The grout delivery system is connected to the drillhead at the top of the pile that is being inserted, allowing the grout to flow through the pile and out the bottom. Grout is used as a flushing fluid during drilling.

3. A collar is installed around the pile to capture flushing flow rising to the surface around the pile.

4. Rich grout is prepared on surface and pumped to the subsea injection point via a subsea throttling valve.

5. Fresh water is also supplied from the surface vessel.

6. The grout mixture dilution occurs subsea with surface-supplied fresh water. Subsea (rather than surface-based) mixing reduces the time delay between a decision to change the grout/water mix (grout density) and the injection of the modified grout mixture into the hole.

7. Some combination of water and grout is injected into the hole during insertion of the pile (i.e. drilling), controlled by a throttling valve.

8. Typically, a highly diluted grout is used during the pile insertion (drilling) stage in order to flush cuttings from the hole.

9. Once pile insertion is complete, a rich grout solution (at the final water/cement ratio) is used to anchor the pile.

10. The pressure of the grout entering the hole is controlled via a throttling valve situated at the connection between the grout supply hose and the drill assembly. This pressure control function is important in order to avoid overpressuring the foundation or damaging/ disconnecting the collar.

11. When flushing grout exits the hole, the cuttings are separated from the grout, e.g. through a filter.

12. The density of the grout is measured as the grout exits the hole. Specialist equipment for doing this has been successfully tested during the research program. By making such measurement, it is expected to be able to determine when all the weak, flushing grout has exited the hole and the hole 
is completely filled by the undiluted, rich grout. This also is the basis for QA/QC on grout quality.

13. Due to environmental concerns in some jurisdictions, it may be necessary to maintain a completely closed loop system, not allowing grout to mix with the ambient seawater until it is cured. This means that the weak flushing grout cannot be simply discharged into the environment, but instead will either be reused, returned to surface through a tube, or deposited into a sealed form at the anchor

\subsubsection{Availability of Sea Floor Drilling Rigs}

Micropiling technology takes advantage of the recent introduction of Remotely Operated Vehicle (ROV) based "robotic" seafloor drilling rigs. There are now over 14 such rigs in the world $^{2}$. A listing of the fleet of seabed drill rigs is shown on Table 1 below together with images of the "Rovdrill2" rig which is owned and operated by Canyon Offshore. This rig is regularly used on marine renewable projects in UK waters for geotechnical drilling and sampling.

Table 4 List of Robotic Seabed Drilling Rigs

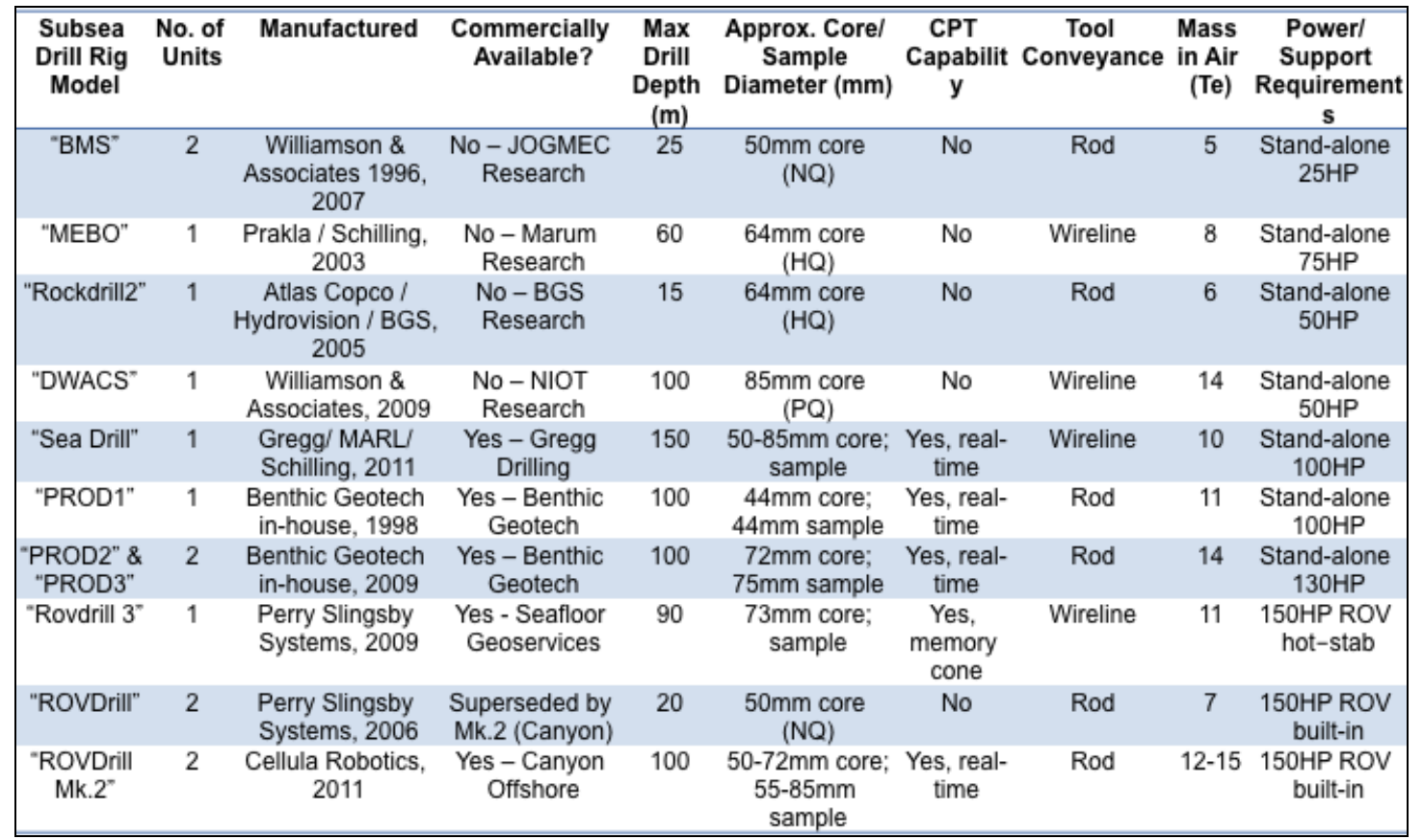

2 Edmunds, J. Machin, J., Cowie, M. "Development of the ROVDrill Mk.2 Seabed Push Sampling, Rotary Coring and In Situ testing System”, Offshore Technology Conference, Houston, TX, 2005, OTC23395. 


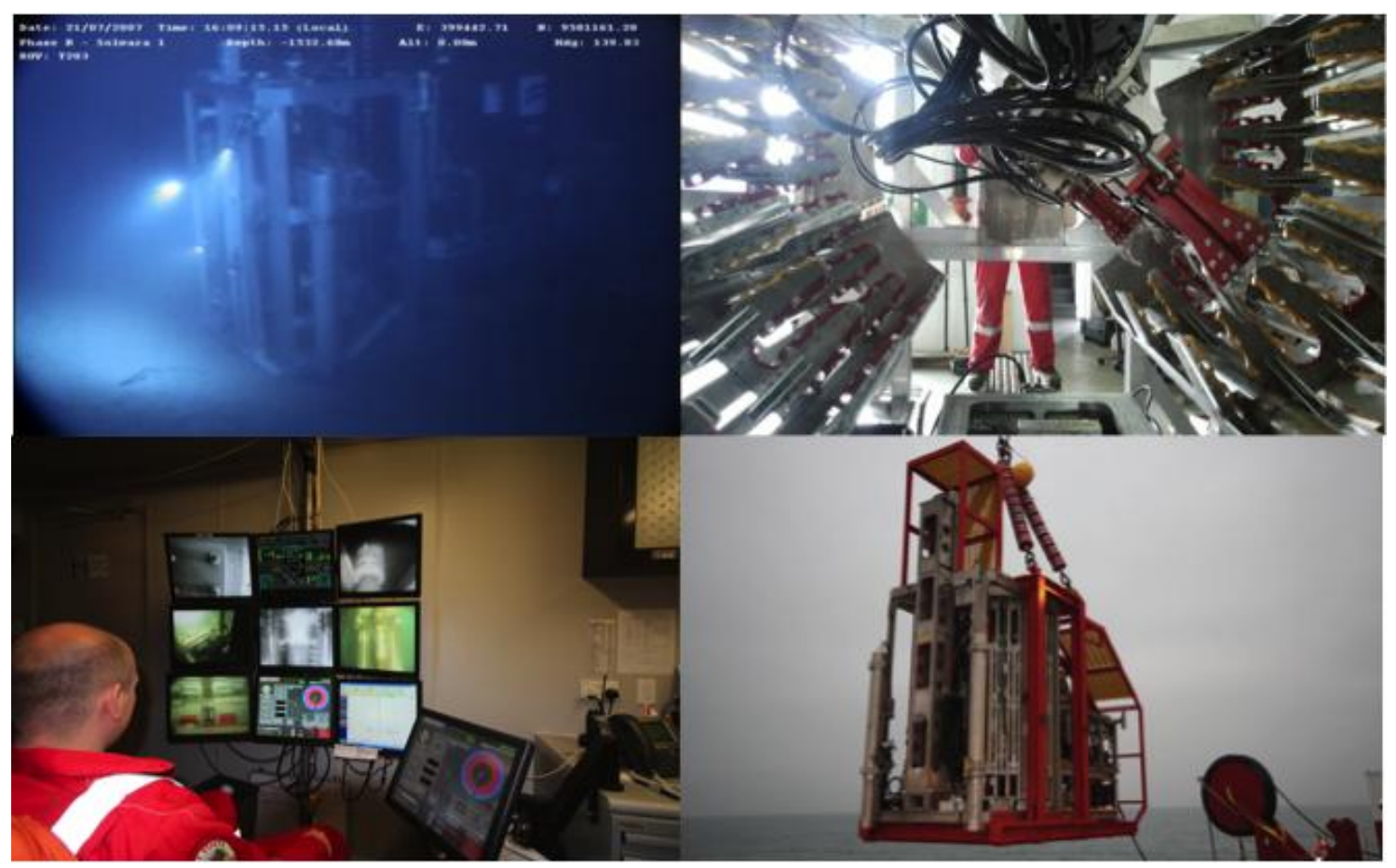

Figure 11 Images of Canyon Offshore Rovdrill2 sea floor drilling rig

\section{Accomplishments}

The technical accomplishments of this project are described in the body of this report and summarized below. The primary accomplishments are:

- Development, testing and demonstration of a grout formulation suitable for grouting drilled micropile anchors in a seawater environment. This was determined to be the key requirement for development of a practical subsea micropile anchoring technology.

- Development of a suite of instrumentation for measuring grout properties and grout injection parameters during installation of marine micropile anchors. Instrumentation suitable for subsea use is a critical element of a Measure-While-Drilling capability, which can significantly reduce the cost of geotechnical surveys required for anchor systems.

- Design and demonstration of a prototype subsea grout dispensing system that incorporates the instrumentation suite. This prototype can be further developed for a complete prototype marine micropile anchor system technology.

Our approach for informing the community of this technology development is to present papers at appropriate conferences and to present the technology to industry groups. We have prepared or are preparing abstracts for submittal to:

- The Offshore Technology Conference 
- The Oregon Wave Energy Trust Wave Energy Conference

- EnergyOcean

- Global Marine Renewable Energy Conference

- Selected EU marine renewable energy conferences

\section{Conclusions}

The tasks accomplished in this study support the following conclusions.

This study developed grout formulations suitable for use in marine micropile anchors in the seawater environment. The project demonstrated both lean formulations for use as a drilling fluid and for cuttings removal, and rich formulations suitable for final grouting.

This project demonstrated that suitable grouts could be mixed and injected into subsea drilled micropile bores and developed and demonstrated a laboratory prototype grout injection system suitable for further development for a marine micropile anchor system.

This study developed a prototype integrated instrumentation system for monitoring and controlling grout injection for a marine micropile anchor system. This project demonstrated the performance of a prototype drilled, grouted marine micropile as an element of an anchor system. The development of grout formulations, an injection system, and an instrumentation system were combined in a successful integrated test of a prototype micropile.

This project developed conceptual designs for several configurations of prototype marine micropile anchor systems. These conceptual designs show the feasibility and practicality of full-scale, fieldable marine micropile anchor systems.

Taken together, these conclusions warrant a Technical Readiness Level of TRL 5 for grouted marine micropile anchor technology.

\section{Recommendations}

\subsection{Design Post-Tensioning System}

For marine applications of micropiles, it is essential that each micropile in an anchor or other bottom fixing assembly be load tested to verify its capacity and that the load be "locked in" to maintain a prestress to counteract the stresses resulting from the applied vertical and/or lateral mooring load to the assembly. Prestressing will limit or restrict structural movement due to anchor steel elongation caused by cyclic and dynamic loads. Micropile prestressing for the purpose of achieving an anchor system capable of resisting vertical and lateral mooring loads is innovative and un-proven in the subsea environment; however, it is vital if micropiles are to be used efficiently for mooring systems. 


\subsection{Design, Fabricate and Test/Demonstrate Single Micropile Prototype That Incorporates Grout Injection and Instrumentation and Post-Tensioning. Test Terrestrially, Pierside, In-Situ, In Shallow Water (<100 M)}

Once the elements of a drilled, grouted marine micropile system have been developed, an integrated test is required to demonstrate the feasibility and practicality of the technology for utilization in MHK, Deepwater Wind and other ocean engineering application. The tests should follow the sequence of terrestrial laboratory/factory checkout tests, tests pierside in shallow water, followed by tests at nominal operating depths, here considered to be 100 meters or less.

\section{Bibliography}

1. Drilled \& Grouted Anchor Specification for Grout Report No. C1418-1-0

2. GPA11DOE Drilled Grouted Anchors Test Plan \& Report Grout Monitoring System

3. Environmental Review - Grouted Pile Anchors

4. GPA11 -DOE Drilled Grouted Anchors Dual Drill Heads Conceptual Designs

5. Federal Highway Administration, FHWA-SA-97-070, "Micropile design and construction guidelines", June 2000

6. API Recommended Practice, 2A-WSD (RP 2A-WSD) Twenty-First Edition, December 2000

7. Department of the Amy, USACE ,EM 1110-1-2908, "Engineering and Design, Rock Foundations", Nov 1994

8. PCI, EM 111O-1-2907, "Tentative Recommendations for Prestressed Rock and Soil Anchors", Feb 1980

9. Federal Highway Administration, FHWA-1F-99-015, "Geotechnical Engineering Circular No. 4, Ground Anchors and Anchored Systems", June 1999

10. Department of the Amy, USACE,EC 1110-2-6058, "Stability Analysis of Concrete Structures" ,Nov 2003

11. Bruce and Wolthrop, The National Rock Anchor Research Program, "High Capacity Rock Anchors for Dams: Thirty Years of Recommendations for Practice", 2005

12. Gómez, Cadden, and Bruce, "Micropiles Founded in Rock - Development and Evolution of Bond Stresses", 12th PanAmerican Conference on Soil Mechanics and Geotechnical Engineering June 2003

13. Bruce, Benetia and Juran, "High Capacity Grouted Micropiles: The State of Practice in the United States", 15th International Conference on Soil Mechanics and Geotechnical Engineering, August 2001.

14. Naval Civil Engineering Laboratory, "Handbook for Marine Geotechnical Engineering", March 1985

15. Williams Form Engineering Corp. "Ground Engineering Systems", No. 111U

16. Littlejohn and Bruce, "Rock Anchors, State of the Art, Ground Engineering", CIRCA 1975

17. J Halkyard \& Associates, C1070-2-0, "Preliminary Design Report", December 2010

18. CalTrans, "Bridge Design Specifications, Chapter 4, Foundations", November 2003 
19. British Standards BS EN 14199, “ Execution of Special Geotechnical Works Micropiles", 2005

20. "OTEC Anchor Installation Concept Study", CRS-GMS-OA09-RP-02-X5, 18 December 09

21. Burtz, "Behavior and Design of Grouted Anchors Loaded in Tension", MS Thesis, University of Florida, 2003

22. Smith and Calvert 1975. The use of sea water in well cementing. Journal of Petroleum Technology, Society of Petroleum Engineers SPE 5030.

23. Bruce, Heenan, Wilson; "Quality and Quantification in Rock Drilling and Grouting" Proceedings of Sessions of the Geo-Frontiers 2005 Congress, January 24-26, 2005, Austin, Texas; Sponsored by Grouting Committee and Soil Improvement Committee of the Geo-Institute of the American Society of Civil Engineers.

24. EPA (1997). Heat Pump Environmental Issues Manual: 98.

25. Fitch, G. M. (2003). Minimizing the impact on water quality of placing grout underwater to repair bridge scour damage. V. D. o. Transportation: 34.

26. USACE (2006). Engineering and Design FOUNDATION ENGINEERING: IN-THEWET DESIGN AND CONSTRUCTION OF CIVIL WORKS PROJECTS. Engineer Technical Letter No. 1110-2-565: 154.

27. EN 1997-1:2004 Eurocode 7 Geotechnical design. Part 1: General rules

28. EN 1537:2000 Execution of special geotechnical work - Ground Anchors

29. BS 8081: 1989 British Standard code of practice for Ground Anchorages

30. ASTM C 939-10 Standard Test Method for Flow of Grout for Preplaced Aggregate Concrete (Flow Cone Method)

31. ASTM C 940-10a Standard Test Method for Expansion and Bleeding of Freshly Mixed Grouts for Preplaced Aggregate Concrete.

32. ASTM C 138-10b Standard Test Method for Density (Unit Weight), Yield, and Air Content of Concrete

33. ASTM C 31-10 Standard Practice for Making and Curing Concrete Test Specimens in the Field

34. ASTM C 511-09 Standard Specification for Mixing Rooms, Moist Cabinets, Moist Rooms, and Water Storage Tanks Used in the Testing of Hydraulic Cements and Concretes

35. ASTM C 109-11a Standard Test Method for Compressive Strength of Hydraulic Cement Mortars (2in cube specimens)

36. FHWA-IF-99-015 Geotechnical Engineering Circular No. 4. Ground Anchors and Anchored Systems

\section{Appendix A}

The appendix includes the following documents, which detail the discussions in Section 4.0:

- Drilled \& Grouted Anchor Specification for Grout Report No. C1418-1-0 
- GPA11DOE Drilled Grouted Anchors Test Plan \& Report Grout Monitoring System

- Environmental Review - Grouted Pile Anchors

- GPA11 -DOE Drilled Grouted Anchors Dual Drill Heads Conceptual Designs 


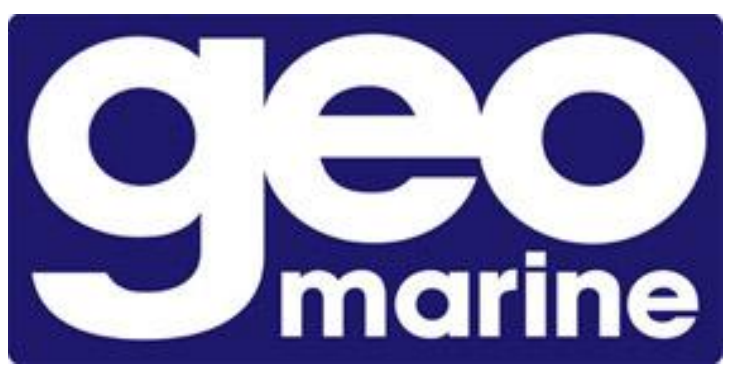

\title{
DOE Drilled \& Grouted Anchor Specification for Grout
}

\author{
Report No. C1418-1-0
}

Prepared for:

Sound \& Sea Technology

Prepared by:

Geomarine Ltd.

A2 Grainger

Prestwick Park,

NEWCASTLE UPON TYNE

NE20 9SJ

United Kingdom

\begin{tabular}{|c|c|c|c|c|}
\hline Date & Status & Rev. & Prepared & Approved \\
\hline $30 / 11 / 2011$ & $\begin{array}{l}\text { Internal } \\
\text { Review }\end{array}$ & 0 & MSF & JM \\
\hline
\end{tabular}




\section{Contents}

1 INTRODUCTION......................................................................................................................... 3

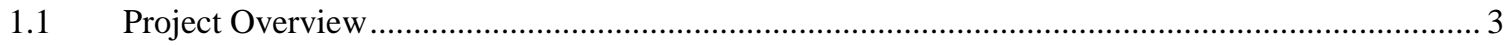

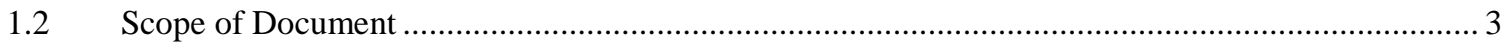

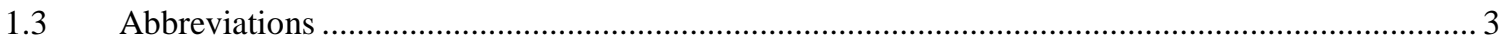

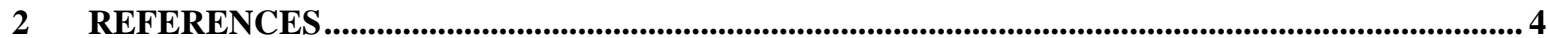

3 GROUT SPECIFICATION

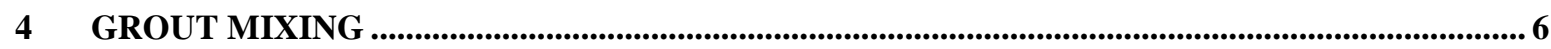

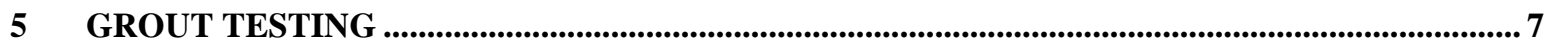

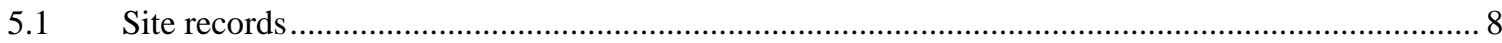

6 ADDITIONAL REPORTS .................................................................................................................... 8 


\section{INTRODUCTION}

\subsection{Project Overview}

This research project is based on the concept of using a remotely operated subsea drill rig, to drill, install and grout small diameter in-situ ground anchors which, when considered in group response, could be capable of withstanding the loadings associated with MHK devices.

One of the objectives of the project is to perform an onshore trial to demonstrate the basic components of the concept.

\subsection{Scope of Document}

One of the critical elements for the successful installation of small diameter ground anchors is identified as the grout. The materials, technology and quality control systems are reasonably well established for the installation of anchorages for civil engineering applications onshore, consequently it is intended to use commercially off the shelf (COTS) technology wherever possible as the basis for this project. However modifications to the onshore installation and quality control methods are likely to be required for subsea application.

This document addresses the material selection and quality control procedures for the selection, testing and verification of the grout for the onshore trial.

\subsection{Abbreviations}

ABS - American Bureau of Shipping

API - American Petroleum Institute

ASTM - American Society for Testing and Materials

BS - British Standards

COTS - Commercially Off The Shelf

DNV - Det Norske Veritas

ISO - International Organisation for Standardisation

MHK - Marine Hydro-Kinetic

QA - Quality Assurance

QC - Quality Control 


\section{REFERENCES}

Foundations for offshore structures in the offshore oil and gas industry are typically designed according to ISO, DNV or API standards. These standards cover the design and installation of piled structures using conventional large diameter piles which are typically of about $20 "(500 \mathrm{~mm})$ diameter or greater.

However no guidance is provide for the use of small diameter piles, typically of about 12" $(300 \mathrm{~mm})$ diameter or less. DNV acknowledge this and have stated alternate design codes, or elements of such codes can be used subject to their review and approval. ABS has also stated that they consider a small diameter drilled anchor system to be an innovative non-standard solution.

Small diameter ground anchors have been used onshore for over thirty years, with various countries developing their own codes or standards. In the UK, BS8081 was published in 1989 and was for a time adopted worldwide although it has recently been superseded by the Eurocodes. In the USA there has been no national standard or code for rock and soil anchors although ASTM standards cover material testing. The U.S. Department of Transportation has produced a comprehensive Geotechnical Engineering Circular on Ground Anchors and Anchored Systems. Table 2.1 lists the standards and documents used in the preparation of this document.

\begin{tabular}{|l|l|}
\hline $\begin{array}{l}\text { Publishing } \\
\text { Body }\end{array}$ & Title \\
\hline $\begin{array}{l}\text { EN 1997- } \\
1: 2004\end{array}$ & $\begin{array}{l}\text { Eurocode } 7 \text { Geotechnical design. Part 1: } \\
\text { General rules }\end{array}$ \\
\hline $\begin{array}{l}\text { EN } \\
1537: 2000\end{array}$ & $\begin{array}{l}\text { Execution of special geotechnical work - } \\
\text { Ground Anchors }\end{array}$ \\
\hline $\begin{array}{l}\text { BS 8081: } \\
1989\end{array}$ & $\begin{array}{l}\text { British Standard code of practice for Ground } \\
\text { Anchorages }\end{array}$ \\
\hline $\begin{array}{l}\text { ASTM C } \\
939-10\end{array}$ & $\begin{array}{l}\text { Standard Test Method for Flow of Grout for } \\
\text { Preplaced Aggregate Concrete (Flow Cone } \\
\text { Method) }\end{array}$ \\
\hline $\begin{array}{l}\text { ASTM C } \\
940-10 a\end{array}$ & $\begin{array}{l}\text { Standard Test Method for Expansion and } \\
\text { Bleeding of Freshly Mixed Grouts for } \\
\text { Preplaced Aggregate Concrete. }\end{array}$ \\
\hline $\begin{array}{l}\text { ASTM C } \\
\text { 138-10b }\end{array}$ & $\begin{array}{l}\text { Standard Test Method for Density (Unit } \\
\text { Weight), Yield, and Air Content of Concrete }\end{array}$ \\
\hline
\end{tabular}




\begin{tabular}{|l|l|}
\hline $\begin{array}{l}\text { ASTM C } \\
31-10\end{array}$ & $\begin{array}{l}\text { Standard Practice for Making and Curing } \\
\text { Concrete Test Specimens in the Field }\end{array}$ \\
\hline ASTM C & $\begin{array}{l}\text { Standard Specification for Mixing Rooms, } \\
\text { Moist Cabinets, Moist Rooms, and Water } \\
\text { Storage Tanks Used in the Testing of } \\
\text { Hydraulic Cements and Concretes }\end{array}$ \\
\hline $\begin{array}{l}\text { ASTM } \\
109-11 \mathrm{a}\end{array}$ & $\begin{array}{l}\text { Standard Test Method for Compressive } \\
\text { Strength of Hydraulic Cement Mortars (2in } \\
\text { cube specimens) }\end{array}$ \\
\hline $\begin{array}{l}\text { FHWA-IF- } \\
99-015\end{array}$ & $\begin{array}{l}\text { Geotechnical Engineering Circular No. 4. } \\
\text { Ground Anchors and Anchored Systems }\end{array}$ \\
\hline
\end{tabular}

Table 2.1: Published References 


\section{GROUT SPECIFICATION}

Grout for anchoring requires certain properties, namely:

- Non-shrinkage (expansive properties beneficial).

- Good pumpability.

- Good strength (minimum unconfined compressive strength of over 6,000psi / approx. $40 \mathrm{kN} / \mathrm{mm}^{2}$ at 28 days is specified in this application).

- Free of chlorides or other salts (high resistance to chemical attack when cured).

Such grouts typically comprise a blend of Ordinary Portland Cement (OPC), selected fillers, plasticizers, expansion additives and waterproofing admixtures. For subsea placement, the addition of anti-washout properties may be beneficial, and manufacturers should be consulted to ensure that none of the chemicals or additives are harmful to the marine environment prior to subsea use.

Due to quality control issues and the relatively small volumes of grout required for each anchor it is recommended that pre-blended bagged grout be used, and mixed using potable water. This will ensure that the QA/QC testing will correlate with manufacturer's recommendations and international design standards.

For the purposes of this project it is recommended that Meyco RBA Grout is used. This grout is designed for rock anchorages and is readily available in the US. A product data sheet and MSDS sheet are attached in Appendix A.

\section{GROUT MIXING}

For mixing the grout a high speed, high shear colloidal grout mixer should be used (see figure 4.1). The high-speed shearing action of a colloidal mixer achieves greater hydration of the cement by wetting each individual particle, and mixing time is significantly lower than conventional paddle mixers.

This type of mixer provides an extremely efficient and rapid means of producing high quality grout. ChemGrout Inc. (www.chemgrout.com) is a major manufacturer of grouting equipment in the USA. 


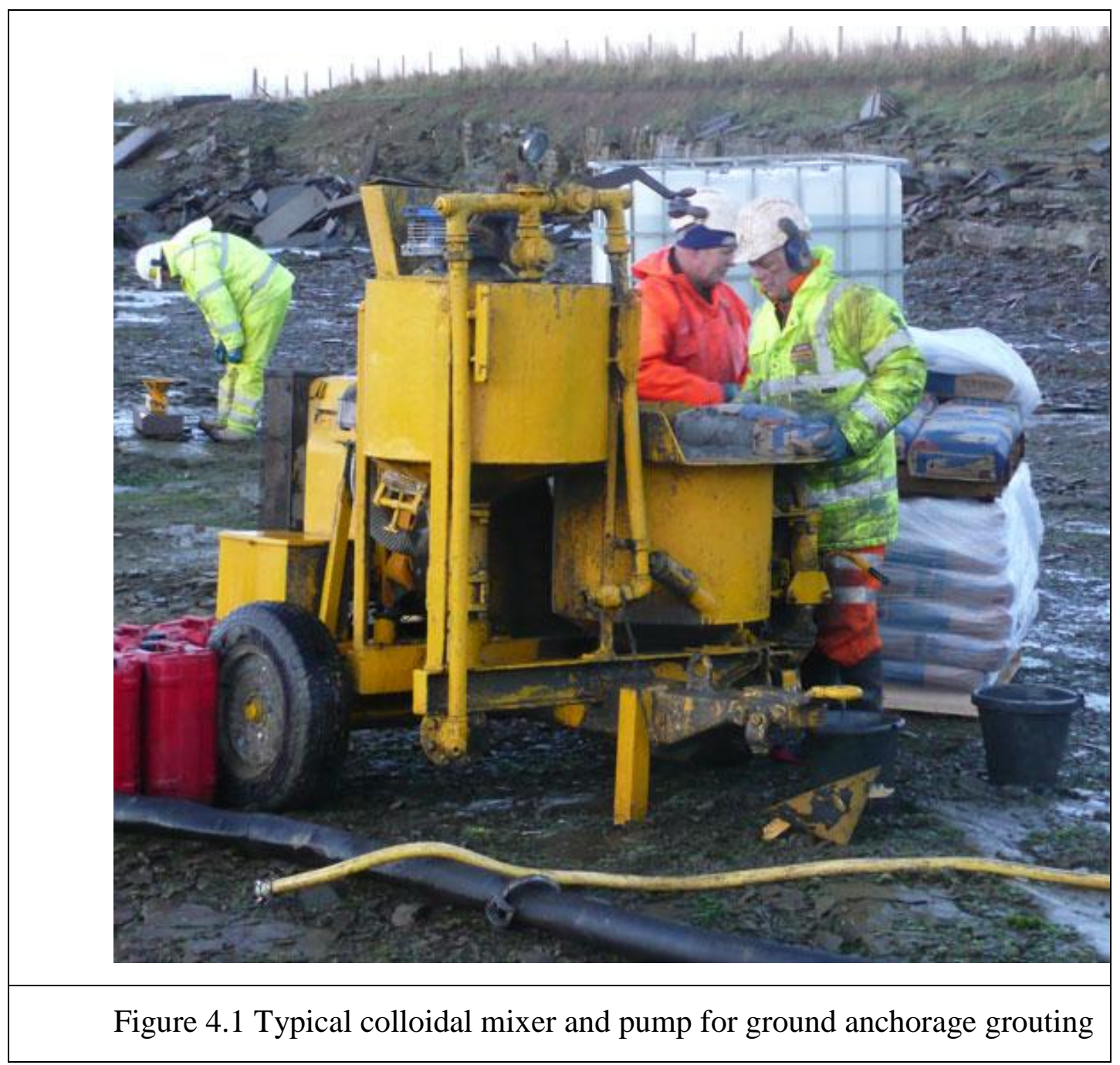

Grout should be mixed in individual batches for each anchor, and mixed in accordance with the manufacturer's recommendations with a water-to-cement ratio of 0.40 to 0.45 by weight.

Each batch should be mixed for at least 2 minutes before being placed into a holding tank where it should be kept in continuous movement until pumped to its final location.

\section{GROUT TESTING}

After mixing, the following tests should be performed on each batch of grout in accordance with ASTM (or equivalent) standards:

- 1 No. flow cone test in accordance with reference 4

- 1 No. bleed test in accordance with reference 5

- 1 No. Density test in accordance with reference 6 
- The air temperature should be recorded while grouting operations are in progress. (A subsea temperature gauge on the drill rig would also be required).

- Six (6) cubes should be taken for unconfined strength testing in accordance with reference 7 .

- Grout cubes shall be placed in a water bath for curing in accordance with reference 8 .

- Cubes shall be tested in accordance with reference 9. Two cubes from each batch shall be crushed at intervals of 3, 7 and 28 days. Grout shall have a minimum unconfined compressive strength of 4,000psi / 30N/mm ${ }^{2}$ before any anchor is stressed.

For the trial, remote 'seabed' testing of the grout returns as it exits the annulus at the 'seabed' shall be performed. It is envisaged that a density probe will provide the best means of correlating the quality of the grout with the 'surface' test results. A procedure shall be developed to ensure that 'seabed' grout returns are controlled to match the required quality.

\subsection{Site records}

The following records shall be produced by the anchor installation contractor:

- Daily Site Log for each day on site

- An Anchor Installation Log

- A Grout Log for all grouting operations

- Anchor Proof Test Record (If required)

Proposed formats for the above $\log$ s shall be submitted for review prior to commencing the trials.

\section{ADDITIONAL REPORTS}

Separate reports will be prepared to cover:

- Anchor Design.

- Installation Procedures.

- $\quad$ Proof Testing (if required) 

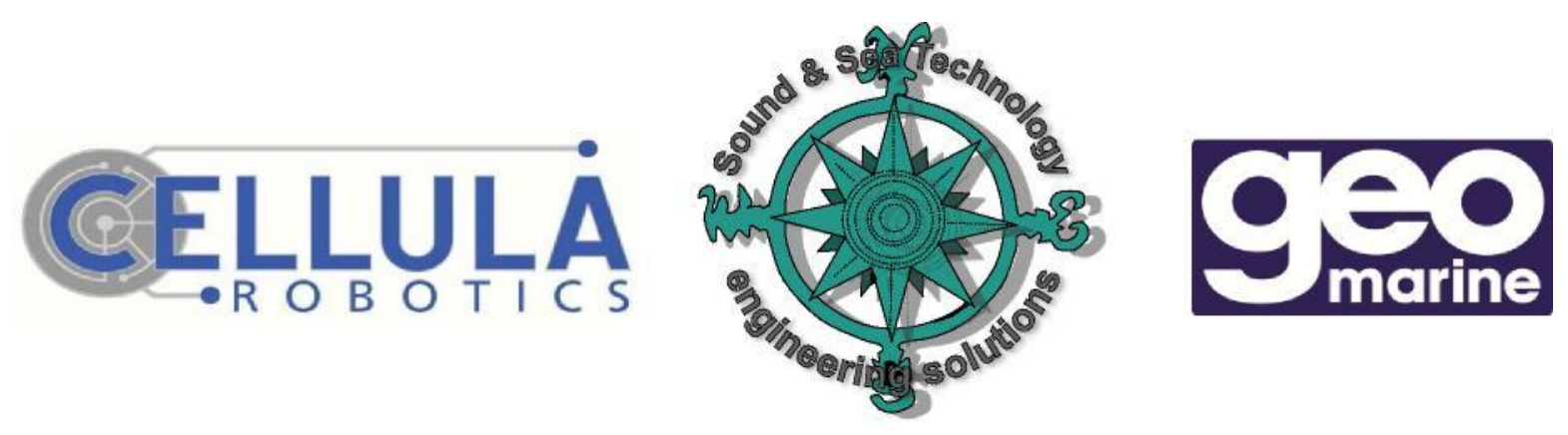

\section{GPA11 DOE Drilled Grouted Anchors}

\section{Test Plan \& Report Grout Monitoring System}

\section{DOE EERE Award DE-EE0003632 \\ Advanced Anchoring Technology}

Document: CRL-GPA11-PL-01

Revision: D09

Save Date: $18-$-Oct-12

\begin{tabular}{|l|l|l|}
\hline Prepared by: & Scott Anderson & Date: 1-Jun-12 \\
\hline Reviewed by: & Eric Jackson & Date: $15-$ Oct-12 \\
\hline Reviewed by: & Robert Taylor & Date: $17-O c t-12$ \\
\hline Approved by: & Dallas Meggitt & Date: $18-$ Oct-12 \\
\hline
\end{tabular}

This document is proprietary to Cellula Robotics Ltd., Geomarine Ltd., and Sound \& Sea Technology. It may not be copied or otherwise distributed without the express consent of Cellula Robotics Ltd., Geomarine Ltd., or Sound \& Sea Technology. 


\section{Revision History}

\begin{tabular}{|l|l|l|l|}
\hline Rev. & Date & Author & Description \\
\hline D01 & 16-May-12 & S Anderson & First Draft for team review \\
\hline D02 & 22-May-12 & E Jackson & Updated overall test plan description \\
\hline D03 & 1-Jun-12 & S Anderson & Updates to incorporate comments \\
\hline D04 & 1-Jun-12 & E Jackson & Draft for Release \\
\hline D05 & 6-Jun-12 & S Anderson & Extensive Revisions \\
\hline D06 & 6-Jun-12 & S Anderson & $\begin{array}{l}\text { Added ref to Obermann pressure sensor and removed } \\
\text { references to gate valve, defined cuttings, added mixer }\end{array}$ \\
\hline D07 & 8-Jun-12 & S Anderson & Updated seabed inclusion test details \\
\hline D08 & 15-Oct-12 & E Jackson & $\begin{array}{l}\text { Included D Meggitt comments } \\
\text { Included Test Results }\end{array}$ \\
\hline D09 & 17-Oct-12 & R. Taylor & Final edit \\
\hline
\end{tabular}




\section{Contents}

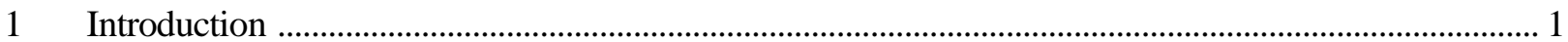

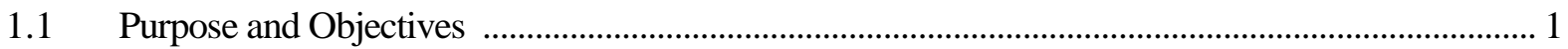

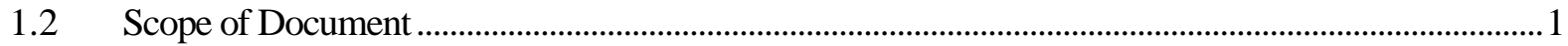

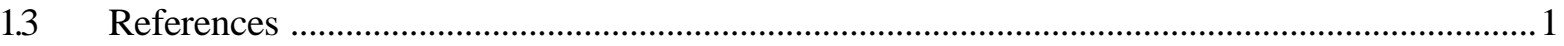

1.4 Abbreviations and Definition of Terms .................................................................................... 1

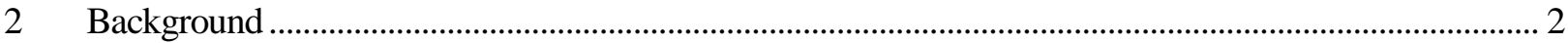

3 Experimental/Investigative Program Overview ............................................................................... 3

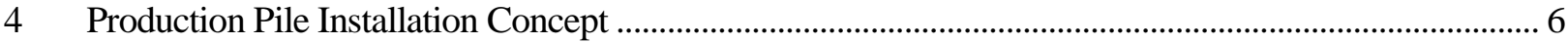

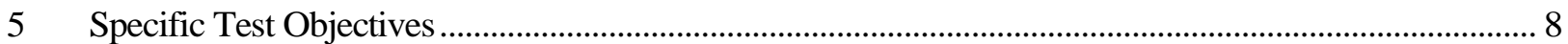

$5.1 \quad$ Test 1: Real-Time Grout Density Sensor............................................................................................. 8

5.2 Test 2: Integrated Test ................................................................................................................ 8

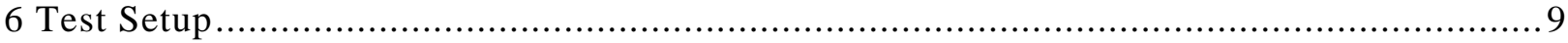

6.1 Equipment ................................................................................................................................. 9

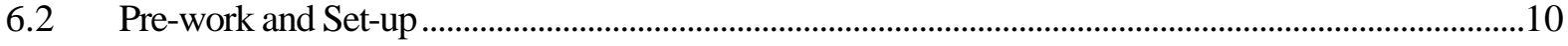

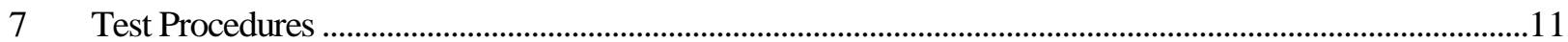

7.1 Ultrasonic Density Sensor Characterization ................................................................................. 11

7.2 Test Sensitivity to Seabed Inclusion.......................................................................................... 11

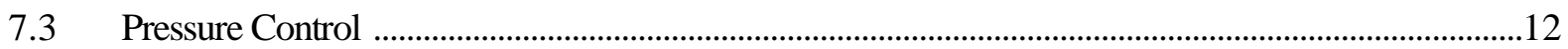

7.4 Simulate Production Grouting Process ............................................................................................. 13

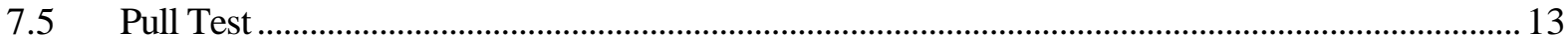

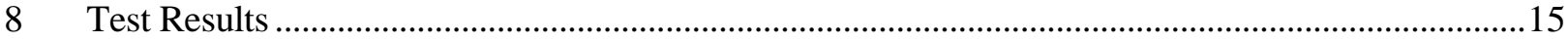

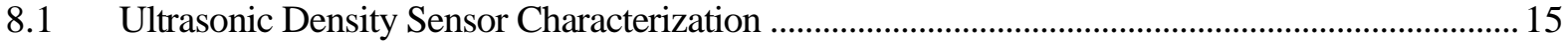

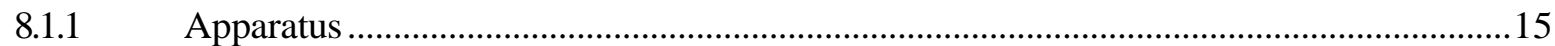

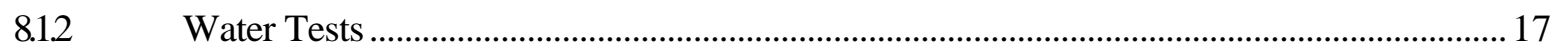

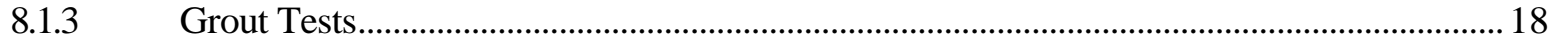

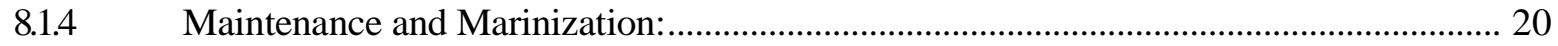

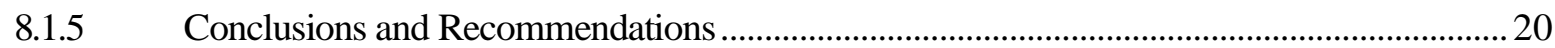

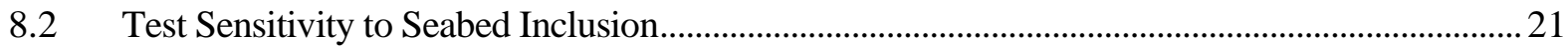

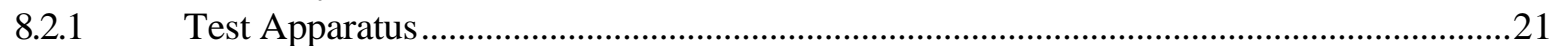

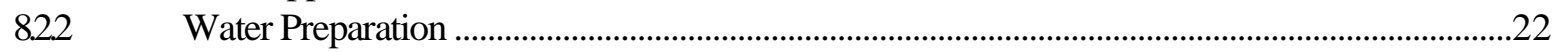

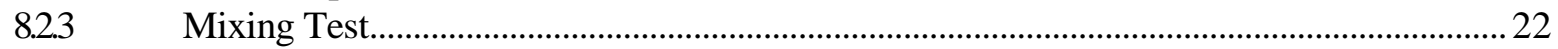

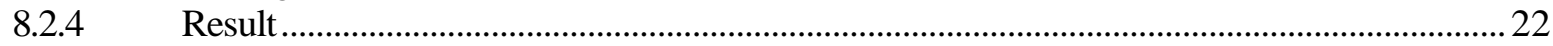

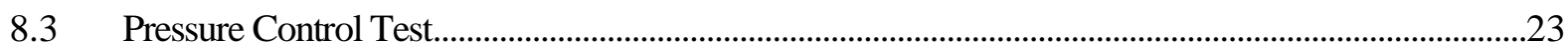

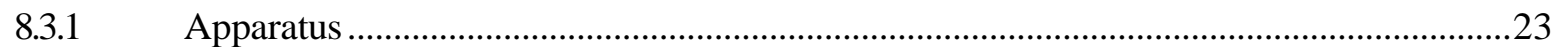

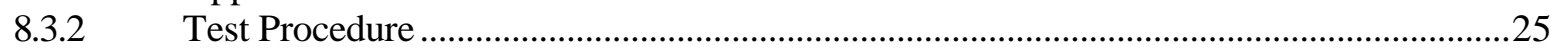

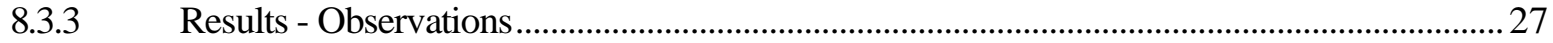

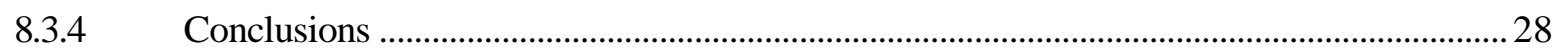




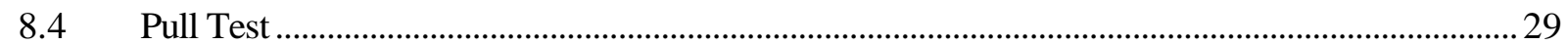

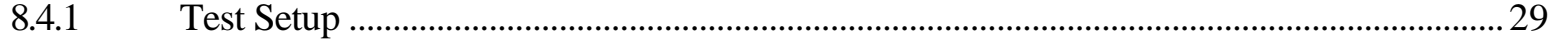

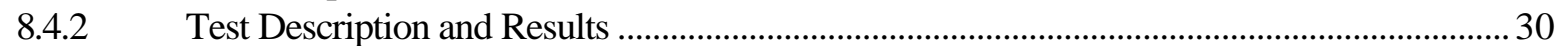

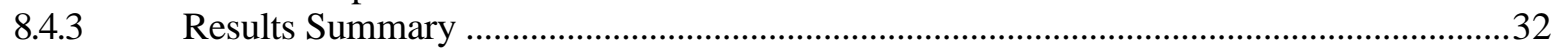

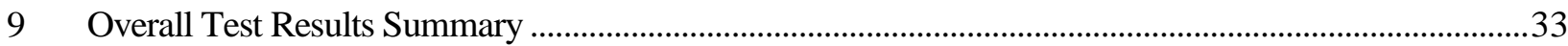

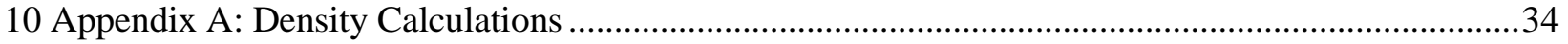

\section{List of Figures}

Figure 1 Conceptual Design for Drilled and Grouted Micropile Anchor System ....................................2

Figure 2 Overall Experimental/Investigative Program .............................................................................4

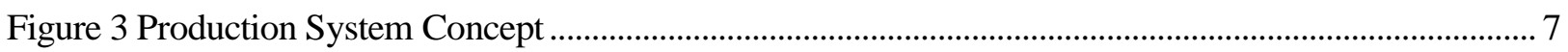

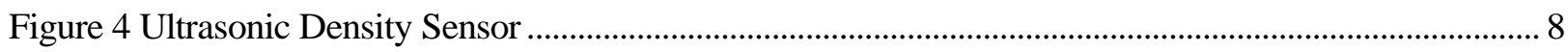

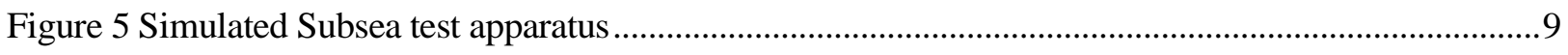

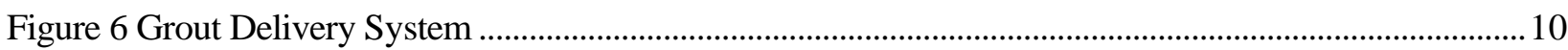

Figure 7 Test Apparatus for seabed sensitivity test .................................................................................12

Figure 8 Simulated Production Grouting and Pull Test Apparatus ..........................................................14

Figure 9 Sensor Characterization Test Apparatus .....................................................................................

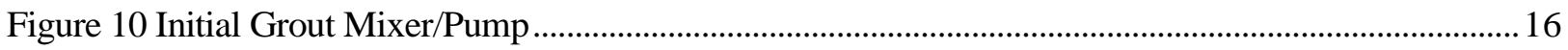

Figure 11 Sensor Characterization Test Assembly ...............................................................................16

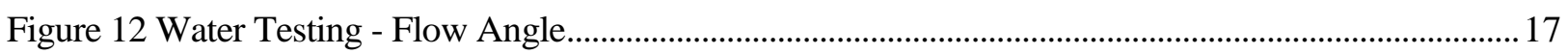

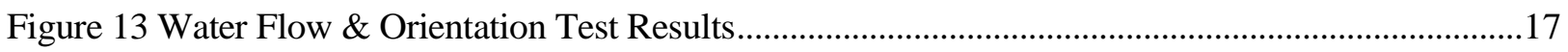

Figure 14 Grout Testing - Thin (Left), Thick (Right) ...............................................................................18

Figure 15 Changing From Water to Weak Grout....................................................................................18

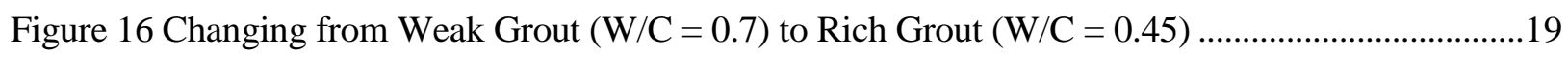

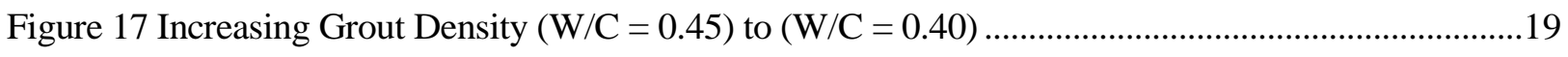

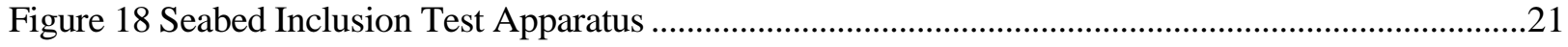

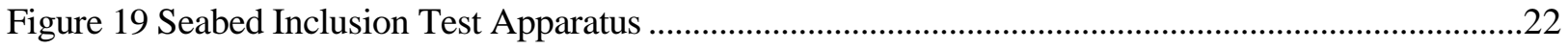

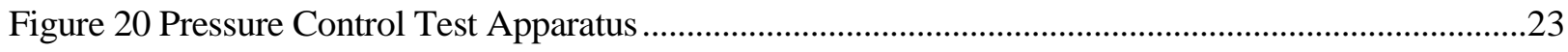

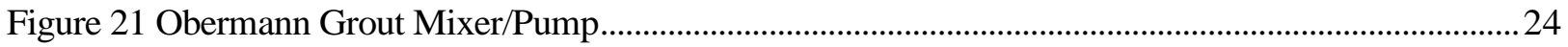

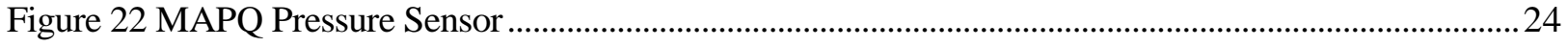

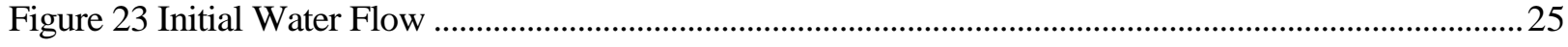

Figure 24 Start of Weak Grout (L) and Continuous Weak Grout (R) .....................................................26

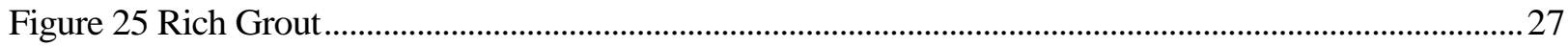

Figure 26 Ultrasonic Sensor after Pressure Test (L) and after Clean Water Flush (R) ..........................28 
Figure 27 Hydraulic Pump with Pressure Gauge (L) Hydraulic Jack $®$..................................................29

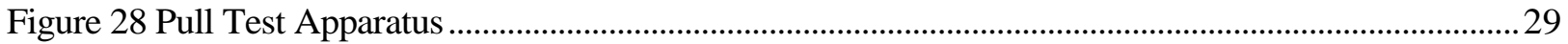

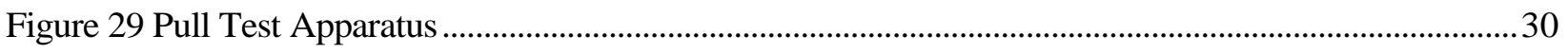

Figure 30 Dried Grout before (3/4" below Tee) and after (3/8" below Tee) first test............................... 30

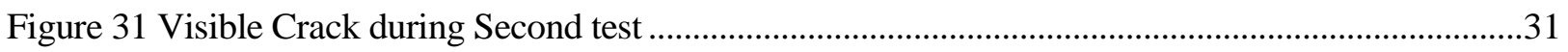

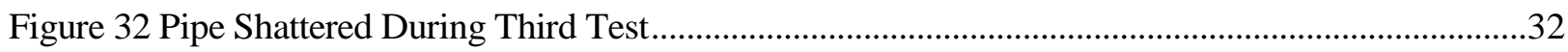

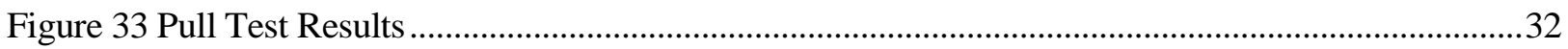

Figure 34 Grout Density vs. Measurement Reading ........................................................................ 34

Figure 35 Water/Cement Ratio vs. Measurement Reading …...............................................................35

Figure 36 Grout Density vs. Water/Cement Ratio...................................................................................35

\section{List of Tables}

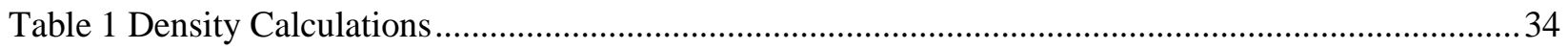




\section{Introduction}

\subsection{Purpose and Objectives}

This document describes testing done to support the development of a grouting system under the DOE Drilled Grouted Anchors project, DOE EERE Award DE-EE0003632, Advanced Anchoring Technology. For purposes of this discussion, "drilled grouted anchors" and "grouted micropiles" are used interchangeably.

The objectives of these tests, as revised from the original project objectives, are as follows:

1. To advance the application of renewable energy anchoring technology from TRL3 (Proof of Concept) to TRL4 (Component Validation in Lab Environment).

2. Conduct tests to support the development of a remotely controlled grouting procedure and grout quality control system suitable for marine Grouted Pile Anchor installations.

The analysis of technology readiness levels (Objective 1) was documented in Reference 1.

This document focuses on the test plan to complete Objective 2 above.

\subsection{Scope of Document}

The scope of this document is as follows:

- $\quad$ Section 1 describes the purpose, objectives and scope.

- Section 2 describes the project background.

- Section 3 describes the overall experimental and investigative methodology.

- Section 4 describes the overall concept for an operational remotely operated subsea grouting procedure.

- Section 5 describes the objectives of the tests done under this project.

- Section 6 describes the test setup.

- Section 7 describes the test procedures and results.

- Section 8 provides a high level summary of the test results.

\subsection{References}

1. Sound \& Sea Technology (2010): Advanced Anchoring Technology, in response to Marine and Hydrokinetic Technology Readiness Advancement Initiative, DOE Funding Opportunity Announcement Number: DE-FOA-0000293

\subsection{Abbreviations and Definition of Terms}

ID Inner Diameter

PSI Pounds per Square Inch

PVC Poly-Vinyl Chloride

TBD To Be Determined

TRL Technology Readiness Level

W/C Water to Cement ratio 


\section{Background}

The most common use of drilled grouted micro-pile anchors in terrestrial applications is for slope stabilization. In this application, post-process, post-cure, pull testing typically is used to verify the quality of the installation. The consequences of failure are low, the installation costs are comparatively low, and there is a human in the loop to correct any problems that occur during the installation process.

In subsea applications, process and quality system must be much different because the environment is much different. The overhead cost of the at-sea installation process is much higher. It is dominated by the cost of a vessel that is expected to be dedicated to the installation. It is much more expensive (and not practical in many applications) to have a human at the installation site (underwater) where visibility can be extremely poor, currents and wave action can be high, and other challenging conditions can be present. Installation sites are typically chosen in high energy environments, leading to large hydrodynamic forces on the tools and tooling during installation.

While drilled, grouted piles are installed underwater today, the large diameter monopiles typically used to anchor or support tidal, in-river hydro and offshore wind energy generation systems are very different from the micropile technology that is the subject of this development. A key difference between large diameter monopile installations and Drilled Grouted Micropiles is the number of piles installed (and therefore grouting operations to be completed). Typically there is just one monopile, with no joints, and only one grouting operation. With drilled grouted micropiles, we expect to install many smaller piles, assembled together in groups of 3 or 4 piles, with typically 8-20 bore holes per anchor assembly. Figure 1 shows a conceptual drilled, grouted micropile anchor system.

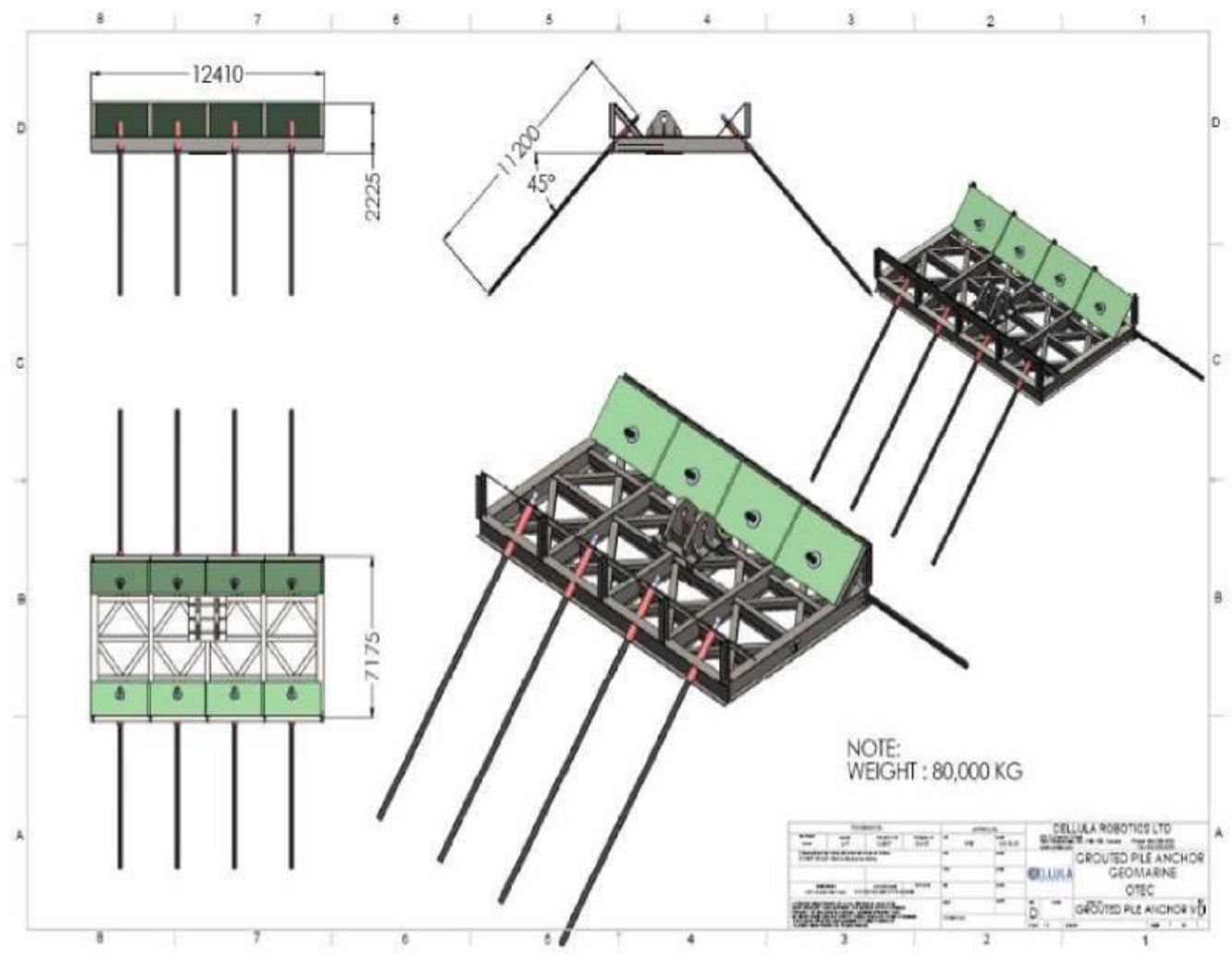

Figure 1 Conceptual Design for Drilled and Grouted Micropile Anchor 
Due to the differences in the installation operations, the requirements for an underwater grout control system for micropiles are much different than for monopiles. The system has to be faster, able to adapt to joints in the piles, able to operate without sensors integrated into the piles (such as the fiber optic temperature sensor used by FoundOcean in a large monopile installation), and capable of remote operation.

The objective of the current effort is to isolate the technically risky parts of the new technology, then prototype them on the bench in order to de-risk them, thereby advancing the technology.

\section{Experimental/Investigative Program Overview}

The overall experimental/investigative program is illustrated in Figure 2. The figure is intended to illustrate the evolution of the test program as we have gained knowledge. The elements in hexagons indicate experiments or investigations - the rectangles indicate learnings. The elements in dashed boxes have not been completed at the time of writing. 


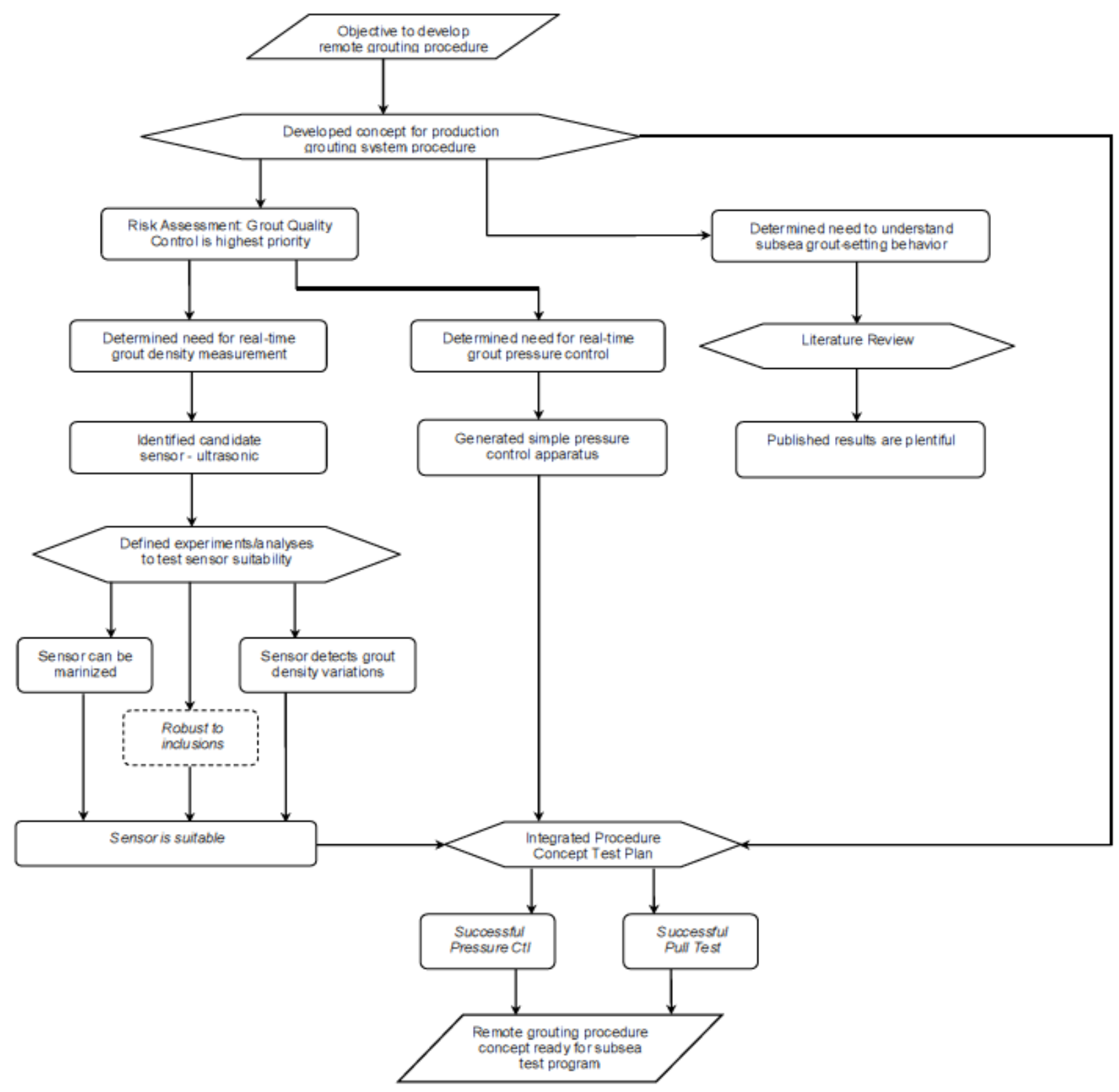

Figure 2 Overall Experimental/Investigative Program 
The overall flow of the investigations, as shown in the diagram, is described briefly as follows:

1. The concept for a production remotely operated subsea grouting procedure is described in the next section. The following results have been derived from evaluation of this concept:

a. understanding the effects of the marine environment (salinity, pressure, temperature) on grout setting times is critical

b. grout quality control is important, especially:

- the ability to perform real-time grout density measurement

- the ability to perform real-time grout pressure control

2. We performed a literature review to learn what data exist on the influence of the subsea environment (temperature, pressure, salinity) on grout-setting time. We found that this issue has been well researched, and there is no need to perform any additional special experiments.

3. We identified a candidate density sensor and defined a series of experiments to evaluate its practicality/suitability for subsea grout measurement application.

4. We identified a simple pressure control apparatus and included testing of this apparatus along with the grout density sensor experiment. To date, the following results derived from these investigations:

a. the off-the-shelf density sensor is easily marinizable to operating depths of $100 \mathrm{~m}$

b. the sensor readily detects changes in grout density over the range of interest

5. We have defined an integrated experiment that will include a "gun-barrel" grout-setting test, combined with use of the grout density sensor and the grout pressure control apparatus. The experiment will conclude with a pull test.

Assuming that the remainder of these experiments is successful, we believe that the drilled, grouted micropile anchor concept will be shown to be suitable for further development for subsea applications. 


\section{Production Pile Installation Concept}

A concept for a full-scale production system is shown in Figure 3. The concept is described as follows:

- A seafloor drill is situated over the target location of the pile. It holds one or more micro-piles, which it inserts by drilling them into the seafloor.

- The grout delivery system is connected to the drillhead at the top of the pile that is being inserted, allowing the grout to flow through the pile and out the bottom - grout is used as a flushing fluid during drilling.

- A collar is installed around the pile to capture flushing flow rising to the surface around the pile.

- $\quad$ Rich grout is prepared on surface and pumped to the subsea injection point via a subsea throttling valve.

- Fresh water is also supplied from the surface vessel.

- The grout mixture dilution occurs subsea with surface-supplied fresh water. Subsea (rather than surface-based) mixing reduces the time delay between a decision to change the grout/water mix (grout density) and the injection of the modified grout mixture into the hole;

- Some combination of water and grout is injected into the hole during insertion of the pile (i.e. drilling), controlled by a throttling valve.

o Typically, a highly diluted grout is used during the pile insertion (drilling) stage in order to flush cuttings from the hole.

o Once pile insertion is complete, a rich grout solution (at the final water/cement ratio) is used to anchor the pile.

- The pressure of the grout entering the hole is controlled via a throttling valve situated at the connection between the grout supply hose and the drill assembly. This pressure control function is important in order to avoid over-pressuring the foundation or damaging/ disconnecting the collar.

- When flushing grout exits the hole, the cuttings are separated from the grout, e.g. through a filter.

- The density of the grout is measured as the grout exits the hole. By doing this, we expect to be able to see when all the weak, flushing grout has exited the hole and the hole is completely filled by the undiluted, rich grout.

- Due to environmental concerns in some jurisdictions, we expect to maintain a completely closed loop system, not allowing grout to mix with the ambient seawater until it is cured. This means that the weak flushing grout cannot be simply discharged into the environment, but instead will either be reused, returned to surface through a tube, or deposited into a sealed form at the anchor. 


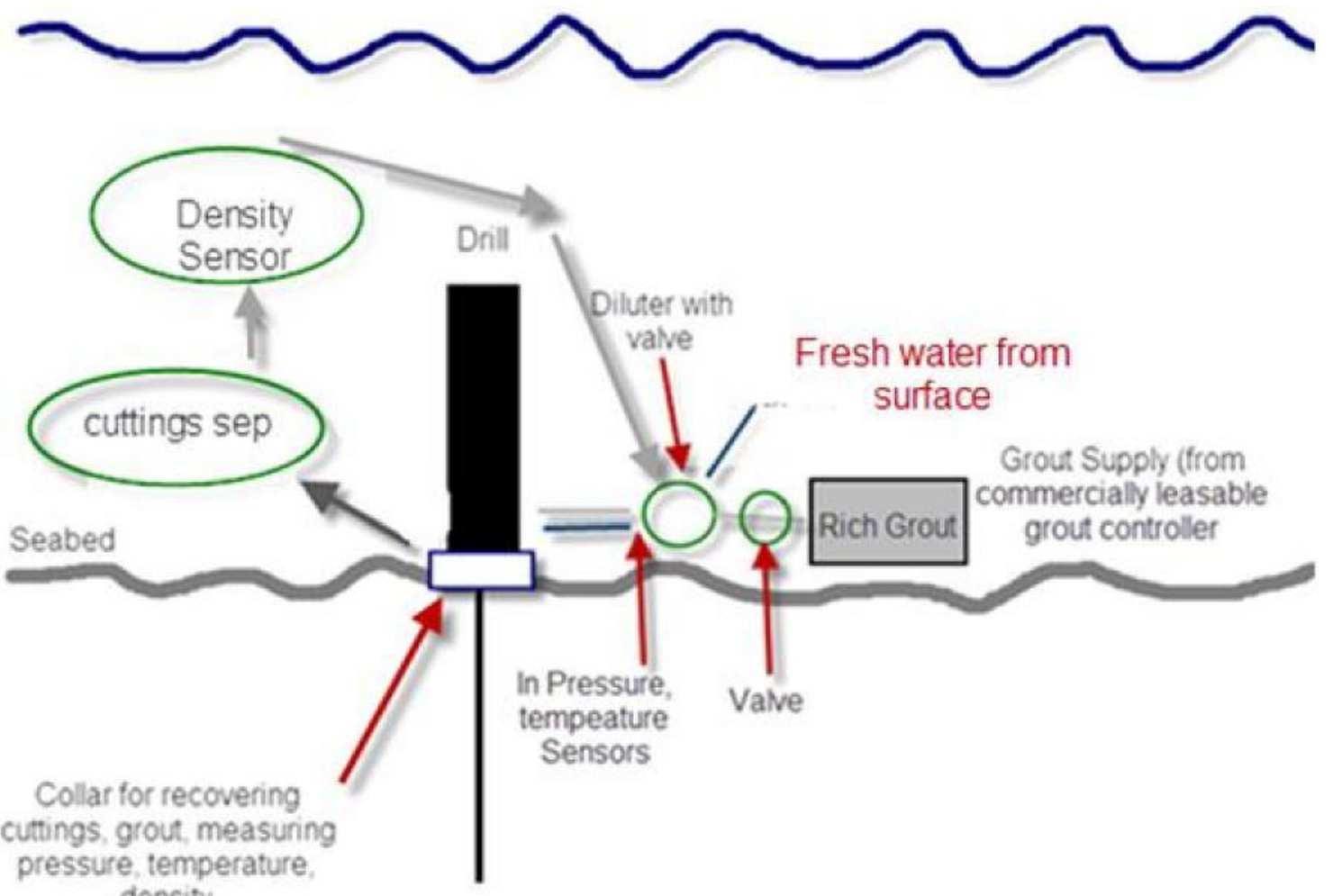

Figure 3 Production System Concept 


\section{Specific Test Objectives}

\subsection{Test 1: Real-Time Grout Density Sensor}

Hypothesis test: we can use an ultrasonic density sensor in our subsea grouting application to analyze the material exiting the drill hole in order to determine when the hole is completely filled with grout of the desired water/cement ratio. This will be a key indicator of a successful grouting installation.

We have chosen an ultrasonic density analyzer as our candidate grout density sensor (see 4). Our research has found that a nuclear density probe has been used to measure density in this application. However, it has the following disadvantages: 1) the probe form factor disrupts flow, 2) the probe form factor has higher potential to incur damage from cuttings passing and by 3 ) its radioactive nature imposes constraints for transport and deployment.

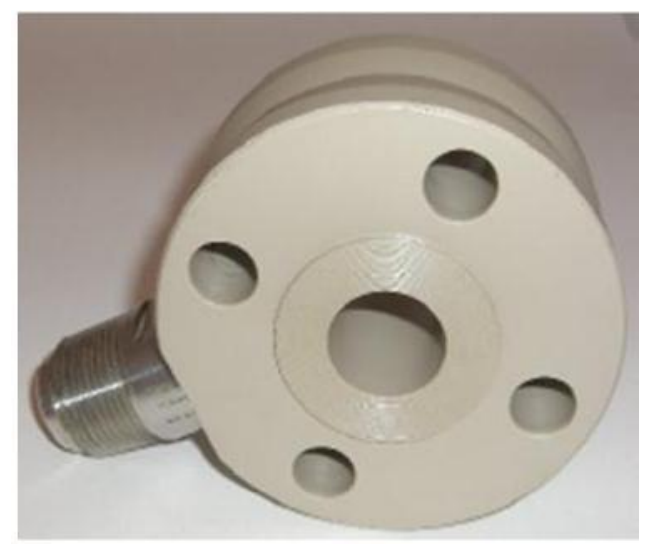

Figure 4 Ultrasonic Density Sensor

Our specific test objectives are stated as follows:

- Is this sensor suitable for grout?

- Can we see step changes in the grout density as we change the water/cement ratio of our grout?

- How accurate is it?

- Does contamination of the grout (e.g. with cuttings, overburden) degrade its performance to an unacceptable level?

- Does the Total Suspended Solids (TSS) output of the sensor aid in distinguishing between changes in density caused by different w/c ratios vs changes caused by cuttings inclusion?

\subsection{Test 2: Integrated Test}

The objectives of this test are as follows:

1. Test the effectiveness of our proposed method for controlling the pressure of the grout at the grout insertion point, i.e. isolating the effect of the weight of the grout being delivered from the ship to the drill. I.e. are we able to limit the injection pressure to reasonable values when the input pressure is too high?

2. Simulate the insertion, grouting, and pull-testing of a subsea anchor using equipment and/or methods that can be readily marinized. 


\section{Test Setup}

\subsection{Equipment}

We will conduct a bench test where we prototype the specific technologies we plan to advance and focus our testing on them. The test setup consists of two parts - the simulated subsea apparatus, and the grout delivery system. The simulated subsea apparatus is shown in Figure 5; the Grout Delivery System is shown in Figure 6.

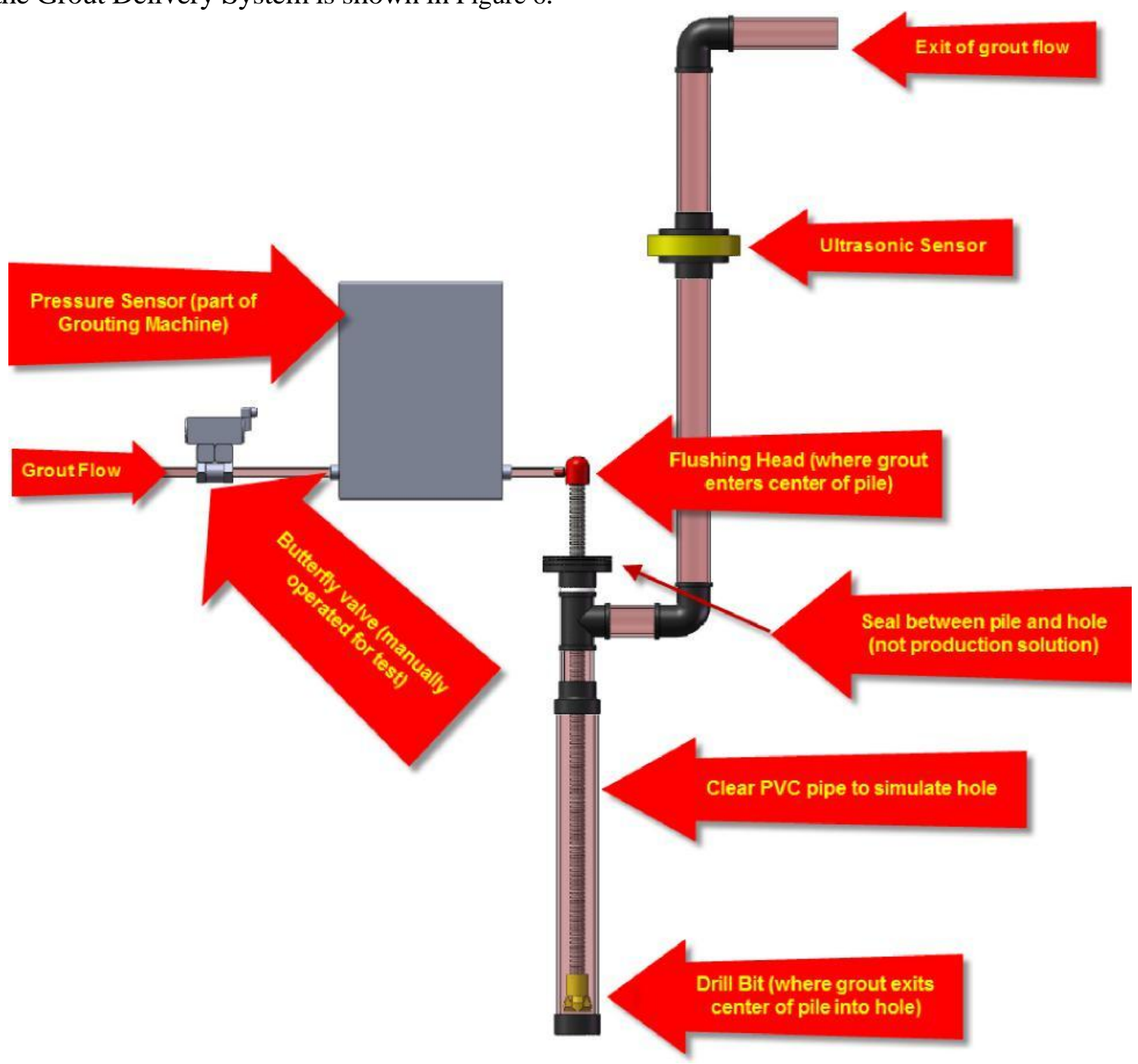

Figure 5 Simulated Subsea test apparatus

The Bench Test apparatus consists of the following:

-103/78 mm diameter grouted pile anchors

o Used in single $3 \mathrm{~m}$ lengths, may be cut shorter for ease of handling 
o Including a drill bit for each length

o The pile anchor will not be deployed with a drill - just inserted into the hole to form the correct flow passage.

o Note that in an actual installation, there will be multiple pile sections coupled with couplers and centralizers, however a simpler apparatus will be used for this test.

- A grout flushing head on top of the drill - this is where grout enters the pile.

- Obermann Grout mixer/pump (leased) with integral pressure and flow logging

- MAPQ Pressure sensor (part of the Obermann grout system)

- A hole - simulated by a pipe and pipe cap ("gun barrel")

- A squeeze seal to keep the grout inside the exit tube. Note that this will be replaced by a sliding seal (similar to a ball screw shuttle) in the production application

- Density Sensor with integral temperature sensor

- $\quad$ Remote controlled valve (used in manual override mode) for pressure control

Consumables:

- $\quad$ Fresh water

- A grout mix typical of what we could use subsea

- $\quad$ Sized sand and gravel from concrete supplier

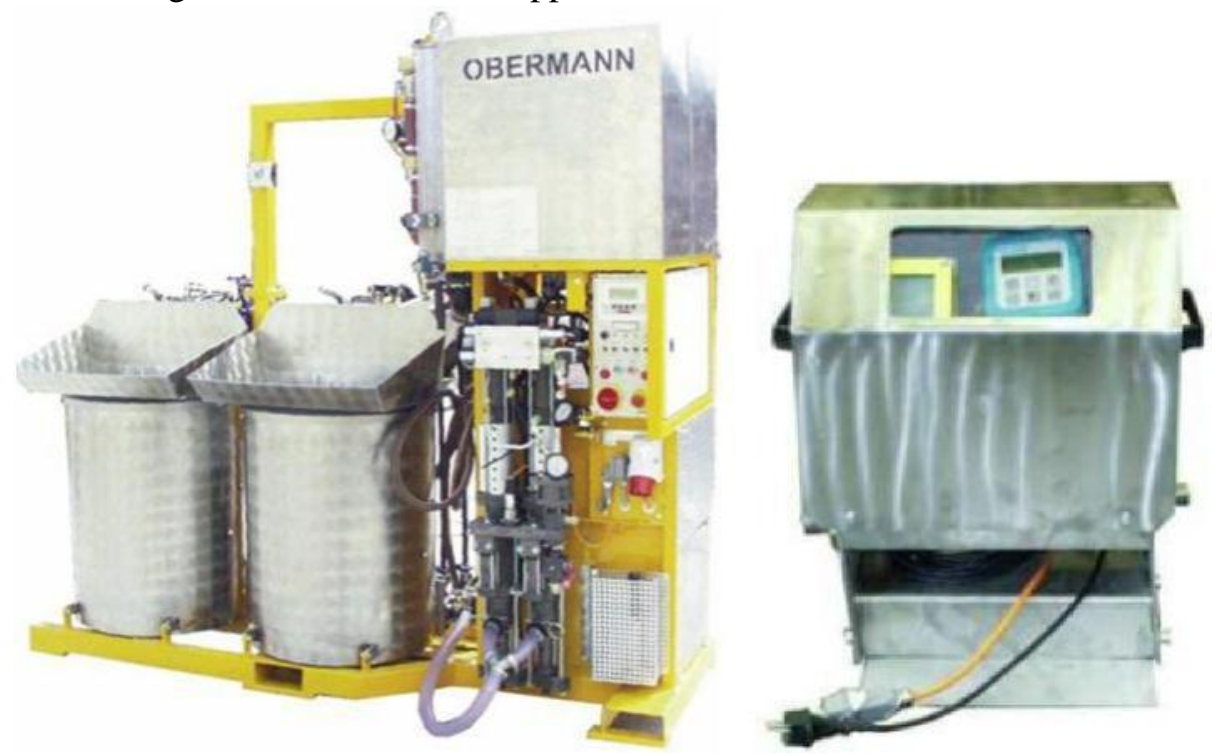

Figure 6 Grout Delivery System

\subsection{Pre-work and Set-up}

The tests will be performed at Con-Tech Systems Ltd. in Delta, BC. Con-Tech will provide the piles and the Obermann grout delivery system. For the grouting tests, the grout will be washed out of the test apparatus using water in between tests. The final test will leave the grout in the apparatus to set in preparation for a final pull test. The pull test will destroy the apparatus. 


\section{Test Procedures}

\subsection{Ultrasonic Density Sensor Characterization}

1. Prepare a grout mix representative of what might be used subsea.

2. Use a section of the test apparatus consisting of two straight lengths of pipe attached to the ultrasonic sensor. As per manufacturer recommendation, orient the pipe vertically. The manufacturer recommends using the sensor in a fully developed flow profile (10 pipe diameters downstream and 5 pipe diameters upstream of any bends

3. Flow water through the sensor to get a control data point. Ensure that flow rate does not affect the measurement.

4. Flow the grout through the sensor in a straight pipe apparatus at full rich to get a control data point.

5. Change density (by diluting with water) to $10 \%$ and $50 \%$ to get calibration points

6. Log the transition point from $10 \%$ grout to $100 \%$ grout.

7. Test Sensitivity to pressure: In a closed loop system, run the grout mixture past the sensor at a number of different pressure ranges, from ambient to at least $20 \mathrm{psi}$, up to 40psi.

Observe the response of the sensor. Pressure is measured by the grouting machine

\subsection{Test Sensitivity to Seabed Inclusion}

1. Using samples of clay, sand, and gravel in three independent tests, we will mix the seabed into a weak grout mixture in order to bring the average density of the mixture to the level of rich grout. We will analyze the sensor data to determine if it is possible to distinguish between a rich grout mixture and a weak grout plus seabed mixture that have the same average density.

2. Get samples representative of seabed clay, seabed sand and measured gravel.

3. Pump weak grout $(\mathrm{w} / \mathrm{c}=0.8)$ with a typical flow rate of $301 / \mathrm{min}$.

4. Using the apparatus shown in Figure 7, for each of three independent tests, let the weak grout fill the sensor tube, then start inserting "seabed" at a rate of 5lbs / cu ft. A manual plunger can be used to force the seabed in, with calibrated marks on the clear tube used to time the plunger movement. This should produce a combined mixture with density matching the density of a water/cement ratio of 0.4 (see Appendix A).

5. Analyze the data collected and compare with data collected in test 7.1 for rich grout. Are there any differences?

6. Through regular inspection and cleaning, evaluate the robustness of the density sensor in this application. Evaluate damage caused by "cuttings". Evaluate requirements for cleaning (does it need to be cleaned in service, can it be cleaned remotely). 


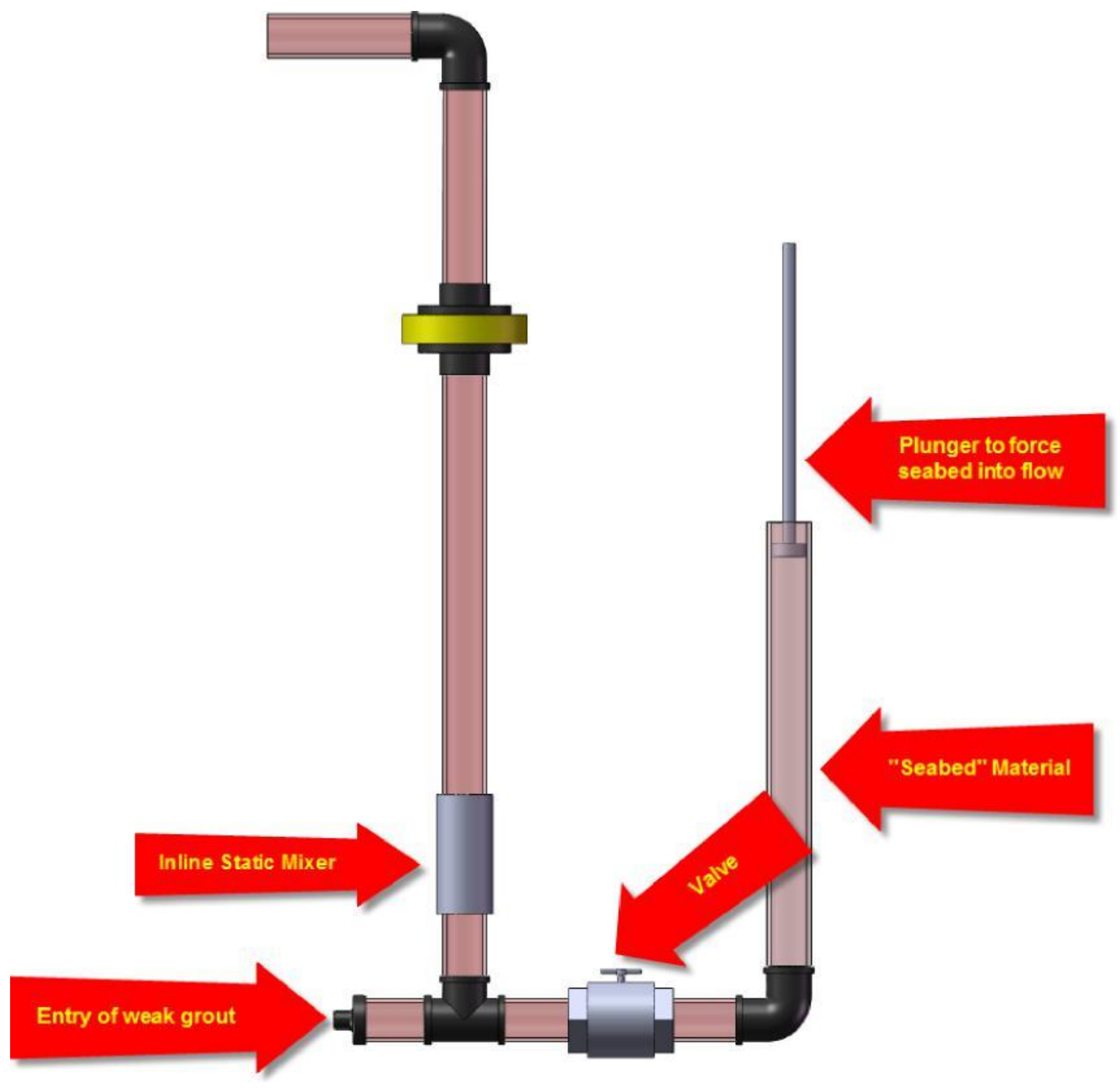

Figure 7 Test Apparatus for seabed sensitivity test

\subsection{Pressure Control}

1. Integrate the apparatus shown in Figure 8.

2. Using the integrated apparatus with a pile partially inserted, monitor pressure at the outlet of the valve.

3. Set the valve to a "nearly closed" position

4. Increase the pressure out of the grout delivery system to simulate subsea operation, e.g. to 2 bar. Monitor the pressure out of the valve, and adjust the valve to a reasonable value, e.g. 0.5 bar.

5. Increase the grout delivery pressure to $4 \mathrm{bar}$, and confirm that the valve can be used to maintain the output pressure to approximately 0.5 bar.

6. Note any difficulties or exceptional behaviors. 


\subsection{Simulate Production Grouting Process}

Simulate the grouting process to be followed during the production through the following steps:

1. Pump a weak grout mixture through the test apparatus.

2. Switch to a rich grout mixture and pump through the apparatus.

3. Stop pumping grout when the density sensor indicates the rich grout has completely filled the hole.

4. Clean the grouting system.

5. Let the grouted hole set.

\subsection{Pull Test}

1. Once the grout has set (from the previous test), install a hydraulic tensioning device on the pile as shown in Figure 8 below.

2. Use the tensioning device to pull the pile from the test apparatus until failure of the pile or test apparatus.

3. Log the estimated force from the tensioning device.

4. Note that the objective of the test is not to evaluate the strength of the installed pile but instead to demonstrate how a pull test could be performed in service. 


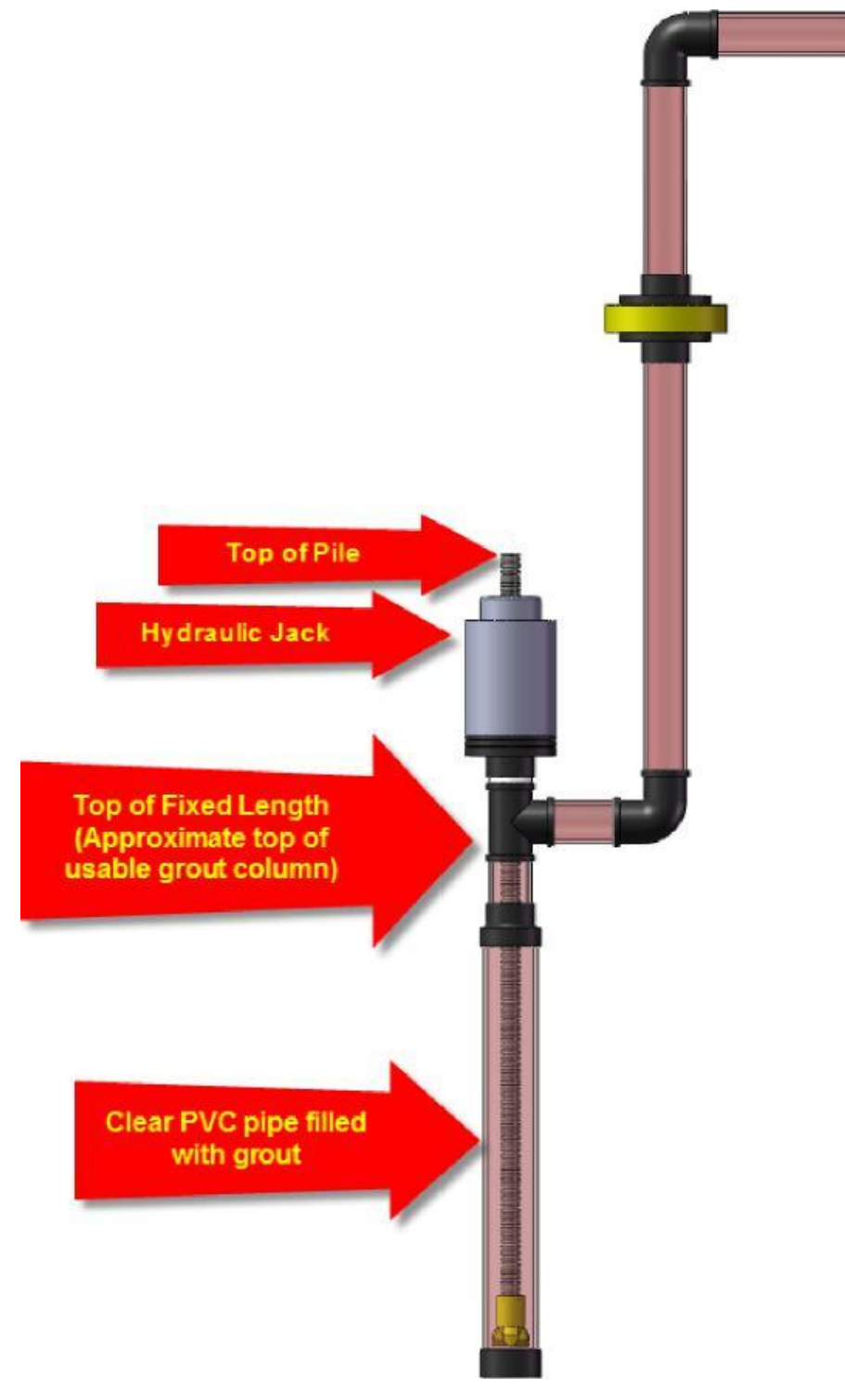

Figure 8 Simulated Production Grouting and Pull Test Apparatus 


\section{Test Results}

\subsection{Ultrasonic Density Sensor Characterization 8.1.1}

\section{Apparatus}

We start with the apparatus as described in Section 7.1.

The inside diameter of the sensor is 2.87" to match the ID of 3" Stainless Steel Sanitary tubing. This is also the nominal ID of 3" schedule 80 piping, which we use for this test.

The sensor comes with a controller that logs time-stamped sensor data to a text file.

We tested at Contech Systems, Delta, BC, because it minimizes transport and logistics, and we can draw on their operational expertise.

Ideally we would use an Obermann grout mixer/pump of the model we would potentially use in production. However, these units are not suitable for small jobs (single 40kg bags) so we used a simpler grout mixer/pump for these tests.

We used Type 10 cement.

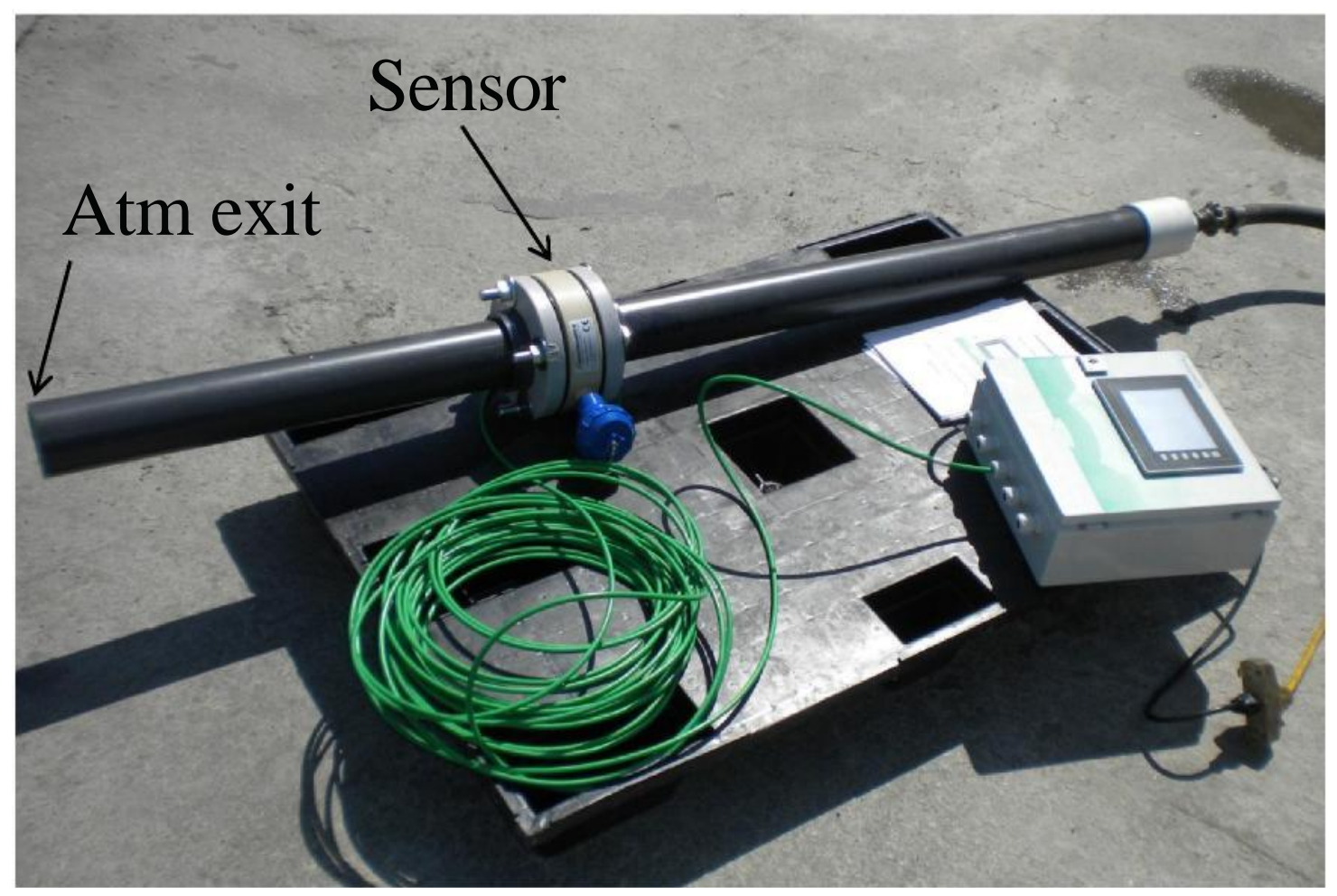

Figure 9 Sensor Characterization Test Apparatus 


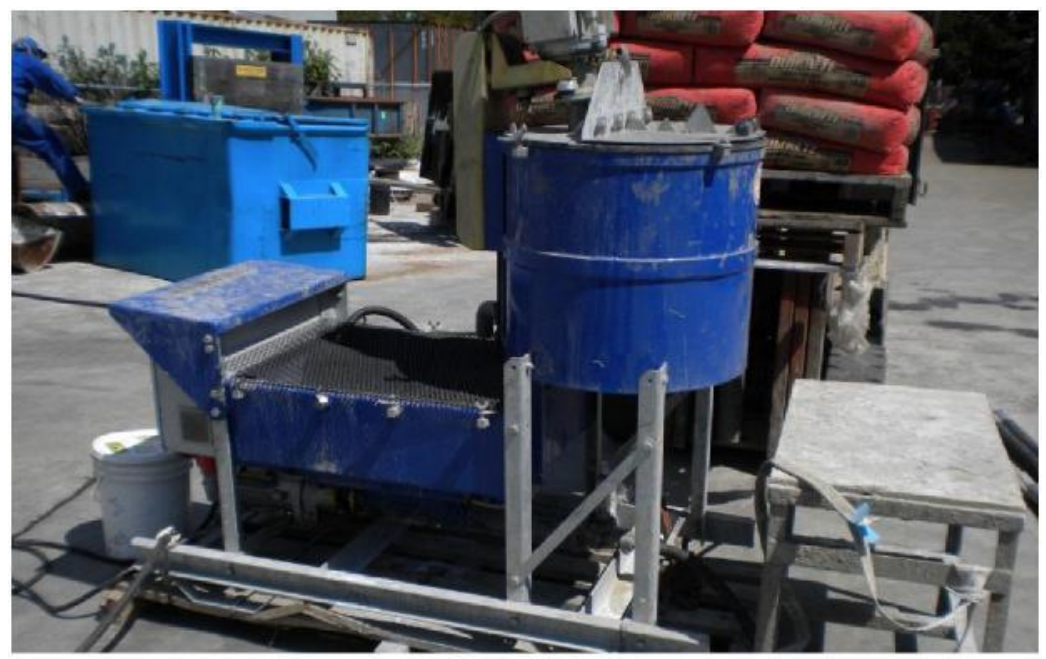

Figure 10 Initial Grout Mixer/Pump

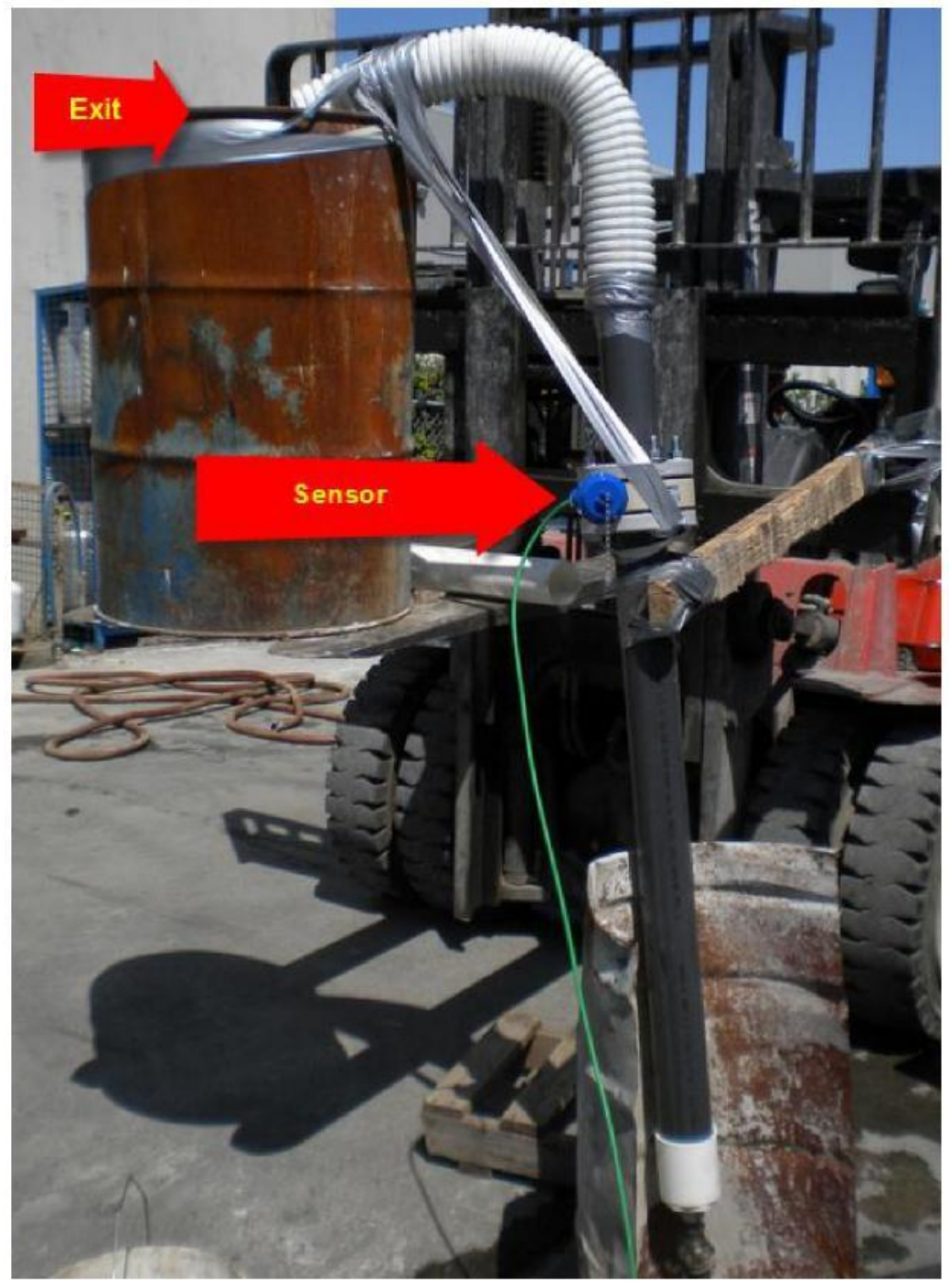

Figure 11 Sensor Characterization Test Assembly 


\subsubsection{Water Tests}

We started the test with water only $(\mathrm{W} / \mathrm{C}=\infty)$ :

1. We ran different flow rates to verify manufacturers claim that flow rate doesn't affect the sensor reading.

2. We ran the apparatus in a close-to-horizontal orientation and the recommended vertical orientation to check for any effects.

Result: Orientation and flow rate had no effect (see Figure 13)
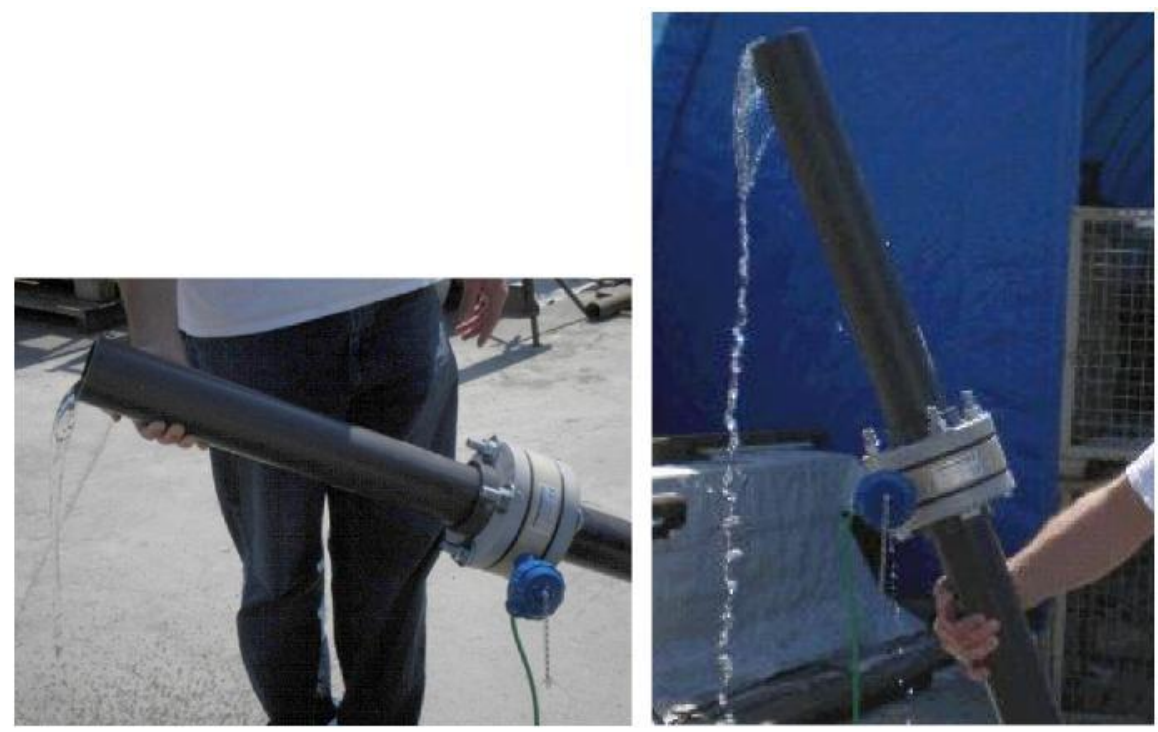

Figure 12 Water Testing - Flow Angle

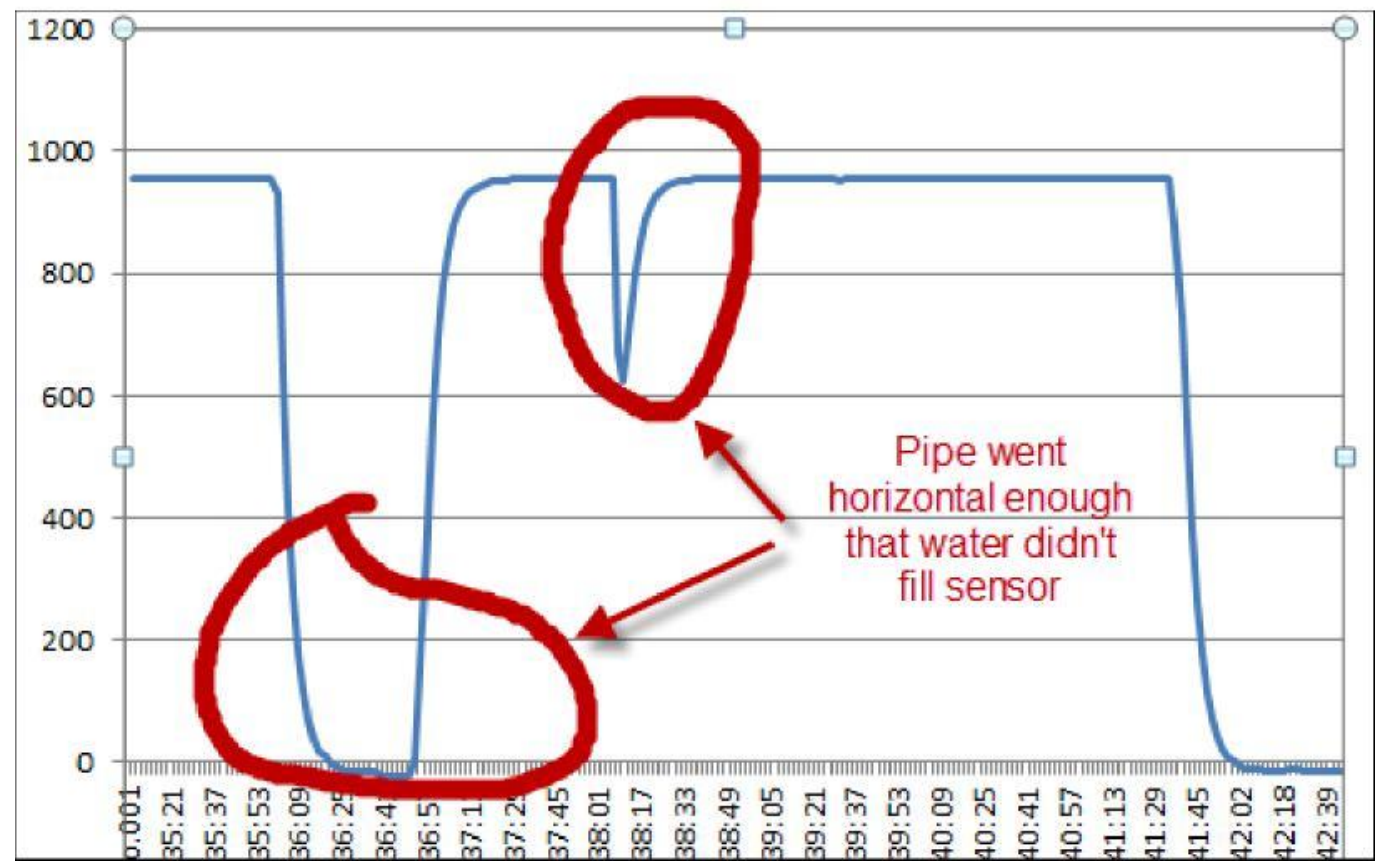

Figure 13 Water Flow \& Orientation Test Results 


\subsubsection{Grout Tests}

We logged data from 4 different W/C (water to cement) ratios, spanning the expected range: 0.8 / 0.7 / 0.45 / 0.4:

- Flow rate was nominally 15 litres/min, which is about half of the machine's capacity

- Flow rate had to be increased to 30 litres $/ \mathrm{min}$ at $\mathrm{W} / \mathrm{C}=0.45$ and below as 15 was not possible with the Grout Mixer/Pump used.
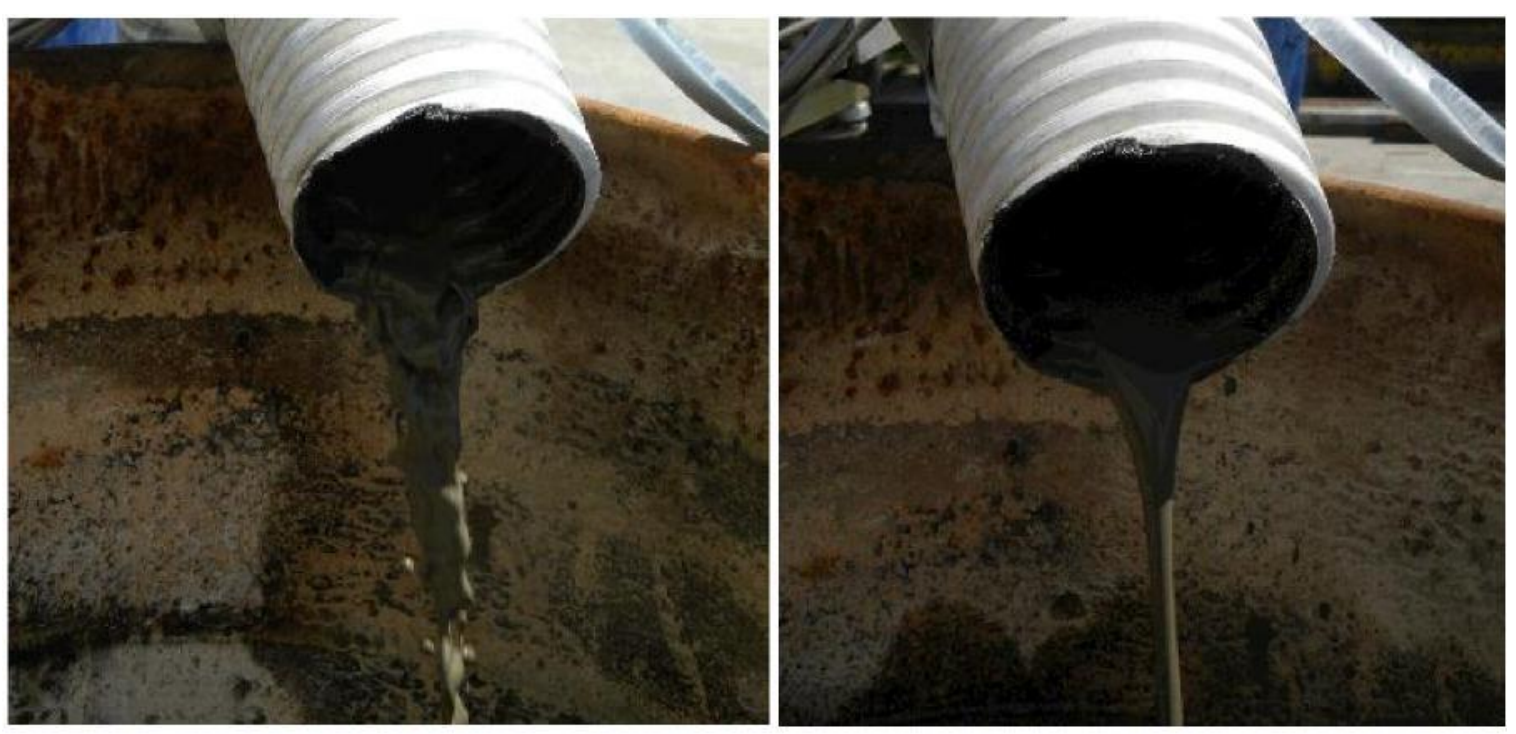

Figure 14 Grout Testing - Thin (Left), Thick (Right)

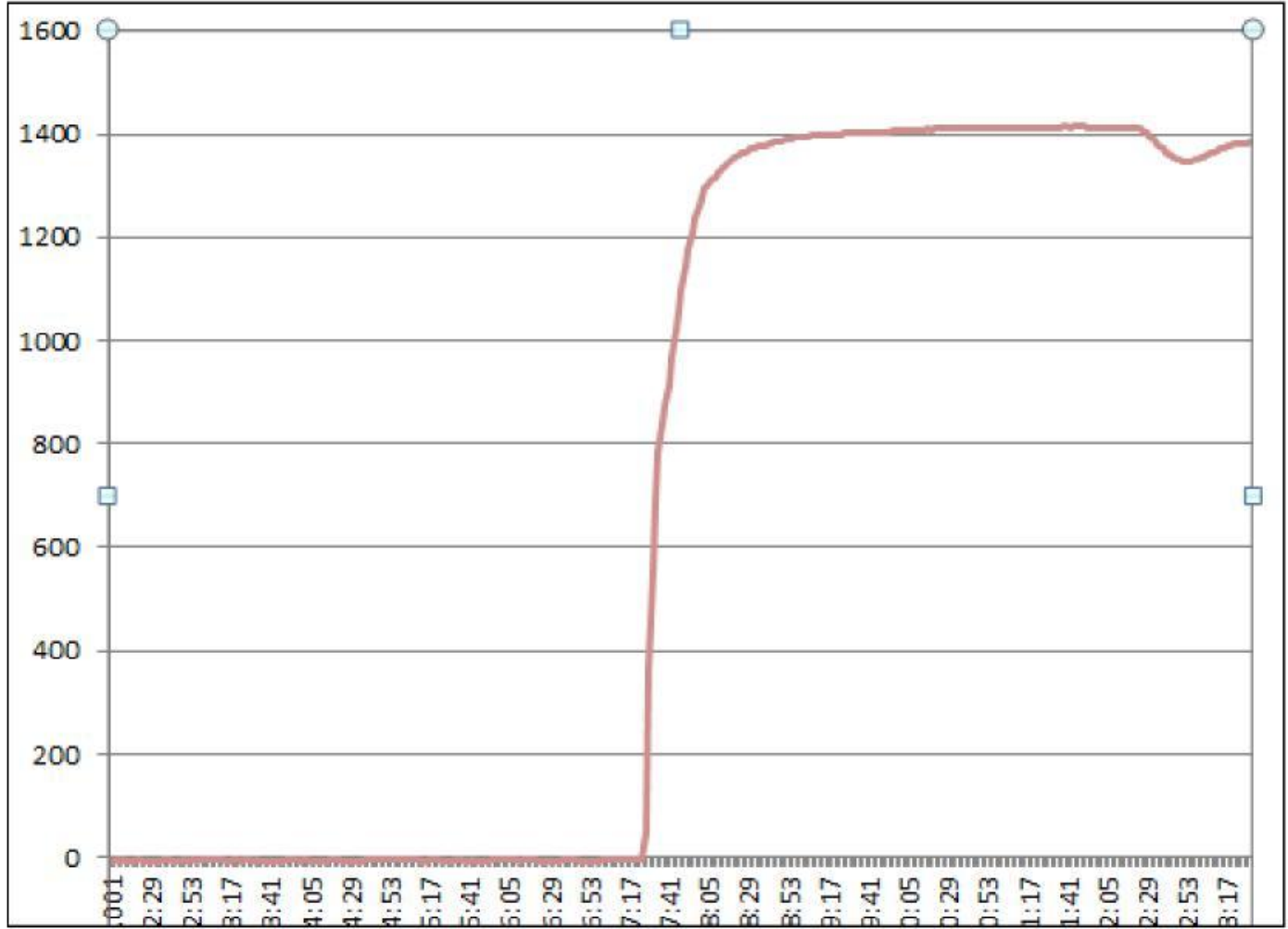

Figure 15 Changing From Water to Weak Grout 


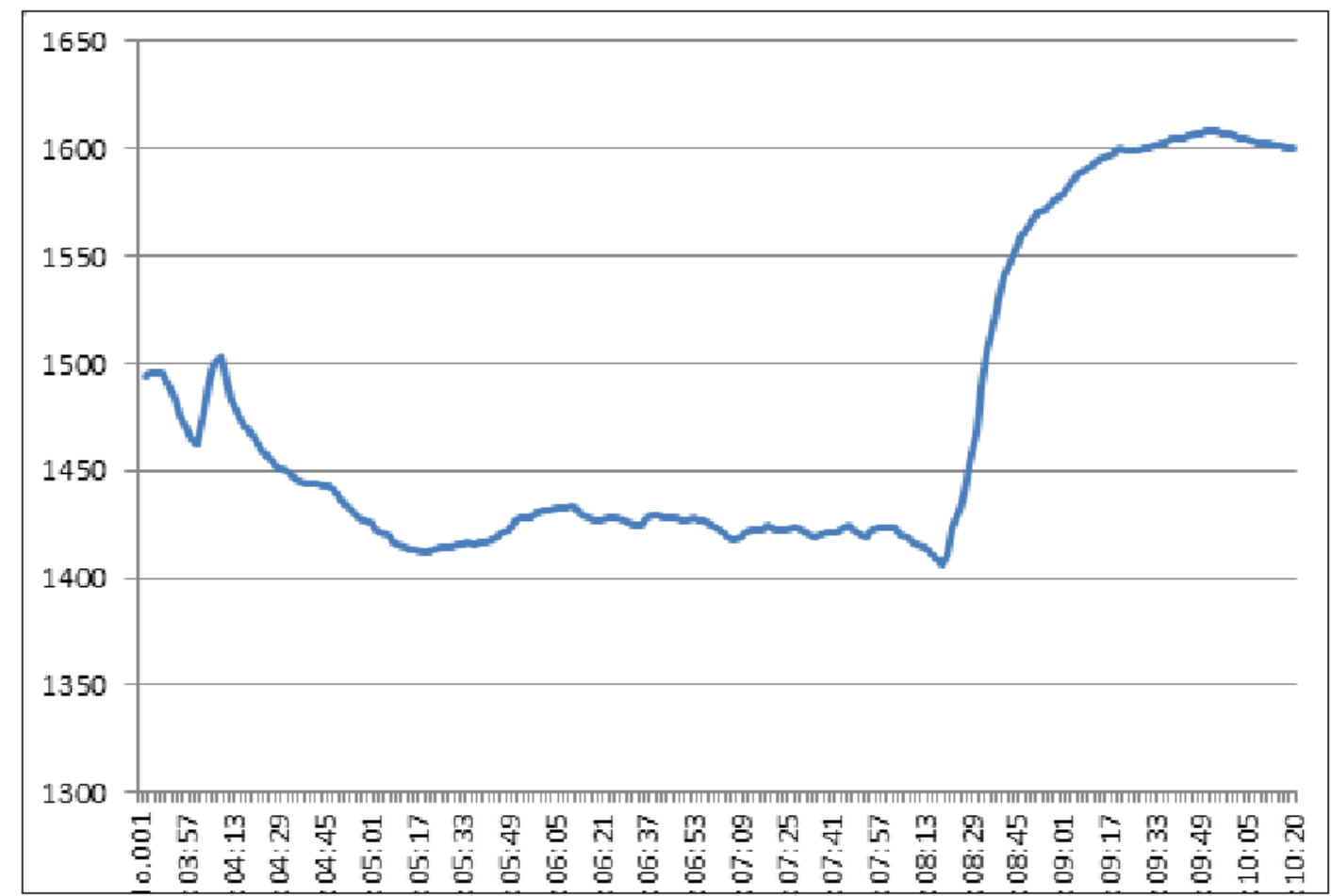

Figure 16 Changing from Weak Grout $(W / C=0.7)$ to Rich Grout $(W / C=0.45)$

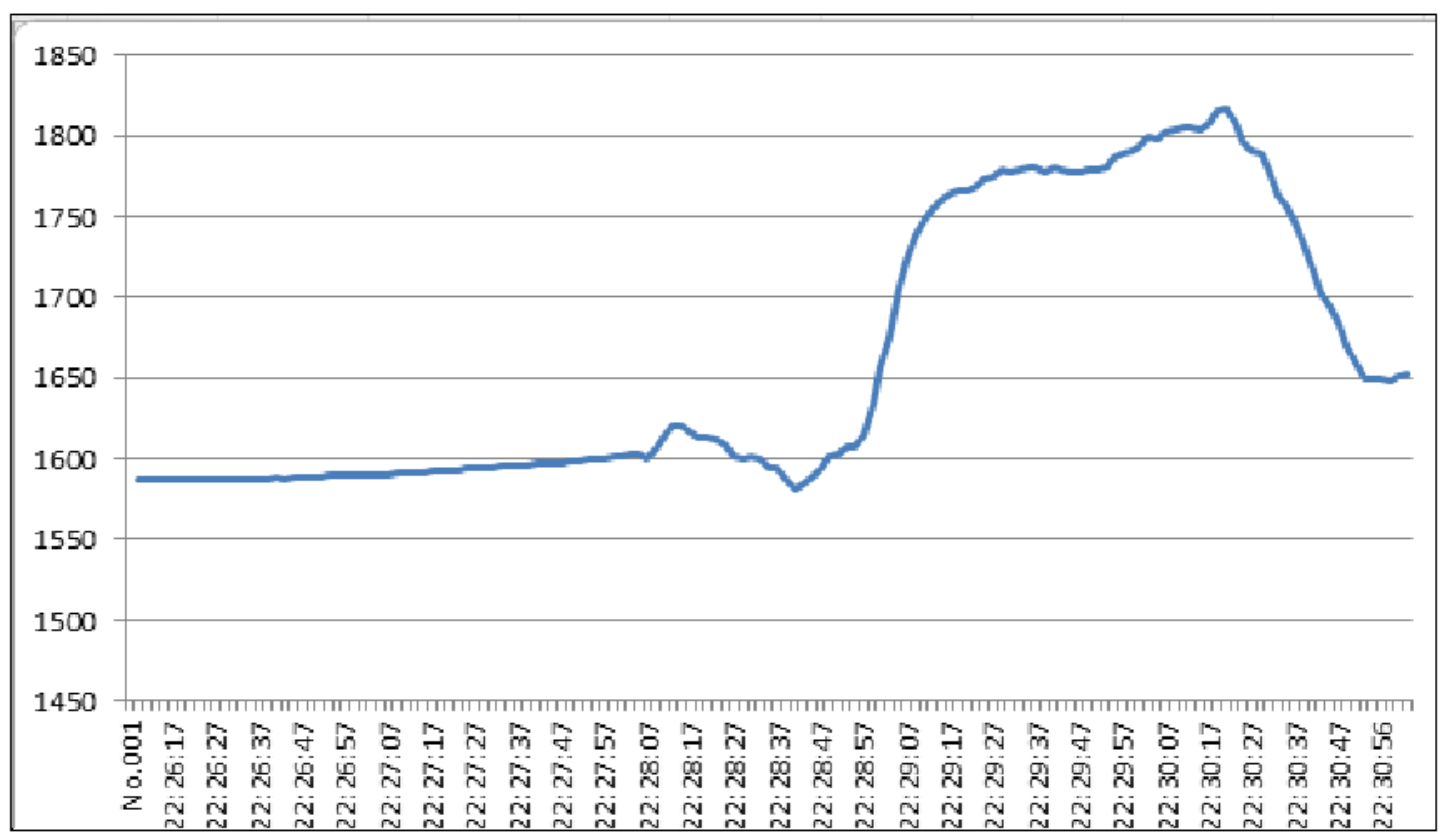

Figure 17 Increasing Grout Density $(W / C=0.45)$ to $(W / C=0.40)$

Result: Clear indication of changes in grout concentration. (Absolute values aren't meaningful as the liquid wasn't calibrated) 


\subsubsection{Maintenance and Marinization:}

The sensor itself is rated for 10 bar, the conduit head just needs to be potted

In the test, we simply cleaned out the apparatus with water. Concrete wastewater (an environmental hazard) was left in barrels to settle out

\subsubsection{Conclusions and Recommendations}

Conclusions:

- The sensor is unaffected by flow rate and orientation.

- The sensor clearly shows changes in grout concentration.

- Marinization and maintenance requirements seem ok so far.

Recommendations:

- We should figure out how to set up liquid calibrations in the sensor and do so for some different $\mathrm{W} / \mathrm{C}$ ratios.

- We should evaluate the accuracy of the density measurements.

- We should do another test introducing foreign materials (sand, gravel etc) to see how the sensor handles these. Suspended solids are also measureable.

- We should think of a way to verify all weak grout has been recovered from the hole (a slug of full rich grout may not be absolutely reliable) 


\subsection{Test Sensitivity to Seabed Inclusion}

\subsubsection{Test Apparatus}

We built the test apparatus with 3" sch. 80 pipe to match the ID of 3" Stainless Steel Sanitary tubing.

We used an inline mixer to mix grout with sand or gravel. We custom made a manual plunger to deliver sand \& gravel into the system. A manual control ball valve was provided to control the delivery of sand \& gravel into the weak grout. A marked 3"sch. 80 clear tube is provided to monitor the feed rate of sand \& gravel.

The ultrasonic density sensor is in-line with a logger that logs time-stamped sensor data to a text file.

We used the Contech Systems plant for our testing.

An Obermann grout mixer/pump, MAPQ Pressure sensor and control valve were provided by Contech to be used for this test.

We used Type 10 cement and a weak grout with water/cement ratio of 0.8 .

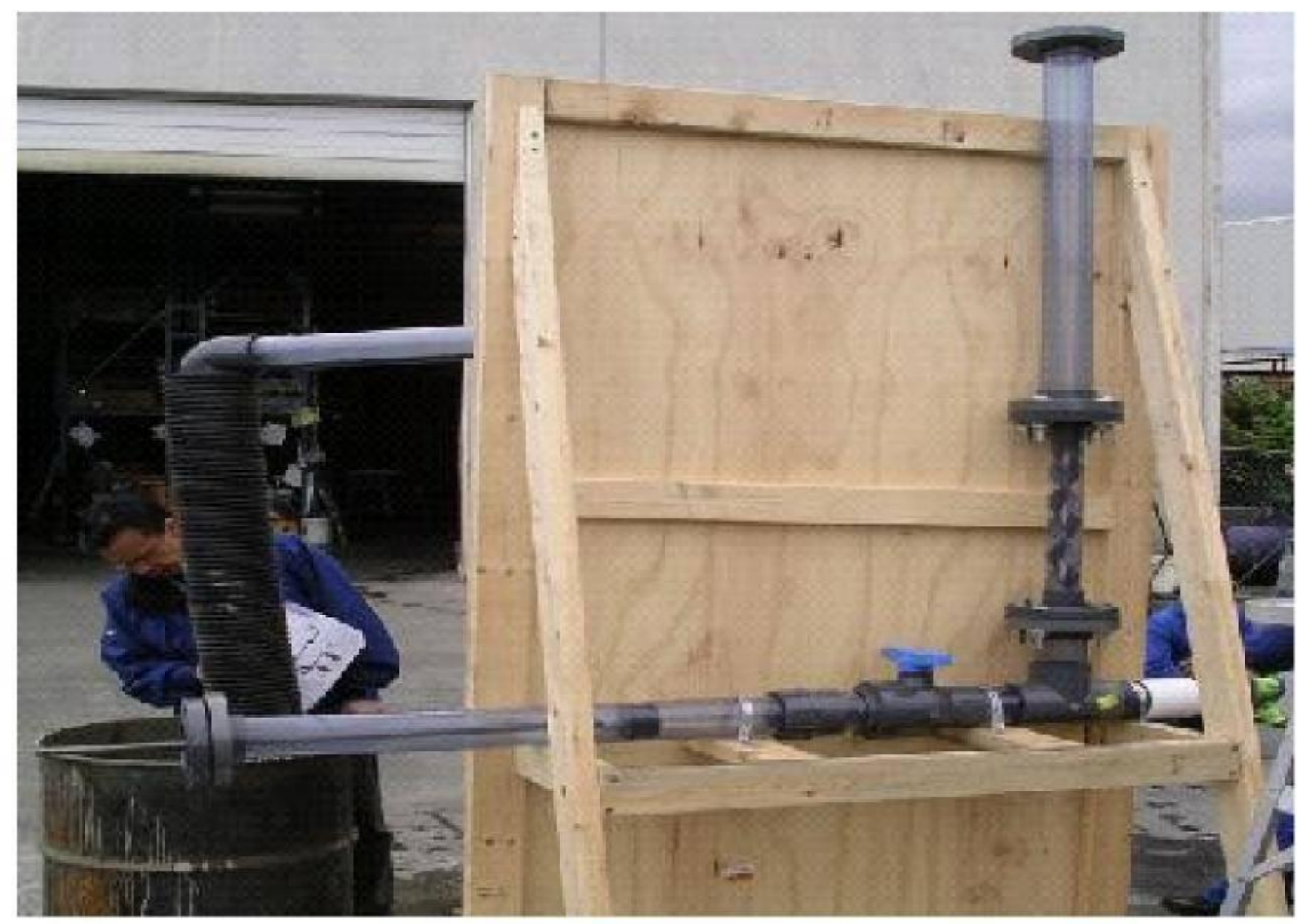

Figure 18 Seabed Inclusion Test Apparatus 

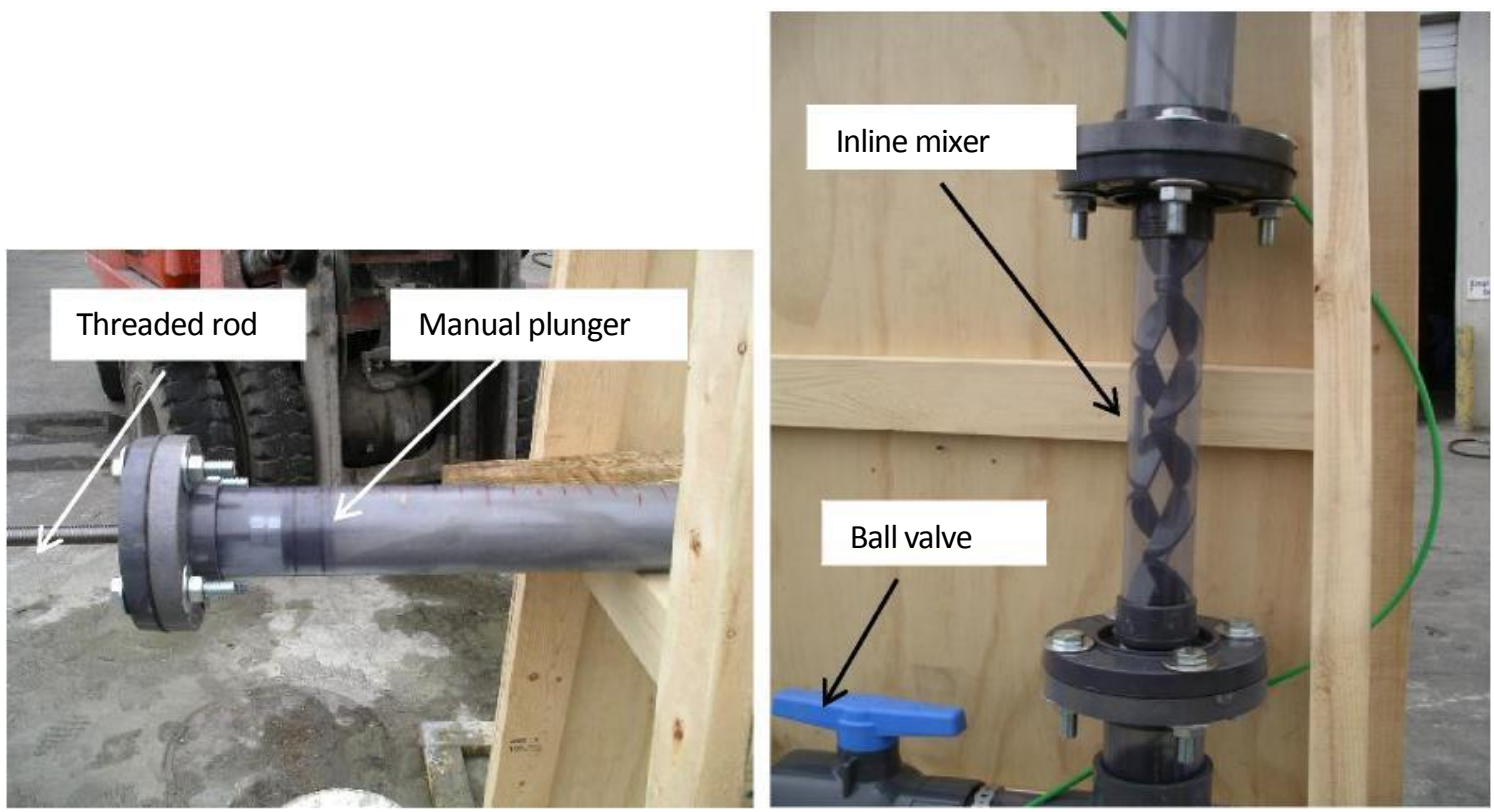

Figure 19 Seabed Inclusion Test Apparatus

\subsubsection{Water Preparation}

We started with water only $(\mathrm{w} / \mathrm{c}=\infty)$

The flow rate on the Obermann pump was set to 301/min and pressure relief to 4 bar. The flow control valve was adjusted so that the MAPQ Pressure sensor read 0.5 bar.

Water filled the system to eliminate air pockets and to provide a fluid path for sand \& gravel to mix with the grout.

\subsubsection{Mixing Test}

We started with a weak grout $(w / c=0.8)$ solution.

Our manual plunger was set to deliver sand or gravel at a delivery rate determined by the turns/sec of the threaded rod.

The density sensor was mounted on a vertical member (as recommended by the manufacturer)

The grout flow rate was set to $301 / \mathrm{min}$ and pressure relief to 4 bar at the Obermann delivery system. The pressure was set to read 0.5 bar using the Flow Control Valve. The ball valve was opened to $100 \%$.

As grout reached the sensor, the plunger was manually turned to push the sand into the grout. After several turns, the manual plunger jammed with sand and stopped turning.

We performed a second test with a new bag of grout. We managed to turn the plunger another $1 / 2$ turn but no further. Only a small amount of sand was mixed with the grout; therefore no data was logged.

\subsubsection{Result}

Results were inconclusive, as our apparatus failed to inject sand into the grout mix effectively. 


\subsection{Pressure Control Test}

\subsubsection{Apparatus}

An Obermann grout mixer/pump, MAPQ Pressure sensor and flow control valve were provided by ConTech to be used for this test

We used Type 10 cement and two grout mixtures:

- a weak grout with water/cement ratio of 0.8

- $\quad$ rich grout with $w / c$ ratio of 0.45

The pile anchor used in the test was $1250 \mathrm{~mm}$ long, $40 / 20 \mathrm{~mm}$ diameter with a button drill bit at one end and flushing head at the other end (provided by Con-Tech).

We used 8 sheets of $1 / 8$ " thick neoprene between end flanges as a seal to prevent the grout from exiting around the top of the anchor pile, i.e. to keep the grout inside the flow circuit.

We used, both 3" or 4" clear sch.80 PVC tubes to build our apparatus

We performed the Pressure Test without the Density Sensor (manufacturers claim that flow rate doesn't matter, and we did the weak and rich grout tests previously)

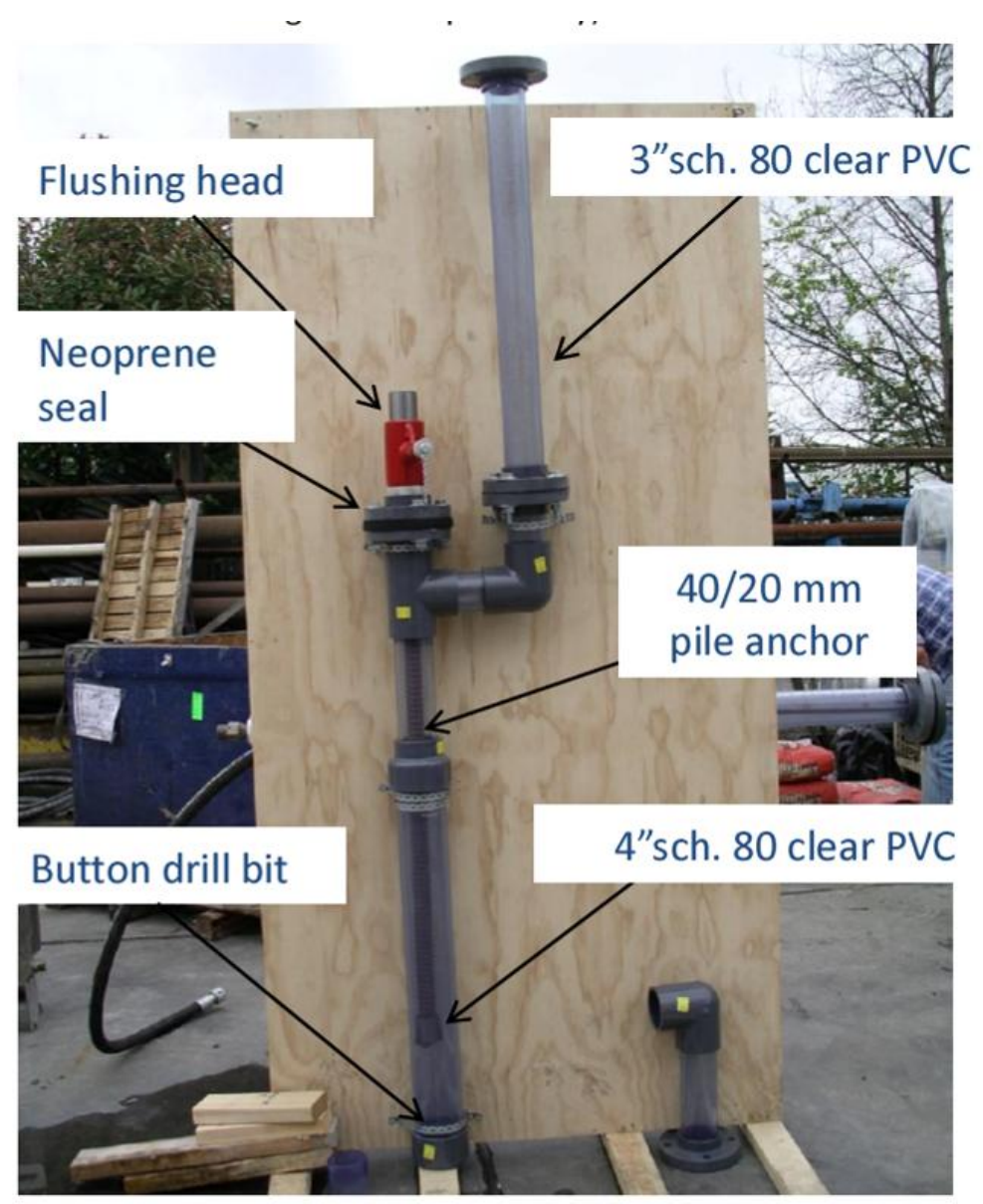

Figure 20 Pressure Control Test Apparatus 


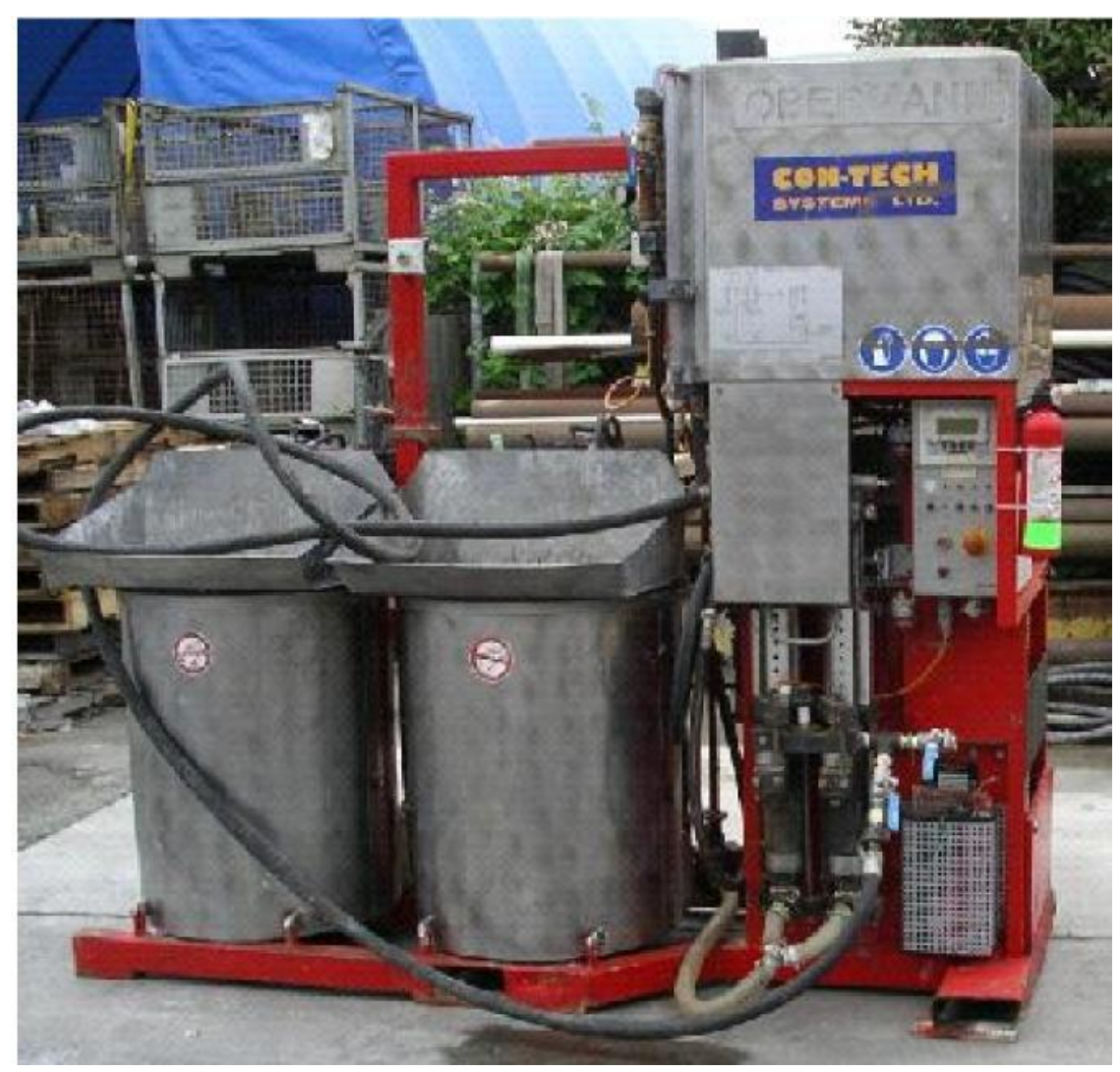

Figure 21 Obermann Grout Mixer/Pump

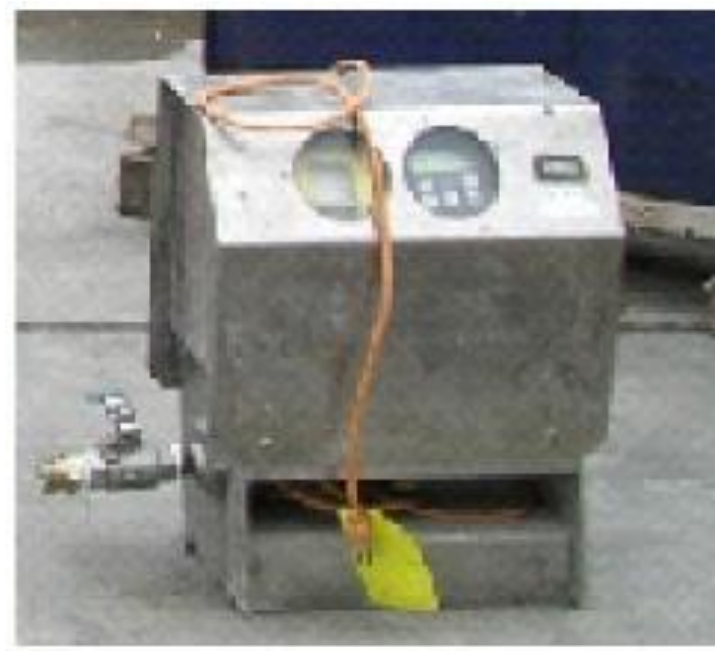

Figure 22 MAPQ Pressure Sensor 


\subsubsection{Test Procedure}

\subsubsection{Water Test}

Started with water $(\mathrm{w} / \mathrm{c}=\infty)$

- Flow Control Valve set to "closed".

- Grout flow rate set to $30 \mathrm{l} / \mathrm{min}$ and pressure to 4 bar at the Obermann delivery system to simulate surface-based grout delivery.

- Flow Control Valve closed.

- Open the Flow Control Valve $\sim 15^{\circ}$ to set pressure sensor to read 0.5 bar.

- Fill the apparatus with water.

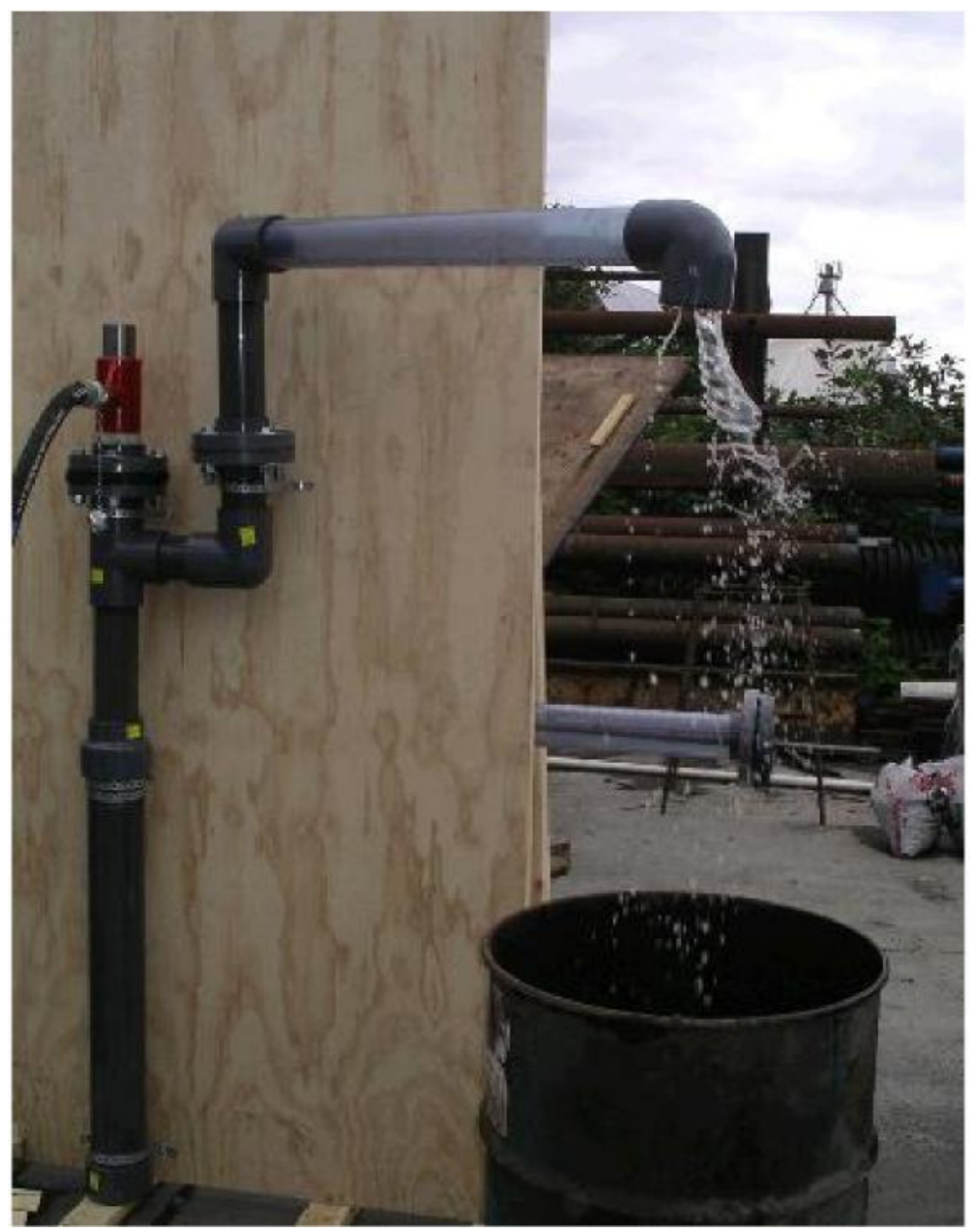

Figure 23 Initial Water Flow 


\subsubsection{Weak Grout}

Weak grout delivery $(\mathrm{W} / \mathrm{C}=0.8)$

- Keep the Obermann delivery system to 4 bar \& 30 1/min to flush out the water.

- After noticing weak grout exiting the system, close Flow Control Valve.

- $\quad$ Set pressure @ Obermann delivery system output to 2 bar and open Flow Control Valve slightly $\left(\sim 15^{\circ}\right)$ for MAPQ sensor to read 0.5 bar (i.e. reducing the pressure of the grout provided by the simulated surface delivery system).

- Increase Obermann delivery system output to 4 bar (simulating pressure variation).

- Monitor the output pressure from the MAPQ pressure sensor and adjust Flow Control Valve to maintain 0.5 bar output; ensure that a simple valve action can be used to set the output pressure to the desired setting.
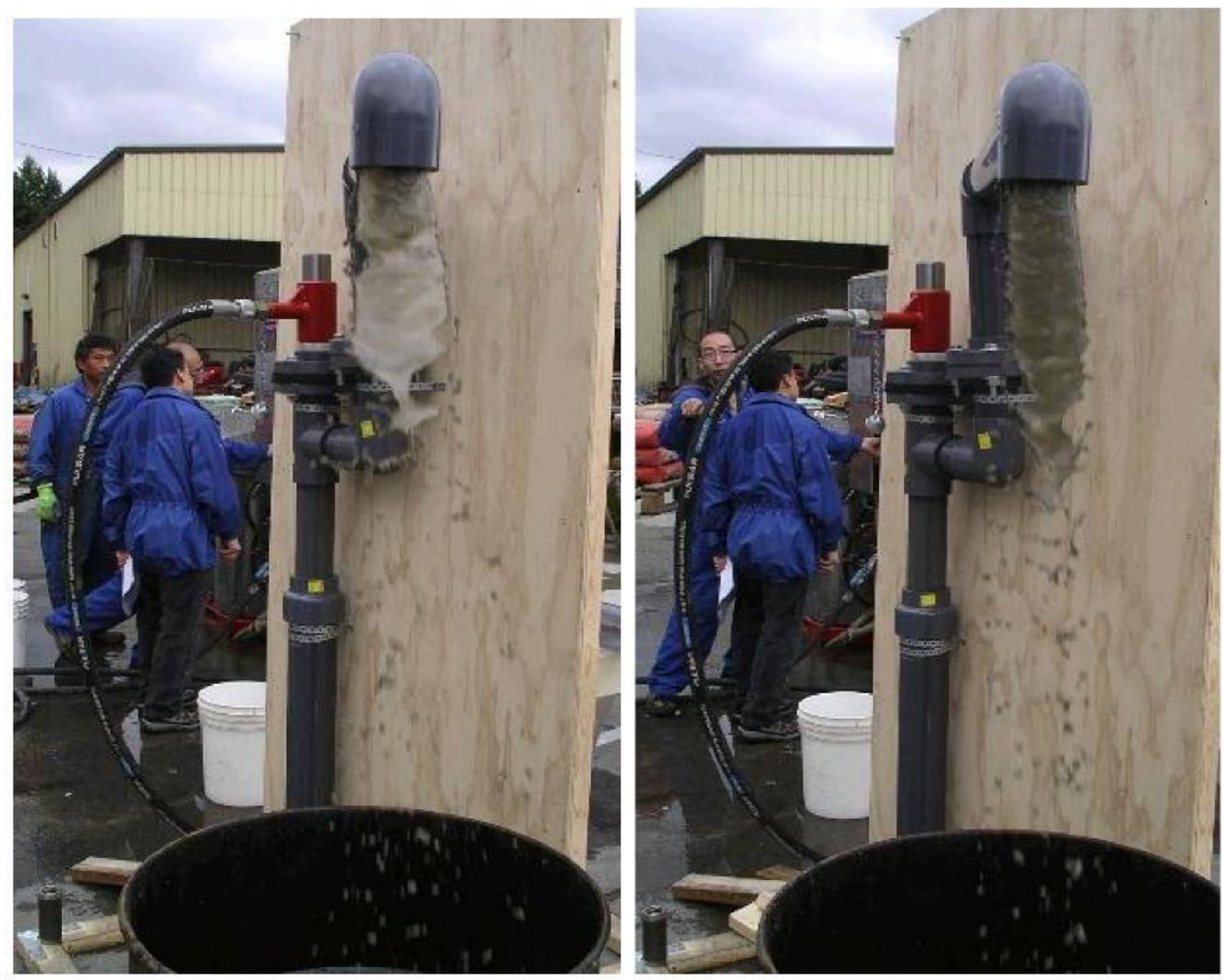

Figure 24 Start of Weak Grout (L) and Continuous Weak Grout (R) 


\subsubsection{Rich Grout}

Rich grout delivery $(\mathrm{W} / \mathrm{C}=0.45)$

- Keep the Obermann delivery system to 4 bar \& 30 1/min to flush out the weak grout.

- After noticing rich grout exiting the system, close Flow Control Valve.

- Set pressure @ Obermann delivery system output to 2 bar and open Flow Control Valve slightly $\left(\sim 15^{\circ}\right)$ for MAPQ sensor to read 0.5 bar (i.e. reducing the pressure of the grout provided by the simulated surface delivery system).

- Set Obermann delivery system output to 4 bar (simulating pressure variation).

- Monitor the output pressure from the MAPQ pressure sensor and adjust Flow Control Valve to maintain 0.5 bar output; ensure that a simple valve action can be used to set the output pressure to the desired setting.

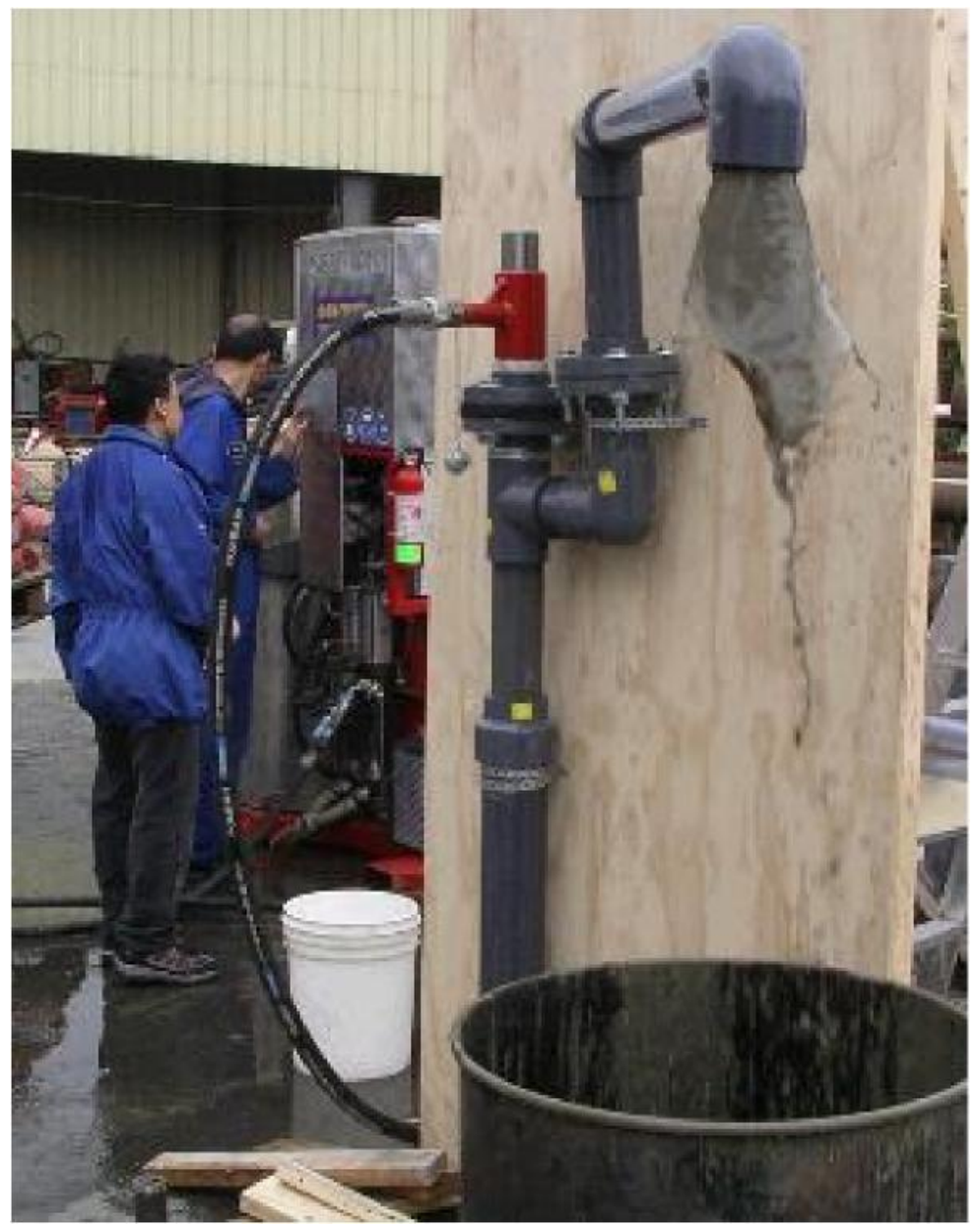

Figure 25 Rich Grout

\subsubsection{Results - Observations}

The manual Flow Control Valve was effective in controlling its output pressure to the desired range with different input pressures and grout densities.

Pressure out of the Obermann delivery was set to 3.9 bar, but the pressure reading would jump quickly from 3.9 to 4.1 or above with small adjustments. 
The output pressure as measured by the MAPQ pressure sensor was easily adjustable from 0.4 to 0.5 bar range. It was relatively insensitive to large changes in input pressure.

The Ultrasonic Sensor showed minimal damage (only surface scratches) after the test. It is easy to clean manually.
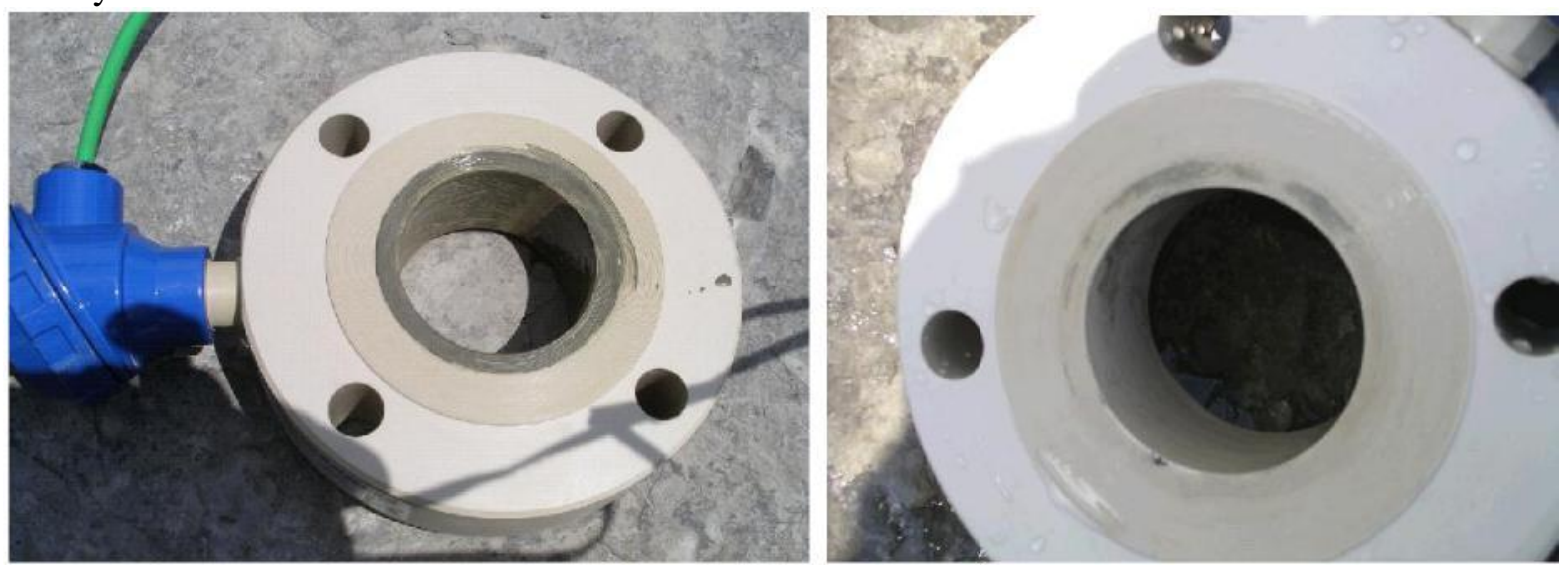

Figure 26 Ultrasonic Sensor after Pressure Test (L) and after Clean Water Flush (R)

\subsubsection{Conclusions}

We were able to use a flow control valve to easily control the output pressure within a reasonable range given varying grout densities and supply pressures.

The Sensitivity to Seabed Inclusion Test was unsuccessful. We need a better way to mix sand or gravel with grout for the test.

Ultrasonic Sensor shows minimal wear during the test. 


\subsection{Pull Test}

\subsubsection{Test Setup}

We are emulating our production system concept with a "Pull Test" that is similar to Gun barrel tests performed by other researchers. A 4" sch. 80 PVC pipe is used to represent a confined hard soils ground condition. A 40mm diameter anchor pile and grout will be place inside the PVC pipe. Grout will set around the anchor pile inside the PVC pipe. A hydraulic jack will be used to pull the anchor pile to determine elasticity and breaking force of the grout and ground interface.

The test was conducted at Con-Tech plant.

Apparatus from the Pressure Control Test was used as the basis for this test, including:

- a combination of clear 4" \& 3" clear schedule 80 PVC pipes, one tee, one elbow, pipe reducer, two pipe flanges,

- a $1250 \mathrm{~mm}$ long $40 / 20 \mathrm{~mm}$ diameter grouted pile anchor with a button drill bit at one end

For the pull testing, the following equipment was added:

- a 100 ton - Orbit ORDH100/8, 100 ton, 10,000 psi hydraulic jack (provided by Con-Tech)

- a Simplex hydraulic pump with pressure gauge and two steel mounting plates by Con-Tech

- Measuring tape

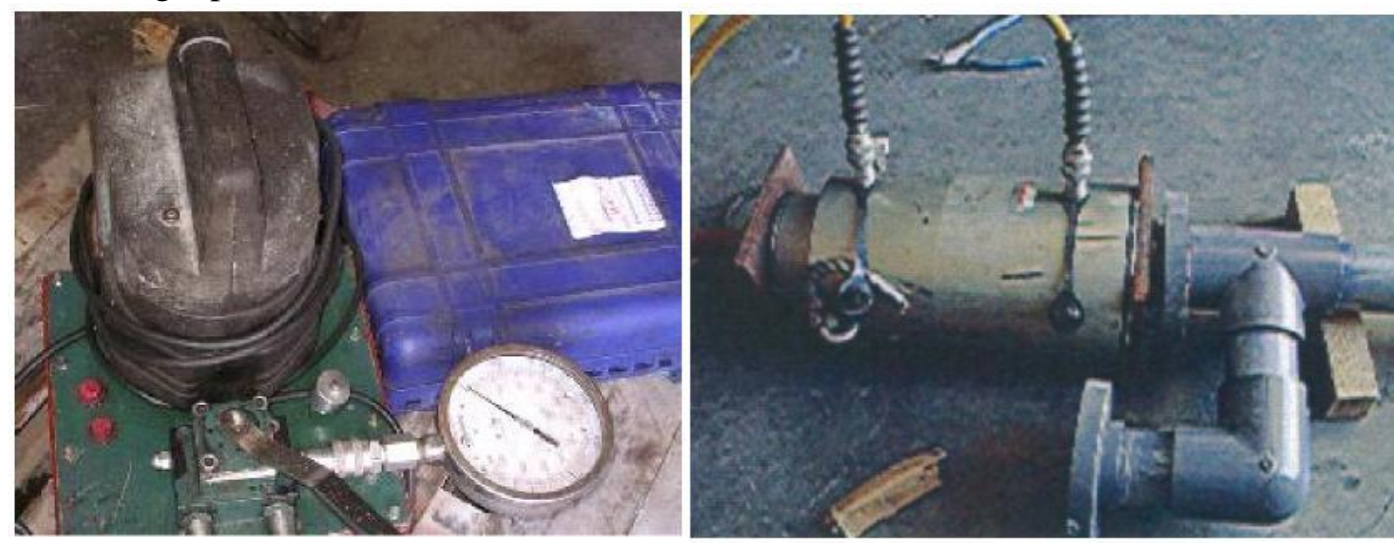

Figure 27 Hydraulic Pump with Pressure Gauge (L) Hydraulic Jack (R)

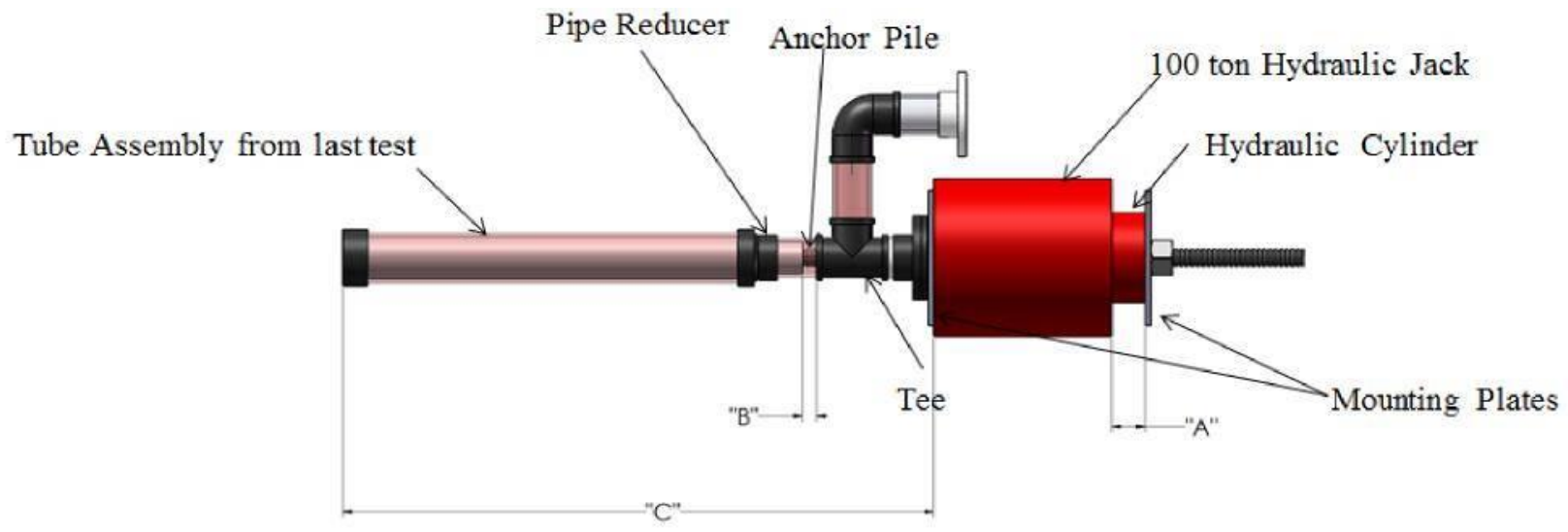

Figure 28 Pull Test Apparatus 
The dimensions in Figure 28 are as follows:

- " $\mathrm{A} "=3$ ",the stroke of hydraulic jack cylinder during the pull test

- "B" = 3/4", where solid grout filled up to

- "C" $\mathrm{C}$ "'-9.63", the overall length of the tube

\subsubsection{Test Description and Results}

1. Pressurized the hydraulic jack to 1200psi $(25,000 \mathrm{lbs})$ for 6 seconds.

Measured dimension " $\mathrm{A}$ " $=3.75$ ", "B" = 3/8" and " $\mathrm{C}$ " $=4$ '-9.5".

After pressure was released dimension " $\mathrm{A}$ " $=3.5$ ". The hydraulic cylinder contracted 0.25 " (from 3.75 to 3.5) after the pressure was released (elastic property of the grout).

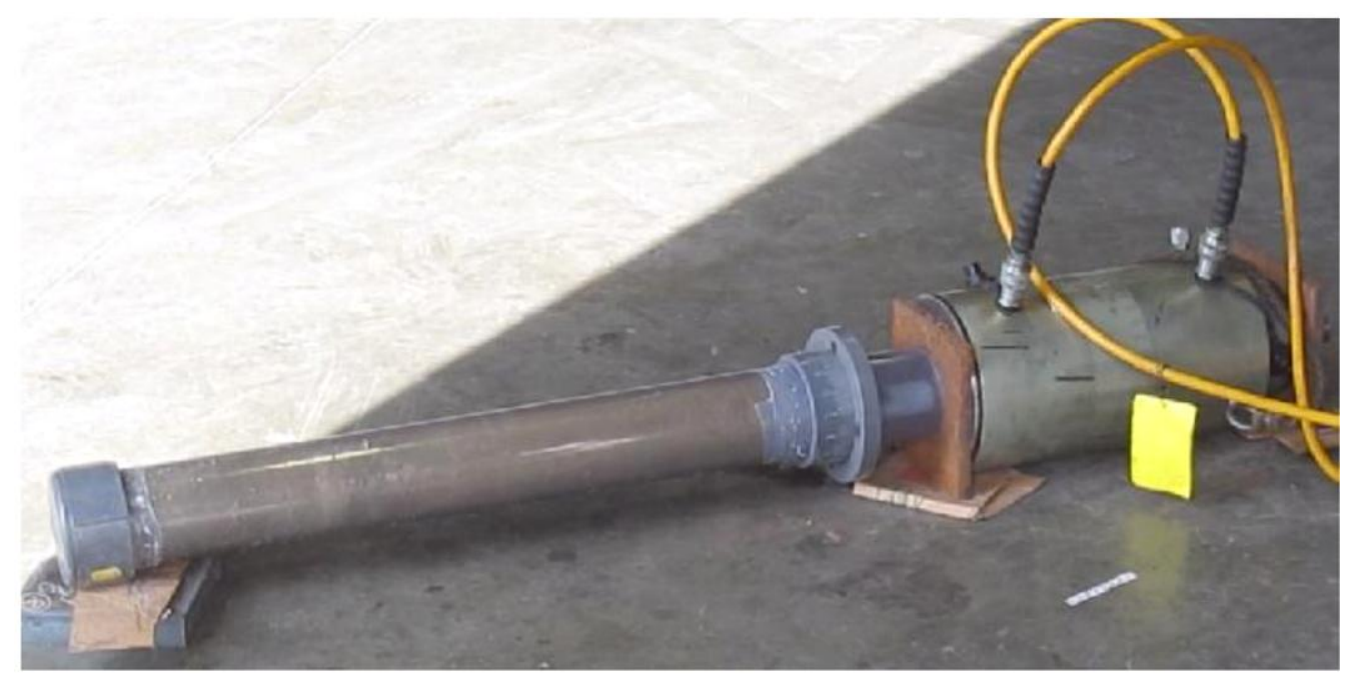

Figure 29 Pull Test Apparatus
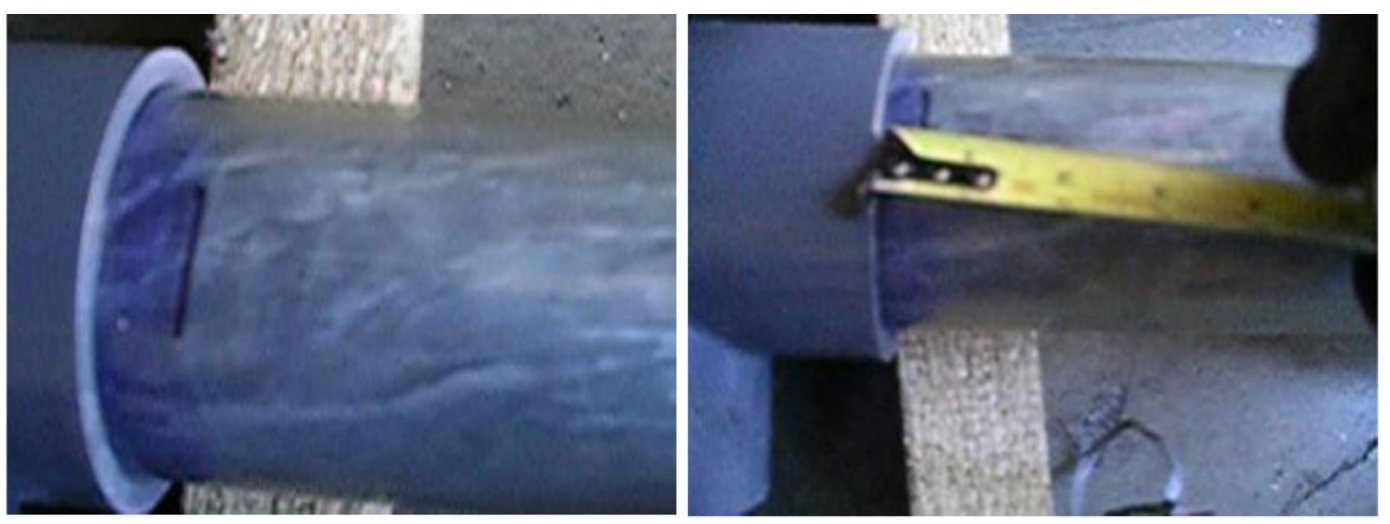

Figure 30 Dried Grout before (3/4" below Tee) and after (3/8" below Tee) first test 
2. Pressured the hydraulic jack to 1300 psi for 10 seconds.

We heard a cracking sound. Measured dimension " $A$ " =4", " $B$ " = 1/4" and " $C$ " = 4'-9.0". A visible crack appeared at the bottom of the 4 " sch. 80 pipe.

Pressure released, dimension A, B \& C didn't change (permanent deformation).
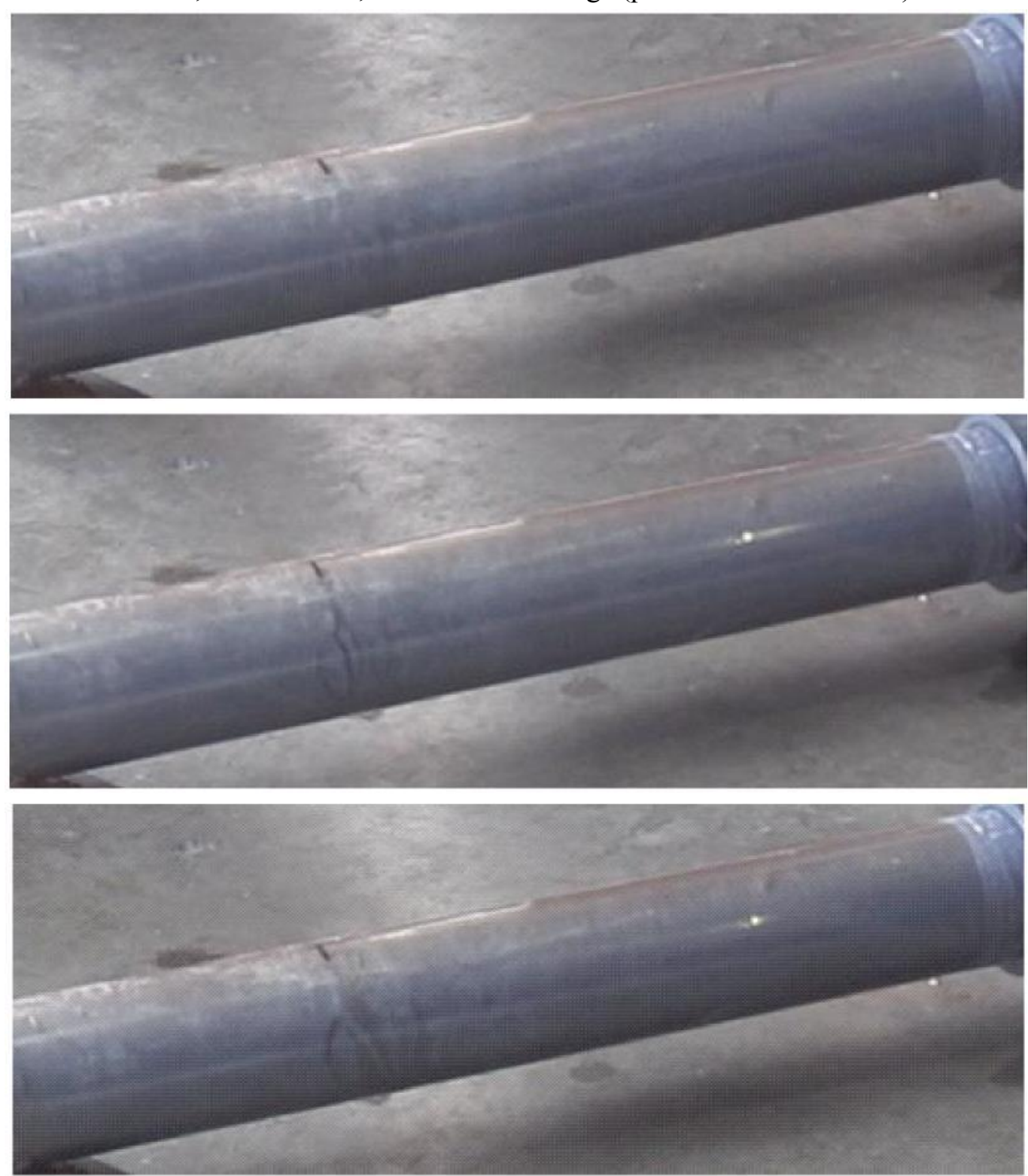

Figure 31 Visible Crack during Second test 
3. Pressurized the Hydraulic Jack to 1500psi for 4 seconds.

The pipe shattered, and the anchor pile \& solid grout pulled out.
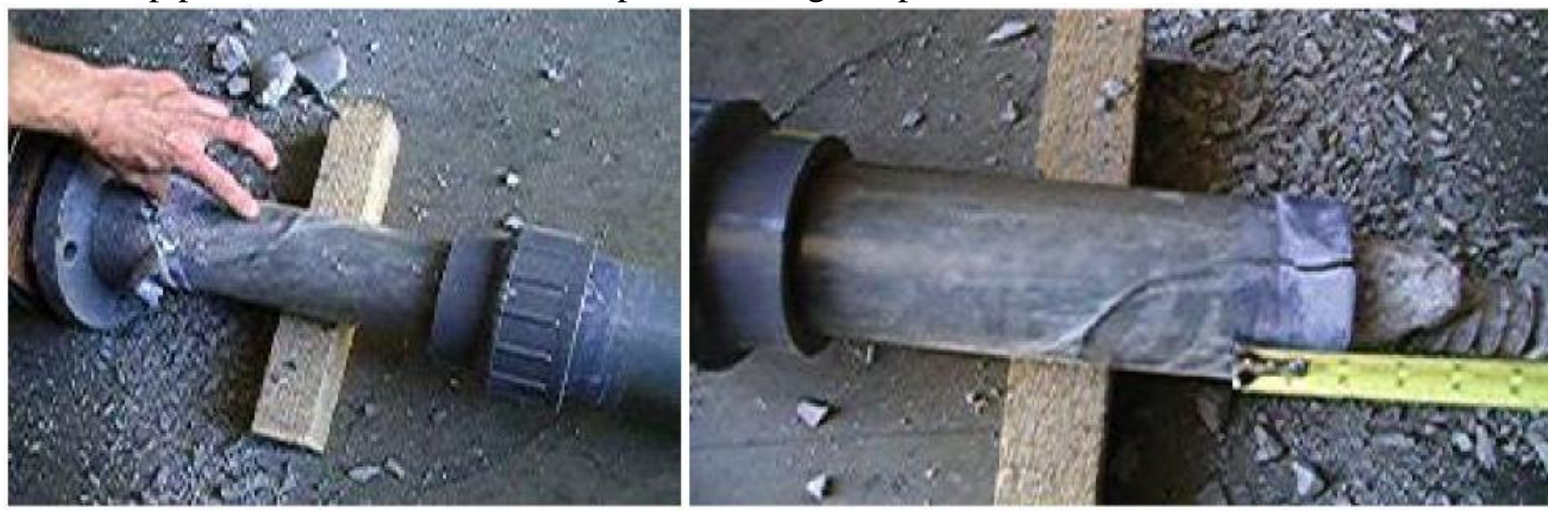

Figure 32 Pipe Shattered During Third Test

\section{Time vs. Force}

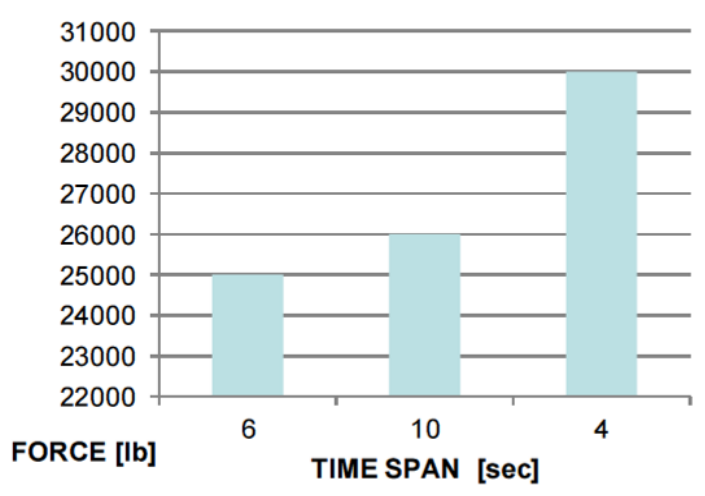

Time vs. Elongation

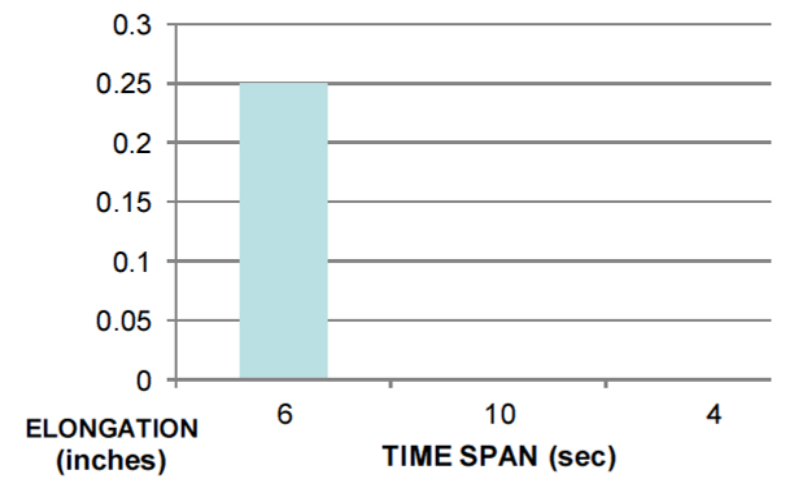

Figure 33 Pull Test Results

\subsubsection{Results Summary}

The force required to separate the grout from the PVC pipe was between 25,000-26,000 lb (1200-1300 psi). A cracking sound was heard at these pressures, and a visible crack appeared at the bottom of the solid grout, perpendicular to the pipe.

The grout appears to have exhibited elastic behavior. The hydraulic cylinder extended and then retracted $1 / 4$ " during the first test. 


\section{Overall Test Results Summary}

The experimental results were intended to determine answers to the following:

1. Will the ultrasonic density sensor adequately signal the transition from the drilling (weak) grout mix to the full rich grout mix?

The ultrasonic density sensor performed very well for this purpose.

2. Does the ultrasonic density sensor perform acceptably in the presence of pressure? Are there any predicted limits of pressure?

3. According to the manufacturer, the ultrasonic sensor is rated for shallow water depths, and from our inspection, it can be readily marinized for use in shallow sea water.

4. Are the changes in grout density due to cuttings and seabed inclusion discernible from changes in grout density due to different water/cement ratios?

This test was unsuccessful. However, the density sensor performed very well over the range of densities, and we see no reason why it would not properly measure the overall density of the combination of grout and particles. If the specific gravity of the seafloor material was significantly different than that of concrete, this mixing of seafloor material with grout could cause errors in measurement and thereby confuse the operator as to when the grout changes from a weak mixture to a rich mixture.

5. Are there any significant issues regarding robustness with this sensor?

Nothing noted. The sensor exhibited very little wear over the course of the tests. In operation, it will need to be inspected on a regular basis.

6. Does the grout pressure control apparatus function? Does it show promise for automation?

The grout pressure control methodology appears to work fine and will adapt readily to automation.

7. Did the grout set properly?

Yes.

8. Did the pull test reveal any irregularities in the experiment?

No. The Pull Test emulated a standard gun barrel test, and the results were within the normal range of behavior. 


\section{Appendix A: Density Calculations}

Density calculation reduces to $\left(\mathrm{G}^{*}\right.$ Density of water $\left.*(1+\mathrm{W})\right) /\left(1+\mathrm{W}^{*} \mathrm{G}\right)$. The specific gravity of cement is about 1.5 , which translates to $93.6 \mathrm{lb} / \mathrm{cu}$. ft or $1.5 \mathrm{gr} / \mathrm{cc}$. This is a typical SG for cement. The results of the calculations are shown in Table 1 and plotted in Figure 34 through Figure 36 to show the rates of changes in the measurements. We will be looking for W/C ratios of somewhere between 0.4 to 0.5 and if the measurements are repeatable there seems to be enough change over this range to be acceptable.

Table 1 Density Calculations

\begin{tabular}{|c|c|c|}
\hline Density Reading & W/C & $\begin{array}{c}\text { Calculated Grout Density lb/cu.ft./(gr/cc) } \\
(\mathrm{G}=1.5 \text { for cement })\end{array}$ \\
\hline 1400 & 0.8 & $76.5(1.226)$ \\
\hline 1425 & 0.7 & $77.6(1.244)$ \\
\hline 1600 & 0.45 & $81(1.298)$ \\
\hline 1625 & 0.4 & $81.9(1.313)$ \\
\hline
\end{tabular}

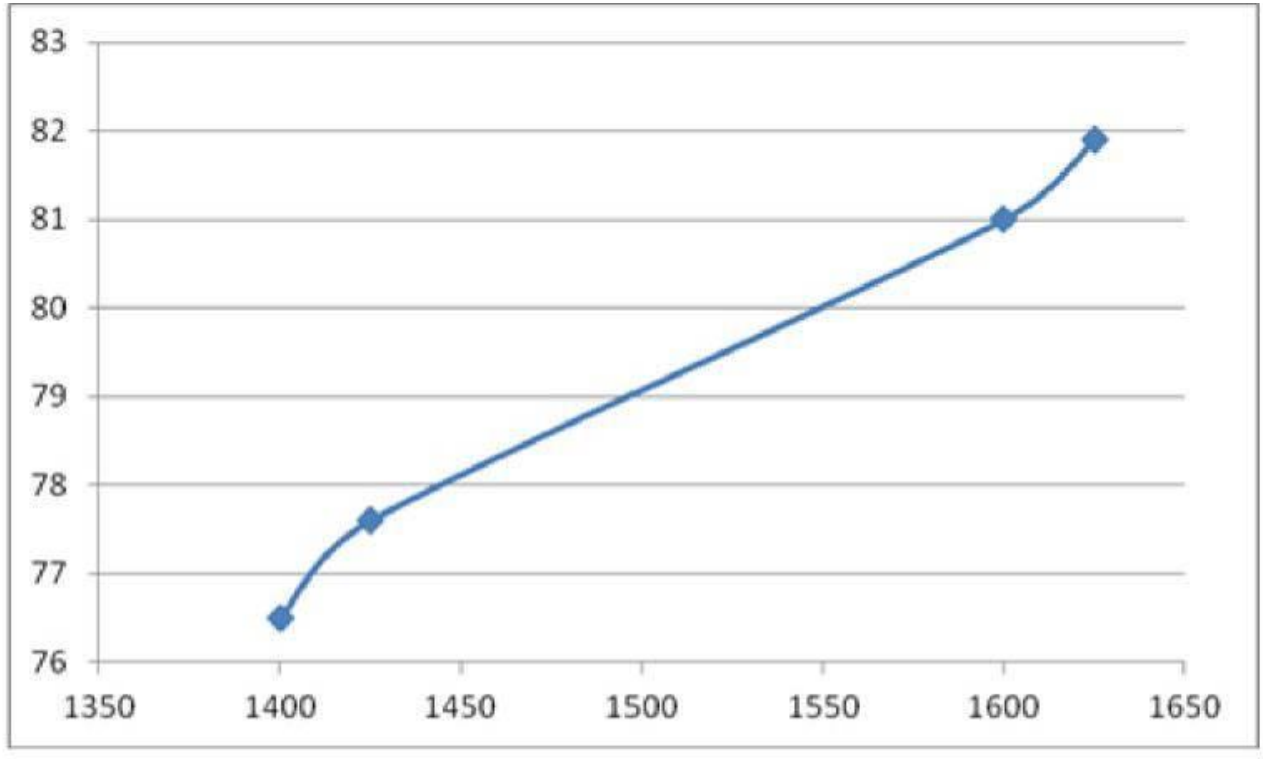

Figure 34 Grout Density vs. Measurement Reading 


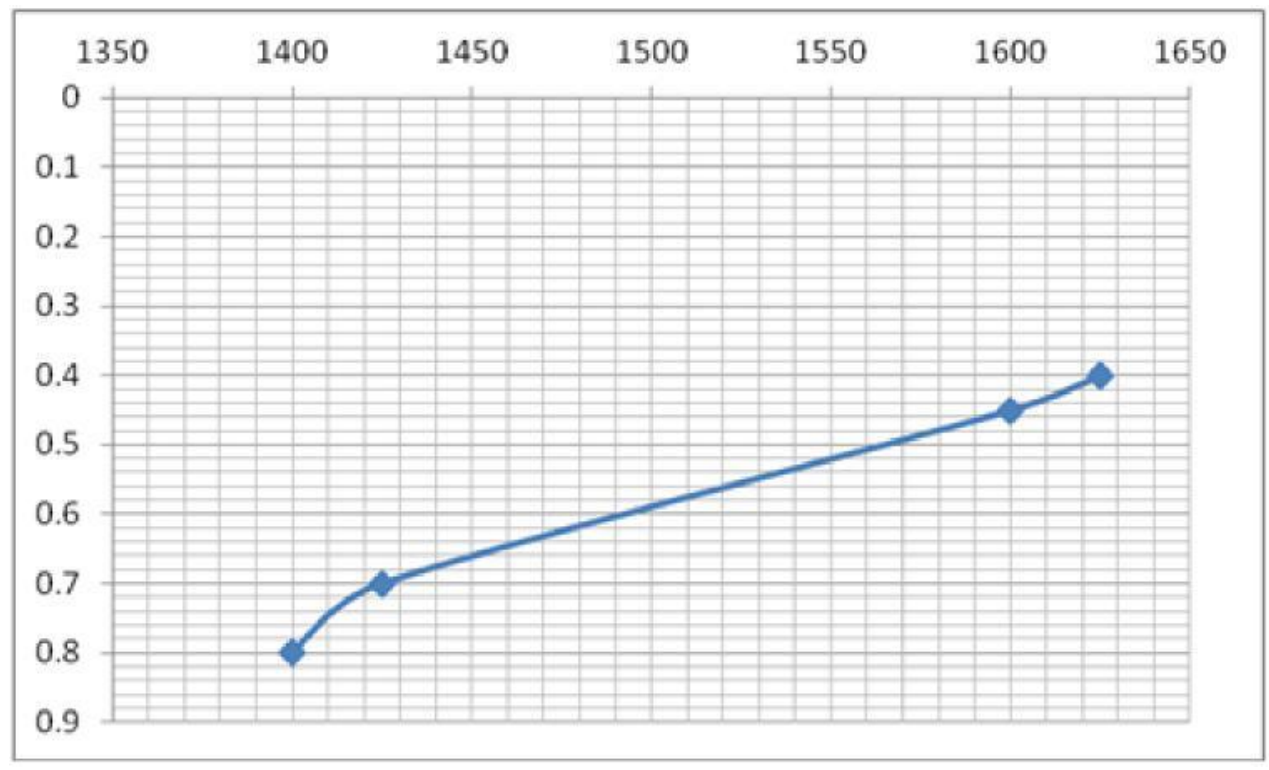

Figure 35 Water/Cement Ratio vs. Measurement Reading

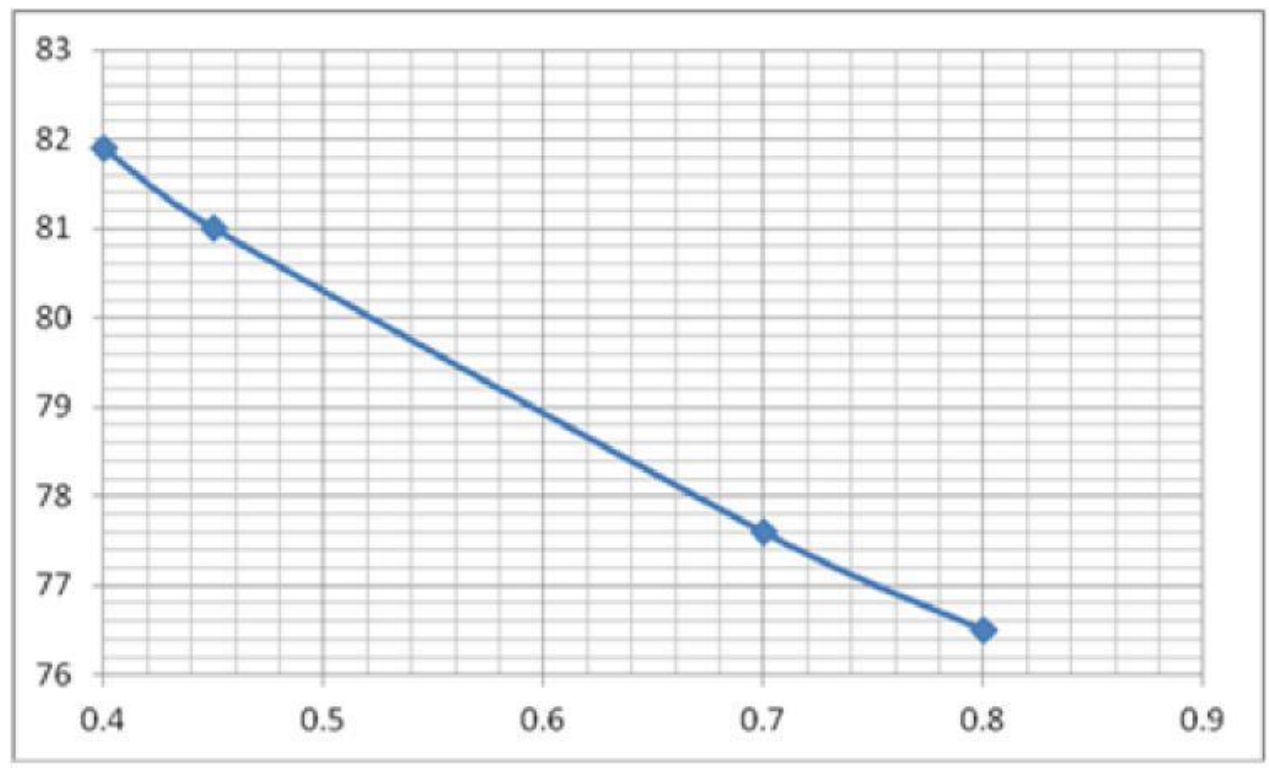

Figure 36 Grout Density vs. Water/Cement Ratio 


\section{End of Document.}

Prepared by:

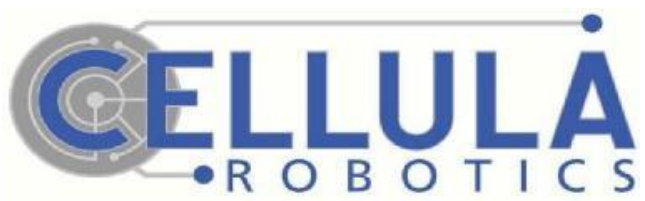

Cellula Robotics Ltd.

632 Carnarvon St.

New Westminster, BC

Canada V3M 1E5

Tel: +1-604-630-5577

Fax: +1-604-525-5570 


\title{
ADVANCED ANCHORING TECHNOLOGY
}

DOE Award Number DE-EE0003632

Environmental Review - Grouted Pile Anchors

\author{
Peter W. Havens, CEP
}

18 January 2012

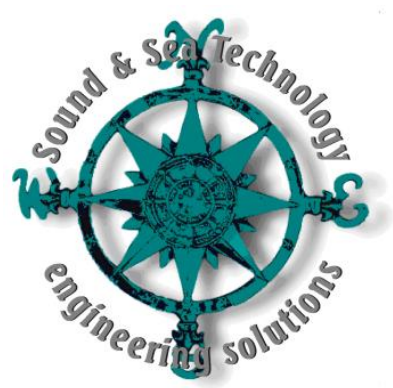

Sound \& Sea Technology, Inc.

3507 Shelby Road

Lynnwood, WA 98097-5524 


\section{Contents}

$1.0 \quad$ Scope 3

2.0 Recommendations 3

2.1 Systems engineering requirements 3

2.2 Design recommendations 3

3.0 Regulatory requirements 4

3.1 National Environmental Policy Act (NEPA) and State Environmental Policy Acts 4

3.2 Clean Water Act 4

3.3 Other Laws 5

4.0 Drill Grouting Reference Background 5

5.0 Potential Consequences 7

5.1 Hazardous Materials and Safety 7

5.2 Terrestrial surface runoff and sediment transport 7

5.3 Alkaline contamination with $\mathrm{pH}$ rise 7

5.4 Cross-contamination (up/down, in/out) of underground aquifers 8

6.0 System Engineering Guidance for Complying with The Clean Water Act, Section 404(b)(1) 8

6.1 Application of environmental requirements 8

6.2 Alternative Consideration 9

6.3 Practicability 9

6.4 Environmental Impact9

6.5 Mitigation 9

7.0 Literature Cited $\quad 10$ 


\subsection{SCOPE}

This is a review of potential environmental consequences from, and compliance requirements for the use of Portland cement grout as a drilling mud (thinned) and as an adhesive and seal for the lower portion of a pile anchor into the ocean bottom. Grout provides an annular seal between drill bores and installed piling anchors. The grout reduces friction between the drilling equipment and the earth and offers some corrosion protection properties.

This review provides a generic view and systems engineering requirements based on this scope. As systems engineering develops solidifies a project from concept to specification, additional specifics for environmental requirements can be raised, considered and applied as appropriate. See Section 6.0 System Engineering Guidance for Complying with The Clean Water Act.

\subsection{RECOMMENDATIONS}

\subsection{Systems engineering requirements}

Installation of grouted anchors shall not cause a $\mathrm{pH}$ change of more than 0.2 units from the naturally occurring variation or any case outside the range of 6.5 to 8.5 within 1 meter of the sediment-water interface vertically and immediately outside the drill entry construction site horizontally.

Grouted anchor installation design shall comply with the Clean Water Act (US) or equivalent legislation of the host country.

\subsection{Design recommendations}

Maintain a written environmental record of design trade studies and alternative analyses demonstrating the identification of the "least environmentally damaging practicable alternative."1 Employ a water quality modeling and decision support program such as CORMIX ${ }^{2}$ to predict and validate environmental consequences during system development and testing. This approach reduces uncertainty and improves the permitting outlook for project applications.

Employ drilling mud recycling and isolate the bore entrance from surrounding waters. During drilling, the recycling system would avoid the release of cement grout into the surrounding

\footnotetext{
${ }^{1}$ Under 404(b)(1) of the Clean Water Act (33 U.S.C. 1344) potential degradation of water quality can be allowed, but only if preceded by consideration of other less damaging alternatives. This information is considered during permit procedures. In the US, discharges of materials will not be permitted without a demonstration from permit applicants that the discharge is the least environmentally damaging practicable alternative (40 CFR 230.10). The term practicable means available and capable of being done after taking into consideration cost, existing technology, and logistics in light of overall project purposes.

${ }^{2}$ http://water.epa.gov/scitech/datait/models/cormix.cfm
} 
water. The drill bore at the mudline would be isolated from the surrounding water and contain the release of cement grout.

Use anti-washout admixtures to the grout to limit potential release of cement grout into surrounding waters.

Use only bottom-up fill (aka tremie) methods to pour the anchor grout.

\subsection{REGULATORY REQUIREMENTS}

\subsection{National Environmental Policy Act (NEPA) and State Environmental Policy Acts}

NEPA and State-equivalent laws require a review of the environmental consequences of a proposed action that is available for public review before implementing the action. These laws are intended to raise the consideration of environmental consequences from afterthought to project development decision making. Federal action proponents are required to comply with NEPA and others are required to comply with similar State-level legislation. All of these laws require analytical documentation that describes the project, assesses potential environmental consequences, includes provision to mitigate ${ }^{3}$ potential adverse consequences and provides evidence to support conclusions.

Internationally, there may be similar laws. The European Union, for example, is a leader in setting up environmental impact assessment requirements for proposed actions. Canada has a Provincially-specific approach that involves environmental review of the project before implementation, somewhat similar to a US permit process.

The NEPA compliance process is typically a critical path work package for any project. The process is highly project and site-specific and must be planned, funded and initiated well in advance (years) of the project installation date.

\subsection{Clean Water Act}

In the US, water quality impacts during construction are covered by the Clean Water Act (CWA). This law is one of few that downloads jurisdiction from the Federal government to the individual States. Each state establishes water quality standards (usually based on water uses), basically extending the reach of the law with greater specificity and applicability.

The CWA regulatory program is based on the US Army Corps of Engineers (USACE) permit program. Potential intended discharges of solid materials in quantity (cubic yards) must be approved through this program. The CWA section 404 requires the USACE public interest review of the project from a Federal perspective. The CWA section 401 requires a State Water Quality Certificate (WQC) review from a State perspective. The USACE permit cannot be

\footnotetext{
${ }^{3}$ Mitigation includes avoiding, reducing and compensating for adverse environmental consequences, in that order of priority. Decisions to include or forego mitigation are based on evidence provided in the impact assessment documentation.
} 
issued without the WQC. The WQC provides a legal document that temporarily modifies water quality standards in a mixing zone surrounding the intended work. The WQC typically contains special provisions for monitoring and construction management. In some cases, a lease or easement is required for use of State-owned submerged lands.

The permitting program will be different in other countries. Generally, US requirements are most stringent so that planning for US compliance will achieve international compliance with minor exceptions.

CWA permitting is very project and site-specific. Compliance involves design decisions that are reported in the project scope documentation submitted to regulatory agencies. The regulatory permit process is typically under political pressure to be conducted without delay. Thus, one can expect a typical CWA 404/401 process to last from 6 months to a year.

\subsection{Other Laws}

Other environmental laws of importance include substantive and procedural compliance that is generally addressed in parallel with the NEPA impact assessment or the CWA permit process. A well-executed NEPA process should identify all compliance requirements. Internationally, these laws would include:

- Historical and Archeological protections

- Coastal land use management

- Aboriginal/native peoples cultural values and activities

- Social considerations such as views and obstructions, minority populations, schools, etc.

- Hazardous materials and hazardous wastes

- Transportation and public services

\subsection{DRILL GROUTING REFERENCE BACKGROUND}

The following information has been excerpted from reference materials. Other information was researched, but not included here as it tended to repeat these statements.

(EPA 1997)

Grouting can prevent surface and cross-contamination of aquifers that have been intruded by the drill bore. Cross-aquifer contamination could result if the borehole penetrates more than one aquifer; and contaminated water from one aquifer flows along the borehole and mixes with clean water from another

There are differing views on the best grouting materials and placement methods. In general, full length grouting of the borehole using the Tremie method and a proper grout can help maximize thermal performance and environmental safety. See state regulations for drinking water wells.

A popular installation method is the Tremie method. This involves a 10-foot overlap between aquifers. The Tremie concrete placement method uses the Tremie Pipe, through which concrete 
is placed below water level. The lower end of the Tremie Pipe is kept immersed in fresh concrete so that the rising concrete from the bottom displaces the water without washing out the cement content. ${ }^{4}$

Grouting of the borehole simply refers to the refilling of the hole which surrounds the well pipe after it is inserted into the vertical hole. The grout can be the cuttings which were removed from the borehole during drilling, or it can be another material such as sand, cement or bentonite. Depending on the material, the grout can be placed back into the hole in one of two basic methods: top-down, or bottom-up. Each method and grouting material has its own advantages and disadvantages, including degree of environmental protection, effect on system's thermal performance, and cost.

Because many types of grouts and placement methods exist, it is best to determine the specific cross-contamination requirements for acceptable types of grout and application methods in your state.

Some states address well construction methods and require specific types of grouts for different geologic formations, and prescribe grouting methods that depend on whether or not the well penetrates an aquifer. New Jersey requires cement grout in consolidated geologic formations and bentonite in non-consolidated formations. In Delaware, the only approved grouting materials are also cement and bentonite clay, although there is no indication of specific requirements to use one or the other in different geologic formations.

(USACE 2006)

(3) Cement particles can be leached into (and contaminate) the water during underwater Tremie concrete placement. Common methods for minimizing this problem include: i) use of antiwashout admixtures in the concrete, ii) isolating the Tremie concrete (or laitance) from the surrounding water; and iii) minimizing over-filling of underwater shells, forms, or other Tremie concrete containment structures.

Jet grouting works as effectively below water as above. However, the discharge exiting the drill hole is much more difficult to control and can cause serious environmental problems by contaminating the surrounding water. Silt curtains can be used, but they become more difficult to install and maintain as the water depth or currents increase. Use of antiwashout admixture will help reduce contamination.

Tremie pipes can be effectively used to place underwater fills. This technique minimizes segregation, is environmentally sound, and helps to minimize spreading of the fill on the bottom. If rock is being placed with a tremie pipe, the pipe diameter should be 3 to 5 times the diameter of the largest rock to prevent plugging. The smaller diameter pipes should be limited to placing naturally rounded aggregate and the larger used for crushed rock.

\footnotetext{
${ }^{4}$ http://en.wikipedia.org/wiki/Tremie, accessed 1/12/12
} 


\subsection{POTENTIAL CONSEQUENCES}

\subsection{Hazardous Materials and Safety}

Portland cement in its dry condition is classified a hazardous material because of concentrations of hexavalent chromium and alkaline salts. Wet cement (pore water $12.5<\mathrm{pH}<13.5$ ) can be caustic. Cement dust can harm skin and lungs. ${ }^{5}$

\subsection{Terrestrial surface runoff and sediment transport}

Installation of vertical closed loop GHP systems requires that boreholes be drilled, resulting in removal of soil and rock chips from the boreholes. This soil may be left adjacent to the borehole and regraded, or removed from the site. If the soil is left on-site, use care to ensure the soil doesn't migrate to nearby surface waters or sewers.

BMPs: If the disturbed soil will be exposed for a lengthy period of time, then another measure may need to be implemented. For example, at Fort Polk, where over 8,000 vertical loops were recently installed, the Louisiana environmental agency had the drillers use large holding tanks for the drilling mud in order to avoid problems associated with erosion and runoff.

\subsection{Alkaline contamination with $\mathrm{pH}$ rise}

EPA National Recommended Water Quality Standards Aquatic Life Criteria (http://water.epa.gov/scitech/swguidance/standards/current/index.cfm)

"For open ocean waters where the depth is substantially greater than the euphotic zone, the $\mathrm{pH}$ should not be changed more than 0.2 units from the naturally occurring variation or any case outside the range of 6.5 to 8.5. For shallow, highly productive coastal and estuarine areas where naturally occurring $\mathrm{pH}$ variations approach the lethal limits of some species, changes in $\mathrm{pH}$ should be avoided but in any case should not exceed the limits established for fresh water, i.e., 6.5-9.0."

State WQ standards are likely to follow the national criteria. See for example the following:

- Washington State WAC 173-201A-030 (http://water.epa.gov/scitech/swguidance/standards/wqslibrary/upload/wawqs.pdf)

"(v) $\mathrm{pH}$ shall be within the range of 6.5 to 8.5 (freshwater) or 7.0 to 8.5 (marine water) with a human-caused variation within the above range of less than 0.2 units [for AA uses]... less than 0.5 units [for $\mathrm{A}$ and $\mathrm{B}$ uses] ... 6.5 to $9.0 \ldots$ less than 0.5 units [for $\mathrm{C}$ uses]."

North Carolina 15A NCAC 02B $.0100 \& .0200$

${ }^{5}$ OSHA at http://www.osha.gov/dsg/guidance/cement-guidance.html 
"(g) $\mathrm{pH}$ : shall be normal for the waters in the area, which generally shall range between 6.8 and 8.5 except that swamp waters may have a $\mathrm{pH}$ as low as 4.3 if it is the result of natural conditions;"

(Fitch 2003)

The primary impact in marine or aquatic concrete pours is the raising of the alkalinity of the surrounding water to very high levels (around 10 to 12). In reference, the Virginia water quality standard is a $\mathrm{pH}$ of 9 maximum.

In a study of bridge pile scour repairs, Fitch found that use of a combination of fabric coverings and antiwashout admixtures mitigated the potential effect of alkalinity pollution during in-water pours.

(USACE 2006)

Army Corps of Engineers advises the use of scour protection matting to avoid washout of wet concrete pours.

"Scour stone can be placed by any of the methods used for placing backfill, discussed previously. Tremie pipes can be used to place relatively thin layers of scour stone underwater with minimal disturbance to the riverine environment. Also, it is possible underwater to mechanically level (via compaction or vibration) scour stone with nominal sizes up to approximately 9-inches (230 millimeters). Such leveled layers of scour stone exhibit enhanced scour protection as compared with layers with rough un-compacted surfaces.

(1) Riprap, Armor Stone. Riprap and armor stone are the most common means of scour protection for Civil Works projects subjected to high currents, waves, and swells. The design of standard riprap and armor stone scour protection is not addressed here, and guidance on this topic can be found in numerous USACE documents, including EM 1110-2-1601 and EM 11102-1100.

(2) Geotextile Mats. Geotextile mats are frequently used for both temporary scour protection, and for permanent scour protection for projects with appropriate service lives. Geotextile fabric, sometimes attached to wood frames to form fascine mattresses, is often used as a filter layer or construction aid between the native soil and the scour stone or riprap."

\subsection{Cross-contamination (up/down, in/out) of underground aquifers}

Inclusion of grout throughout the drill bore.

\subsection{SYSTEM ENGINEERING GUIDANCE FOR COMPLYING WITH THE CLEAN WATER ACT, SECTION 404(B)(1)}

\subsection{Application of environmental requirements}

Design may exceed the relevant environmental requirement. When this occurs, a documented analysis is needed to substantiate final design decisions. This information is used by the project 
proponent to support environmental review and regulatory approvals after final design and before implementing construction. The following guidance is provided as a method to develop an environmental tradeoff analysis in support of design features that exceed environmental standards.

\subsection{Alternative Consideration}

Describe the alternatives that would meet project objectives considering the following:

- The desired alternative.

- Alternatives that would involve meeting the basic environmental requirement (no action, off-site, on-site).

- Alternatives that would involve greater environmental impact.

- Alternatives that would involve lesser environmental impact.

Consider alternatives that would involve both smaller and larger areal coverage as well as alternatives that would be sited in different locations. Focus this analysis on potential alternatives that might have less adverse impact, but consider alternatives that would have more impact, but less adverse impact on the environment overall.

\subsection{Practicability}

Address the practicability of the above alternatives. Practicability depends on cost, technical, and logistic factors. To be practicable, an alternative must be available and capable of being done after taking into consideration cost, existing technology, and logistics in light of overall purposes. If it is otherwise a practicable alternative, a site not presently owned by the applicant that could reasonably be obtained, utilized, expanded, or managed in order to fulfil the overall purpose of the proposed activity should be considered. Technical and logistical factors that should be considered include, but are not necessarily limited to: access, transportation needs, utilities, topography, and available construction techniques. Address the impacts on the client and the public of not implementing the project.

\subsection{Environmental Impact}

Assess the impact (adverse and beneficial) of each alternative on the aquatic ecosystem and the environment overall. Compare the impact of the alternatives and identify which, is the least environmentally damaging practicable alternative and why. Identify practicable alternatives that have no significant or easily identifiable difference in impact from the least environmentally damaging practicable alternative.

\subsection{Mitigation}

If the alternative identified as the least environmentally damaging practicable alternative still has adverse impacts, identify how to further minimize those impacts. During FEED, mitigation can be applied through impact avoidance and minimization. During NEPA and permit processes, 
Federal agencies can also apply impact restoration and compensation to those potentially significant impacts that have not been mitigated in design.

“Mitigation" includes (40 CFR 1508.20):

- Avoiding the impact altogether by not taking a certain action or parts of an action

- Minimizing impacts by limiting the degree or magnitude of the action and its implementation

- Rectifying the impact by repair rehabilitating, or restoring the affected environment

- Reducing or eliminating the impact over time by preservation and maintenance operations during the life of the action

- Compensating for the impact by replacing or providing substitute resources or environments

\subsection{LITERATURE CITED}

EPA (1997). Heat Pump Environmental Issues Manual: 98.

Fitch, G. M. (2003). Minimizing the impact on water quality of placing grout underwater to repair bridge scour damage. V. D. o. Transportation: 34 .

USACE (2006). Engineering and Design FOUNDATION ENGINEERING: IN-THE-WET DESIGN AND CONSTRUCTION OF CIVIL WORKS PROJECTS. Engineer Technical Letter No. 1110-2-565: 154. 


\title{
GPA11 -DOE Drilled Grouted Anchors Dual Drill Heads Conceptual Designs
}

\section{Cellula Robotics Ltd.}

\author{
September 102012
}

CRL-GPA11-PP-01-D02 


\section{Conceptual Designs}

\section{Main Features}

- Utilize Existing Proven Technology - ROVDrill GA as Baseline

- Single Steel Frame Rated for $3 \mathrm{~g}$ or Sea State 6

- Lifting Harness Rated for $3 \mathrm{~g}$ or Sea State 6

- Improved Productivity - Two Tool Arms (independently operated) pivoting in the middle of the tool rack circle each serving one Drill Head.

- Redundancy - The job can be completed with one Mast / Drill Head if necessary

- Six Tool Racks that unfold on deck for Rods Reloading

- Maximize Tool Rack Capacity - 12 rods with drilling heads and 60 rods with connecting bushings.

- Onboard HPU, Subsea Electronics Pods, Sensors and Valve Packs

- Grouting Mixing and Pumping Equipment located on the Surface / Vessel for shallow water.

- Versatile Design - can be used for Rectangular as well as for Circular Subsea Templates 


\section{Conceptual Design 1}

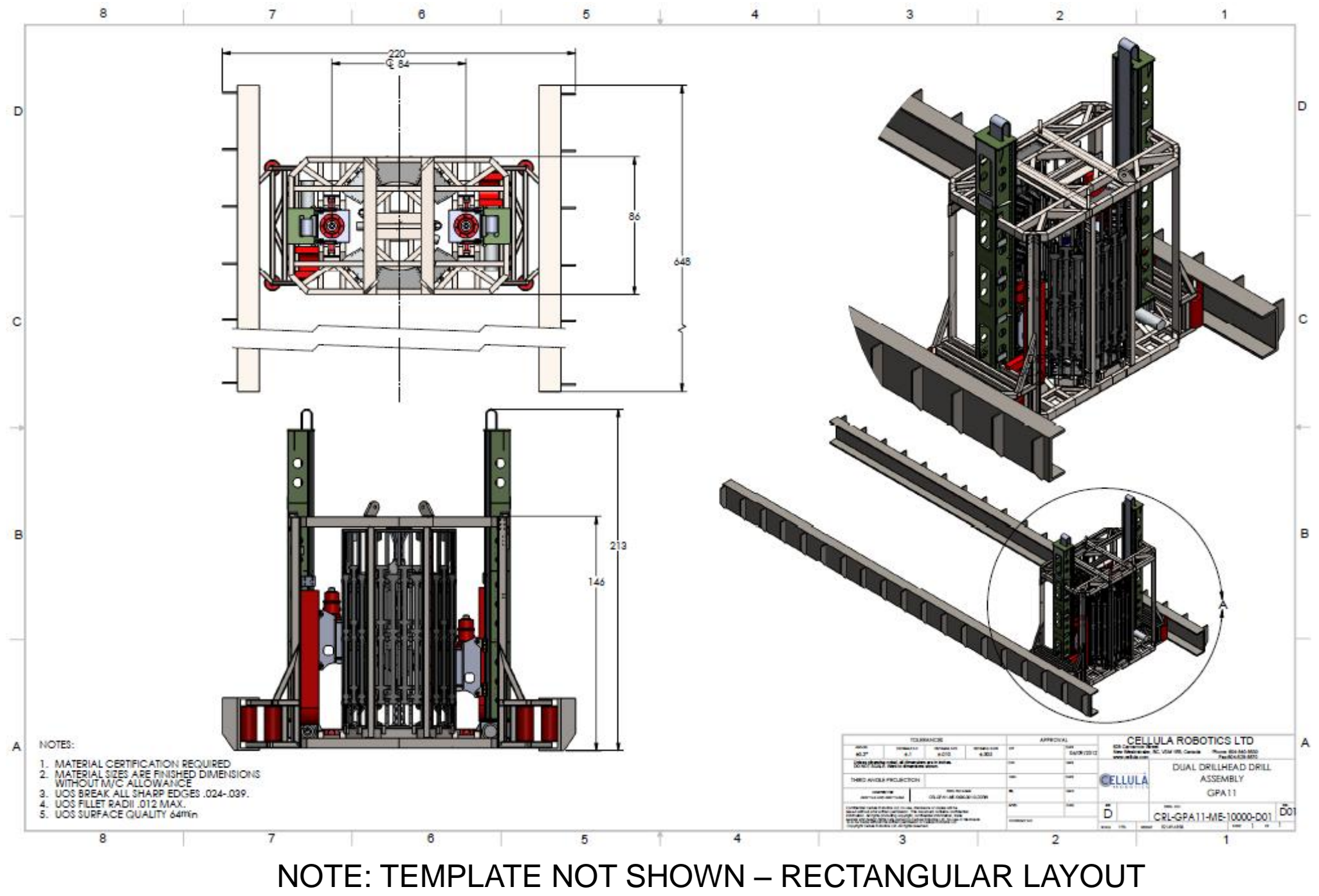




\section{Conceptual Design 1}
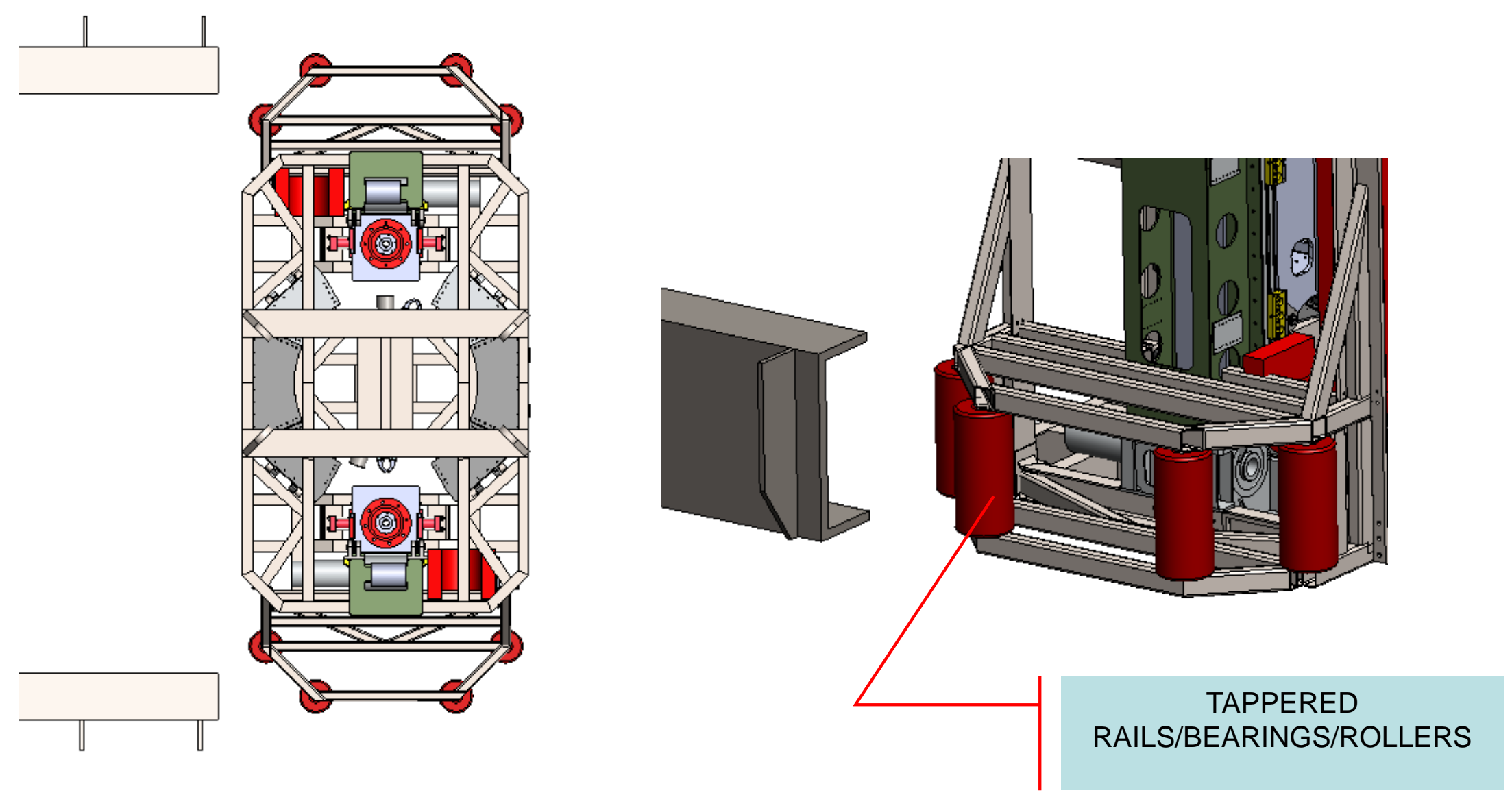

NOTE: TEMPLATE NOT SHOWN 


\section{Conceptual Design 1}
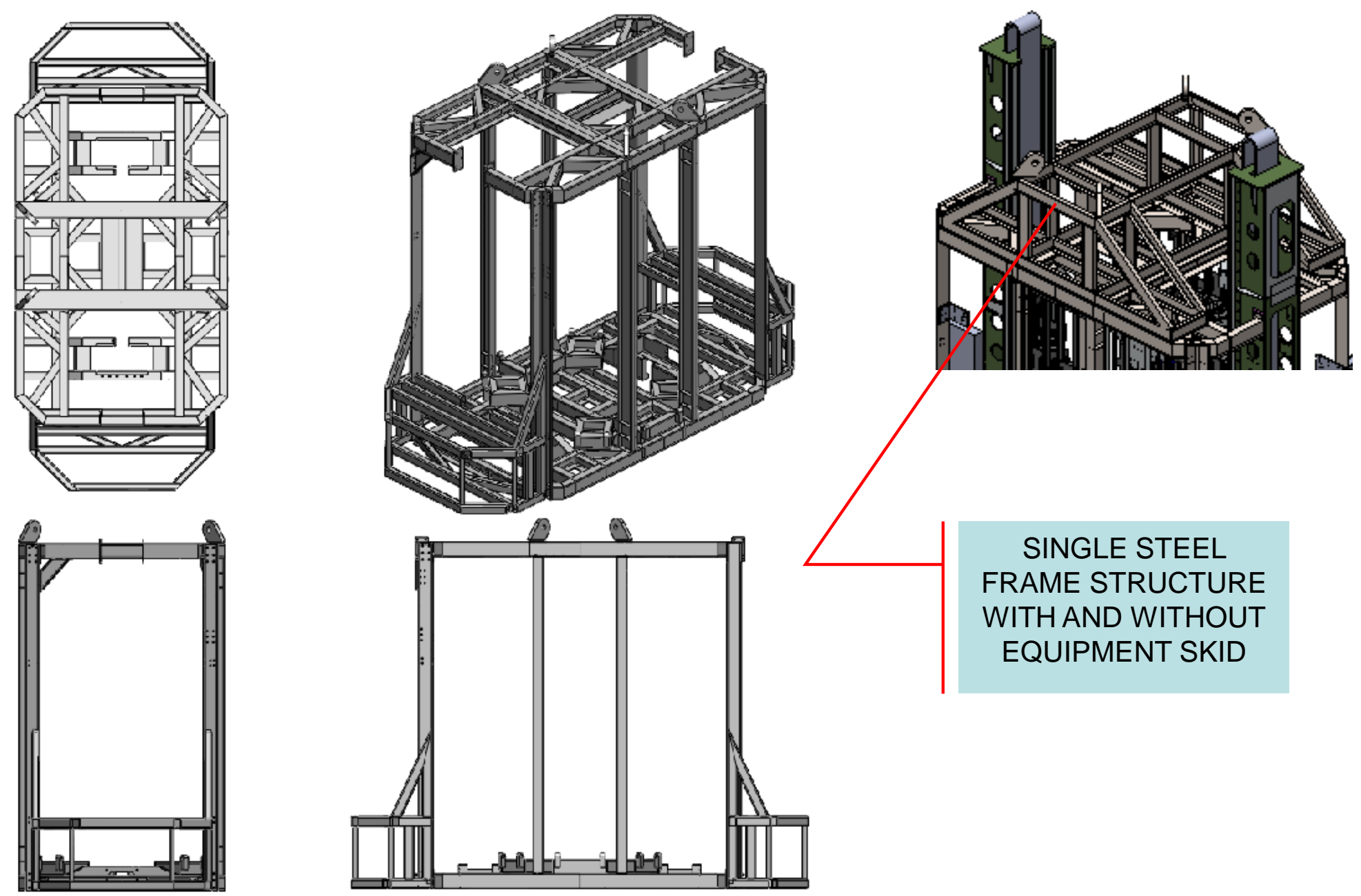

SINGLE STE

FRAME STRUCTURE VITH AND WITHOUT EQUIPMENT SKID 


\section{Conceptual Design 1}

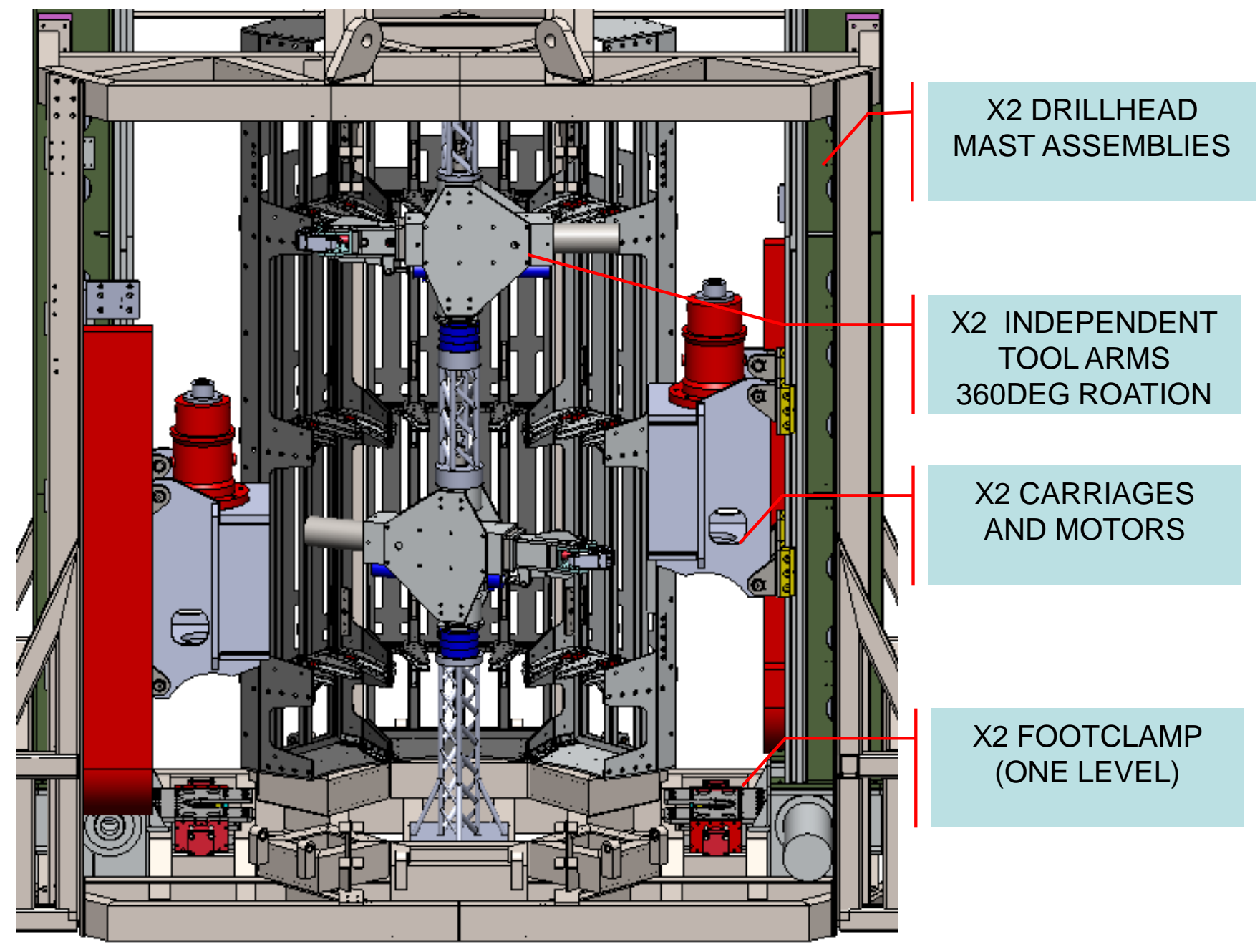




\section{Conceptual Design 1}
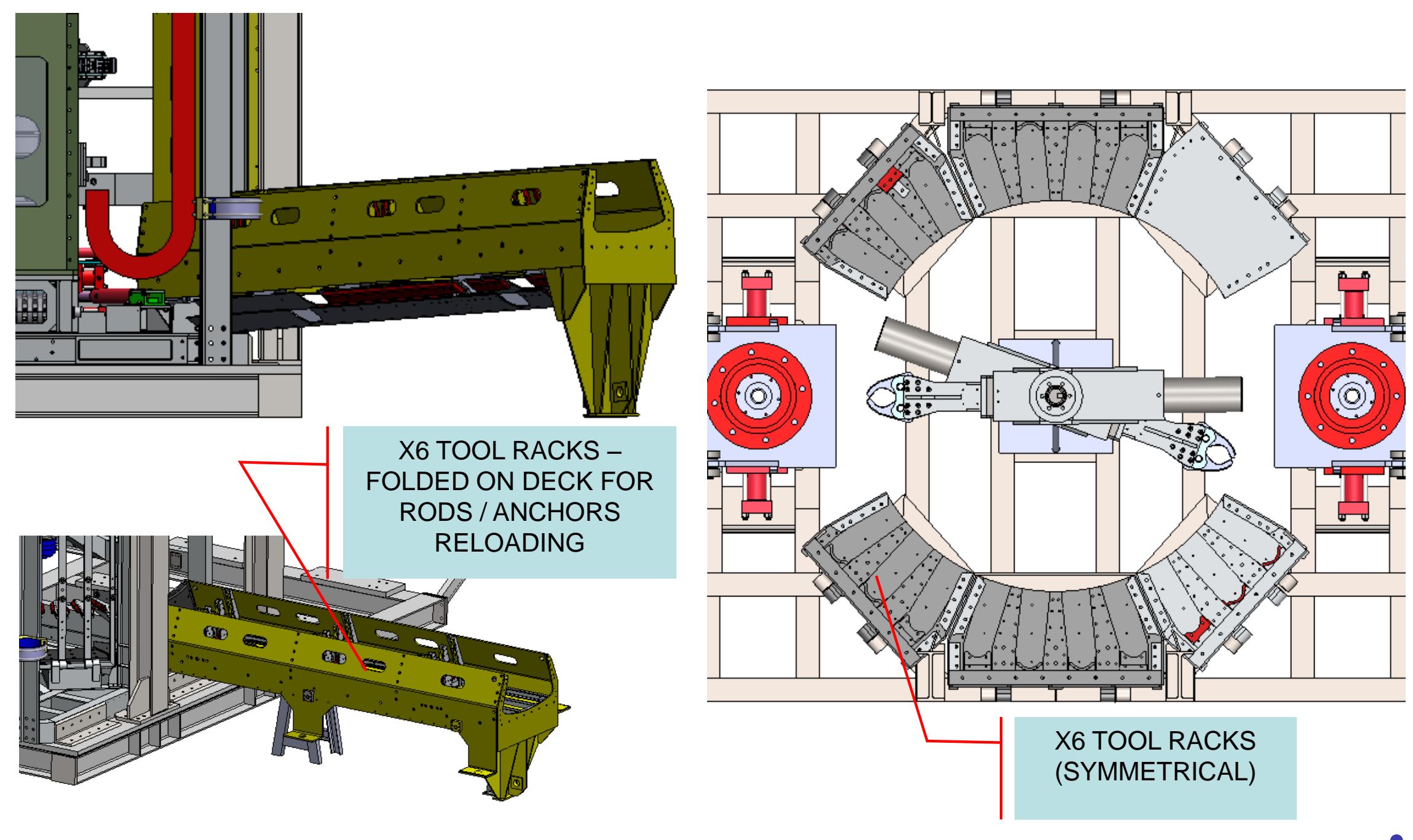


\section{Conceptual Design 1}
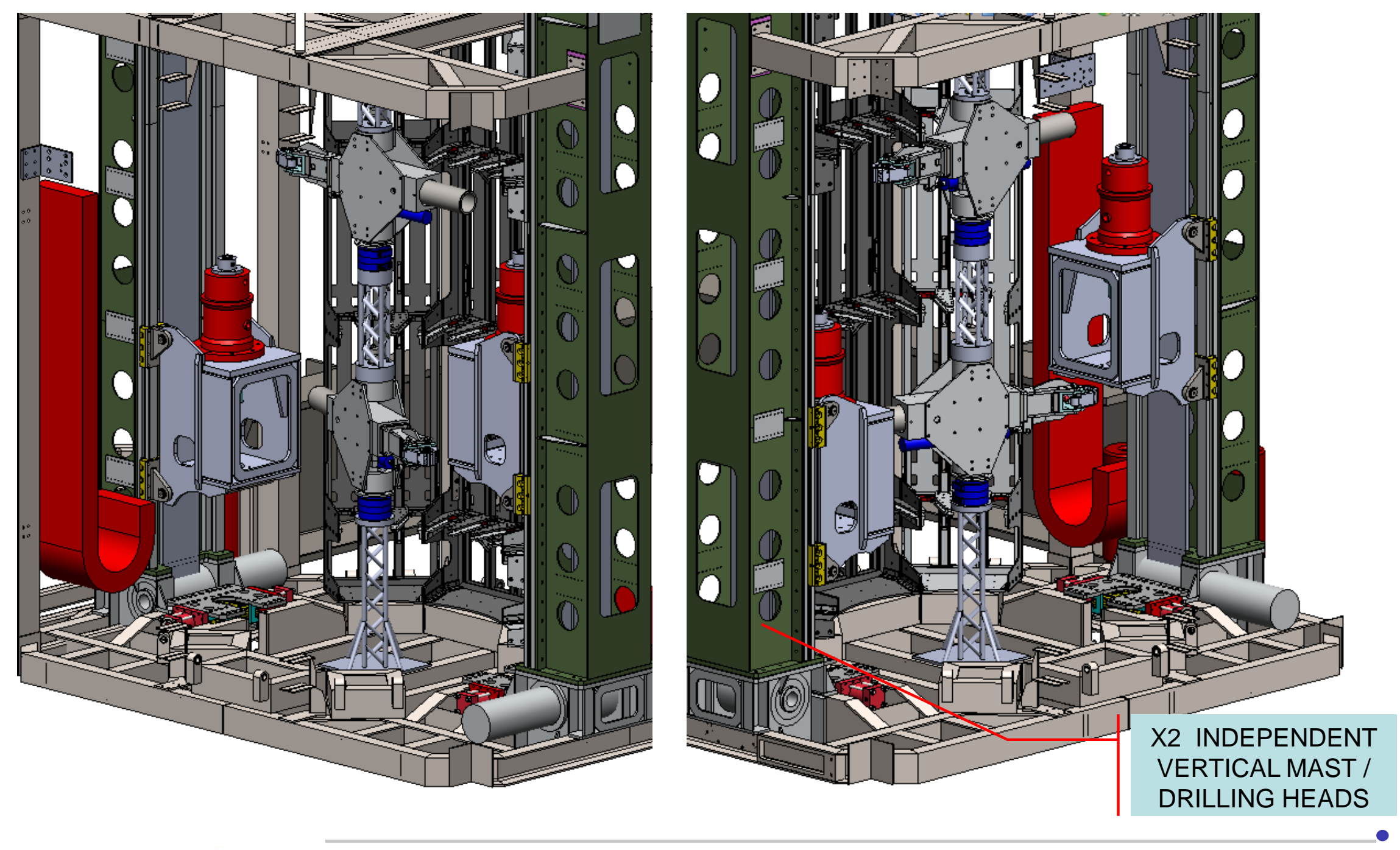


\section{Conceptual Design 1}

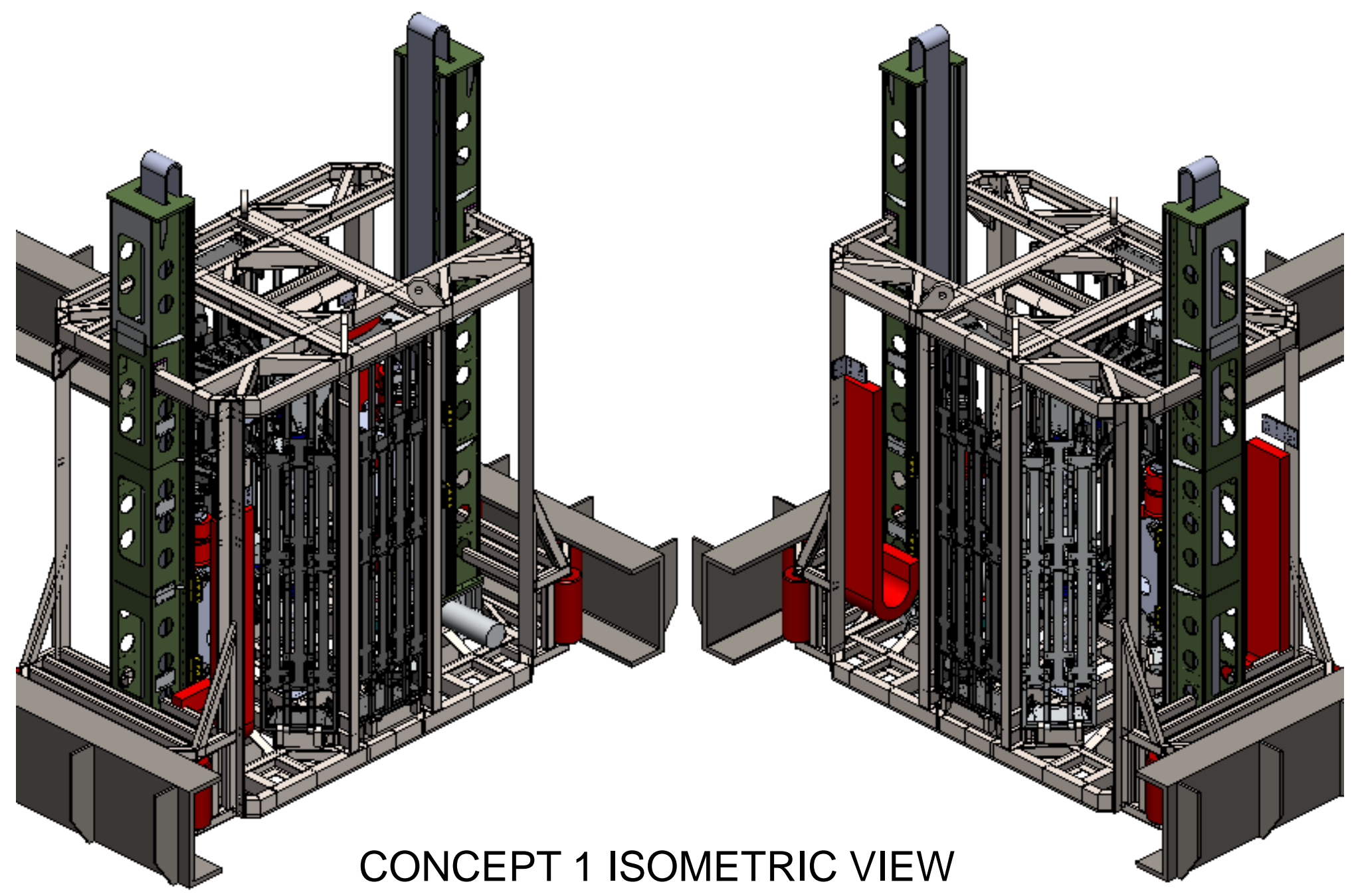




\section{Conceptual Design 2}

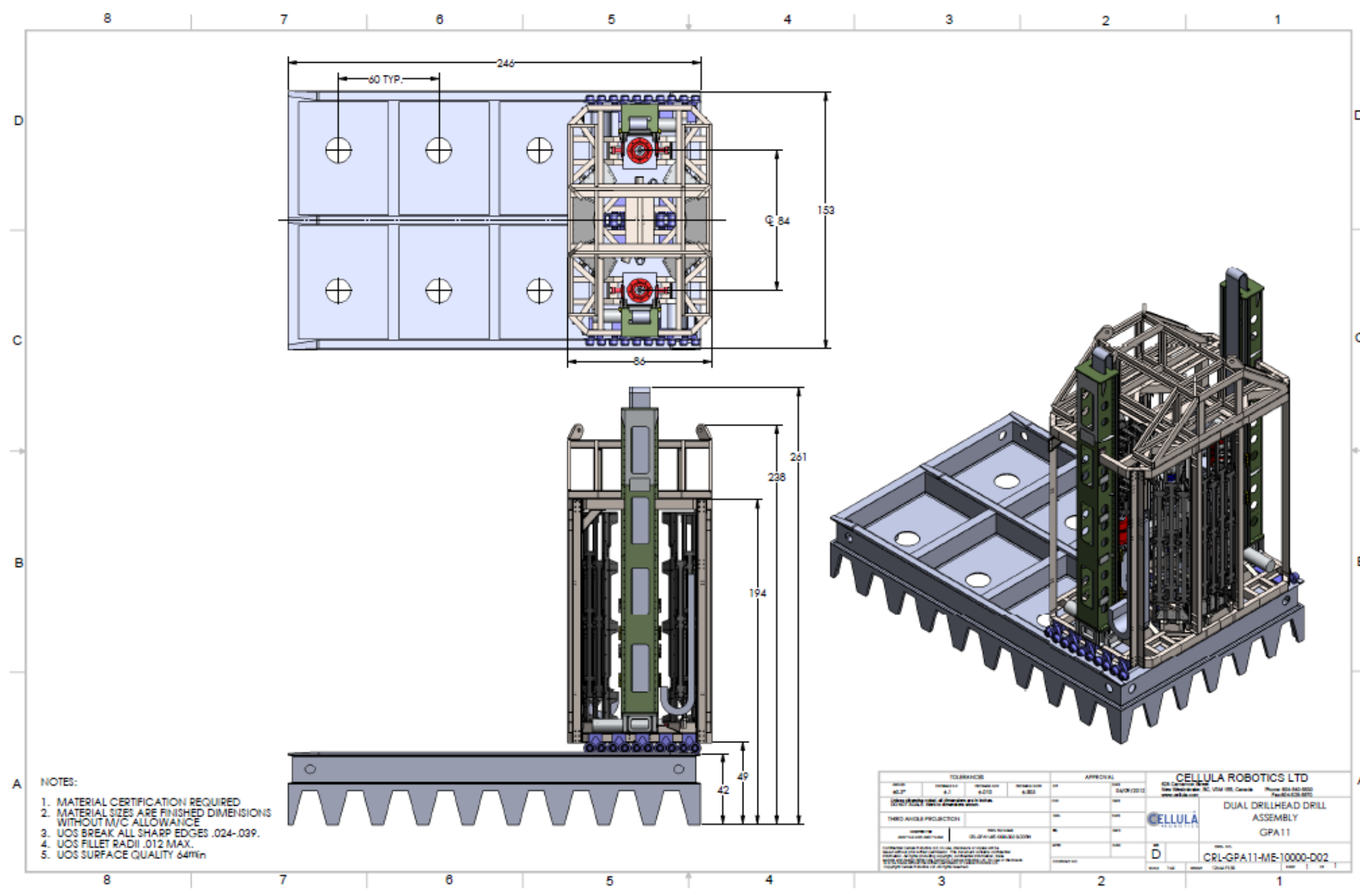

RECTANGULAR TEMPLATE 8 MICROPILES - CHAIN / SHACKLE NOT SHOWN 


\section{Conceptual Design 2}
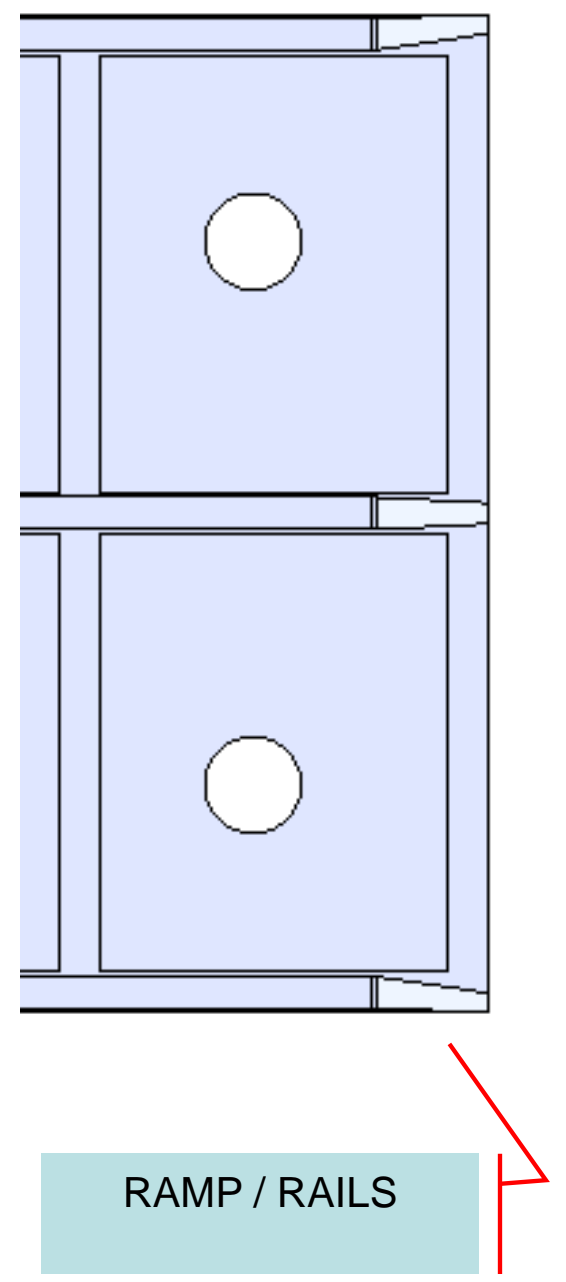
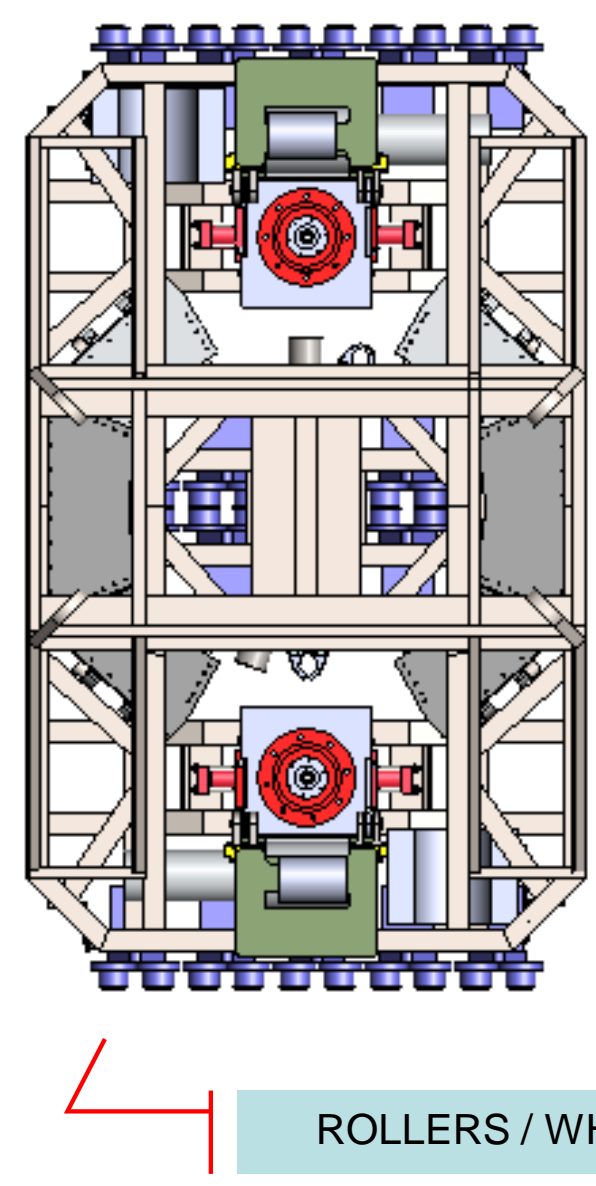

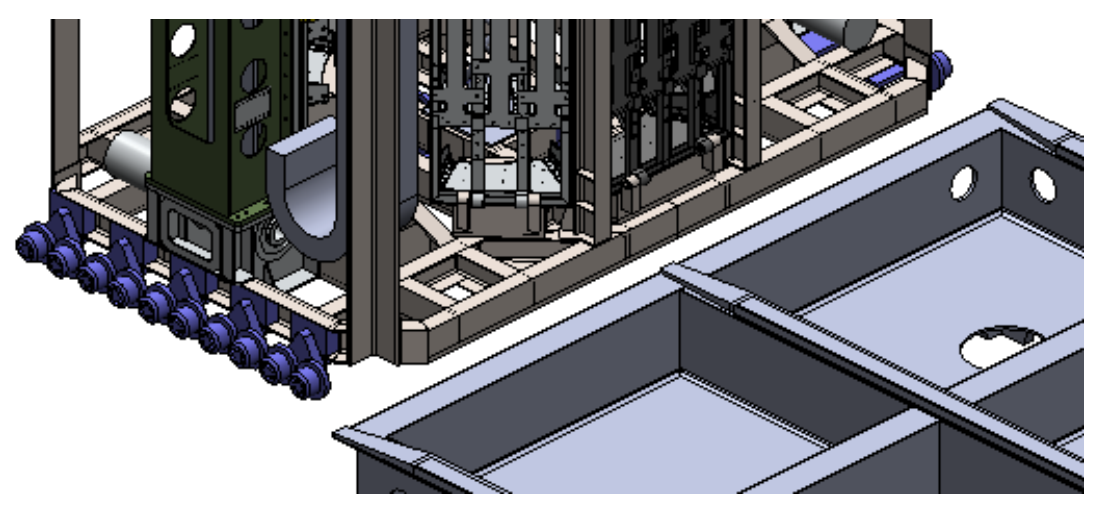

ROLLERS / WHEELS 


\section{Conceptual Design 2}
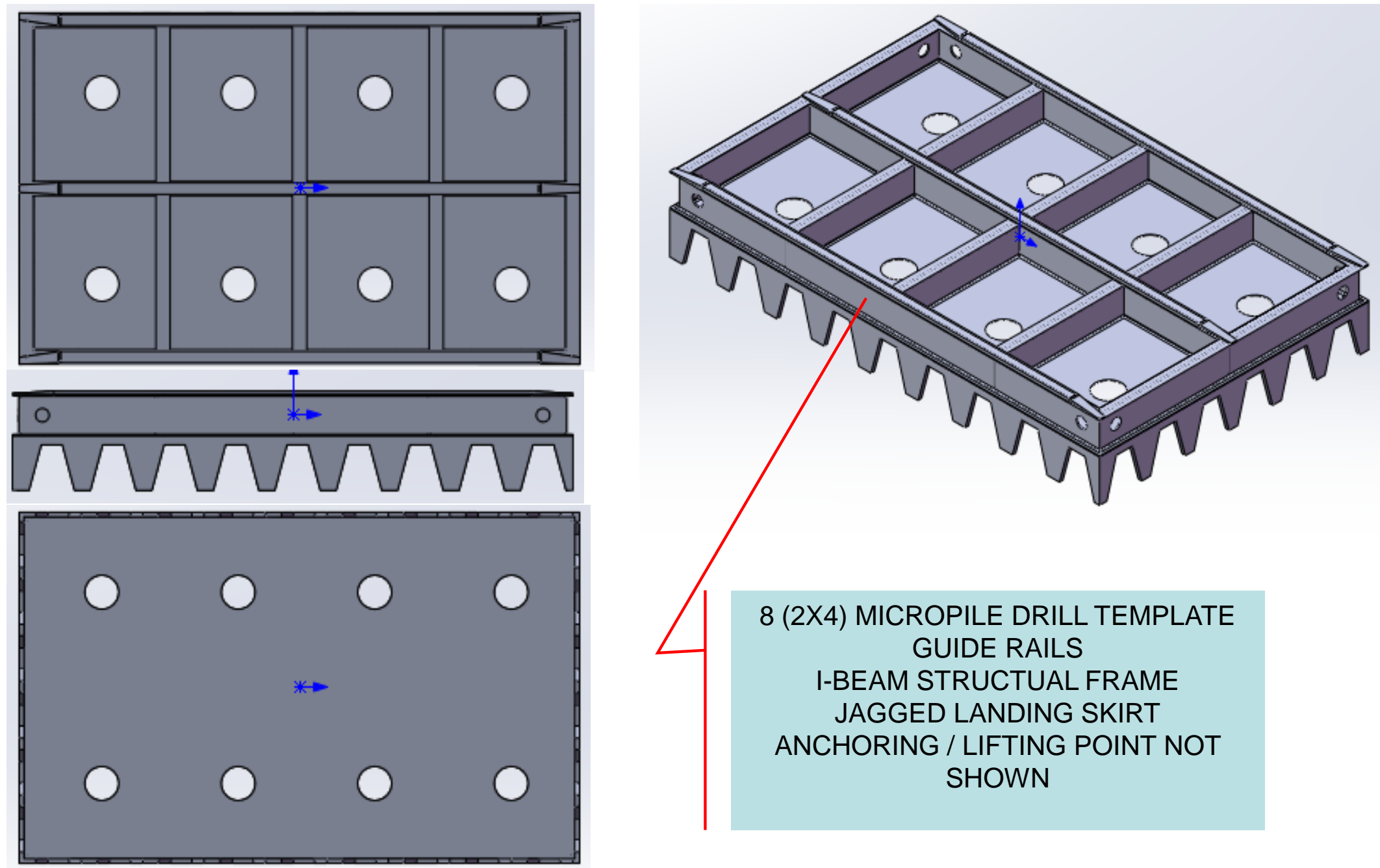


\section{Conceptual Design 3}

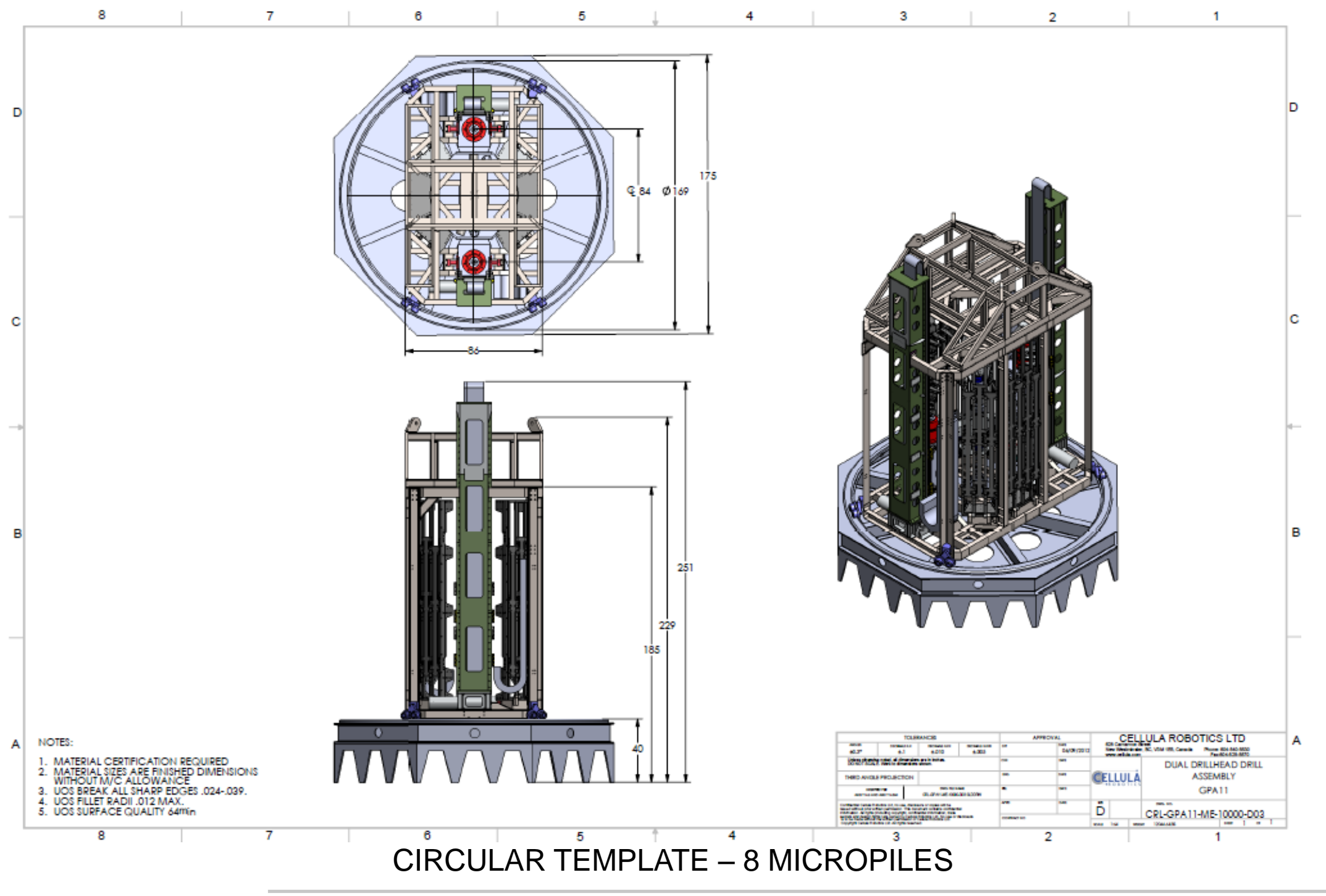




\section{Conceptual Design 3}
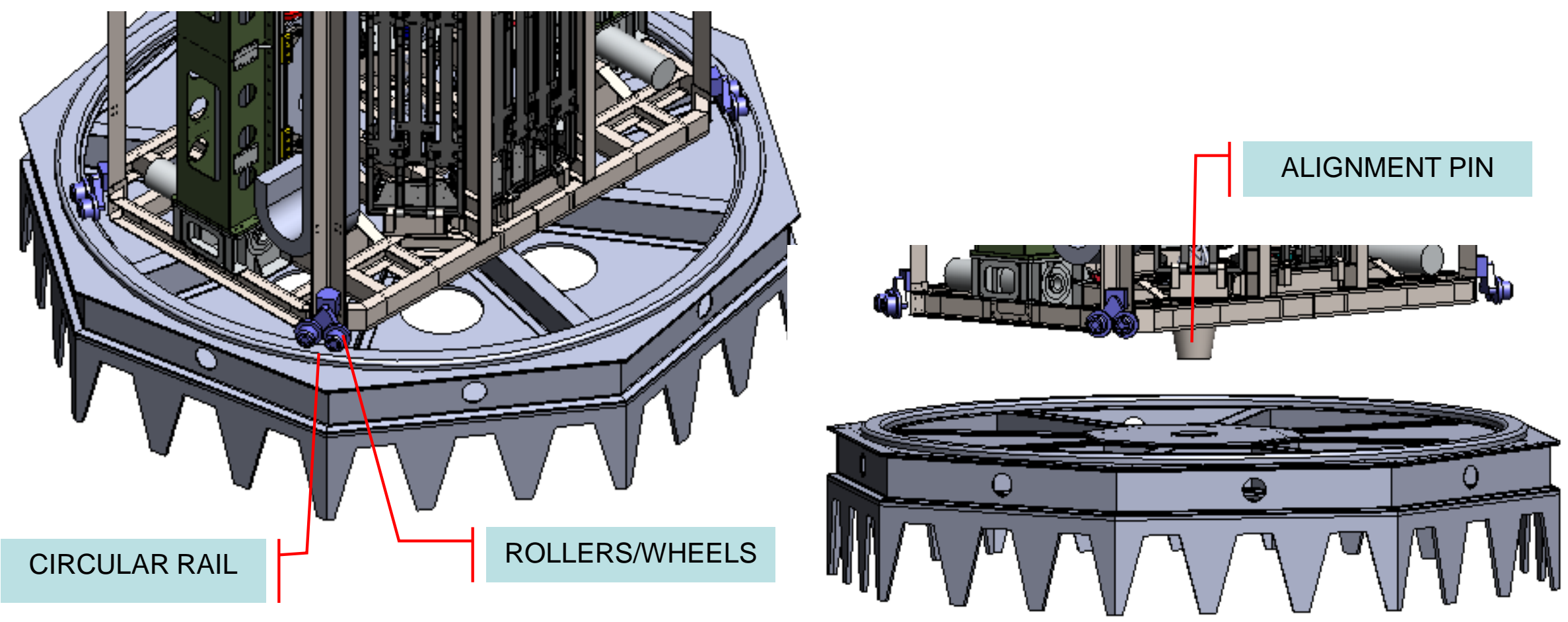


\section{Conceptual Design 3}
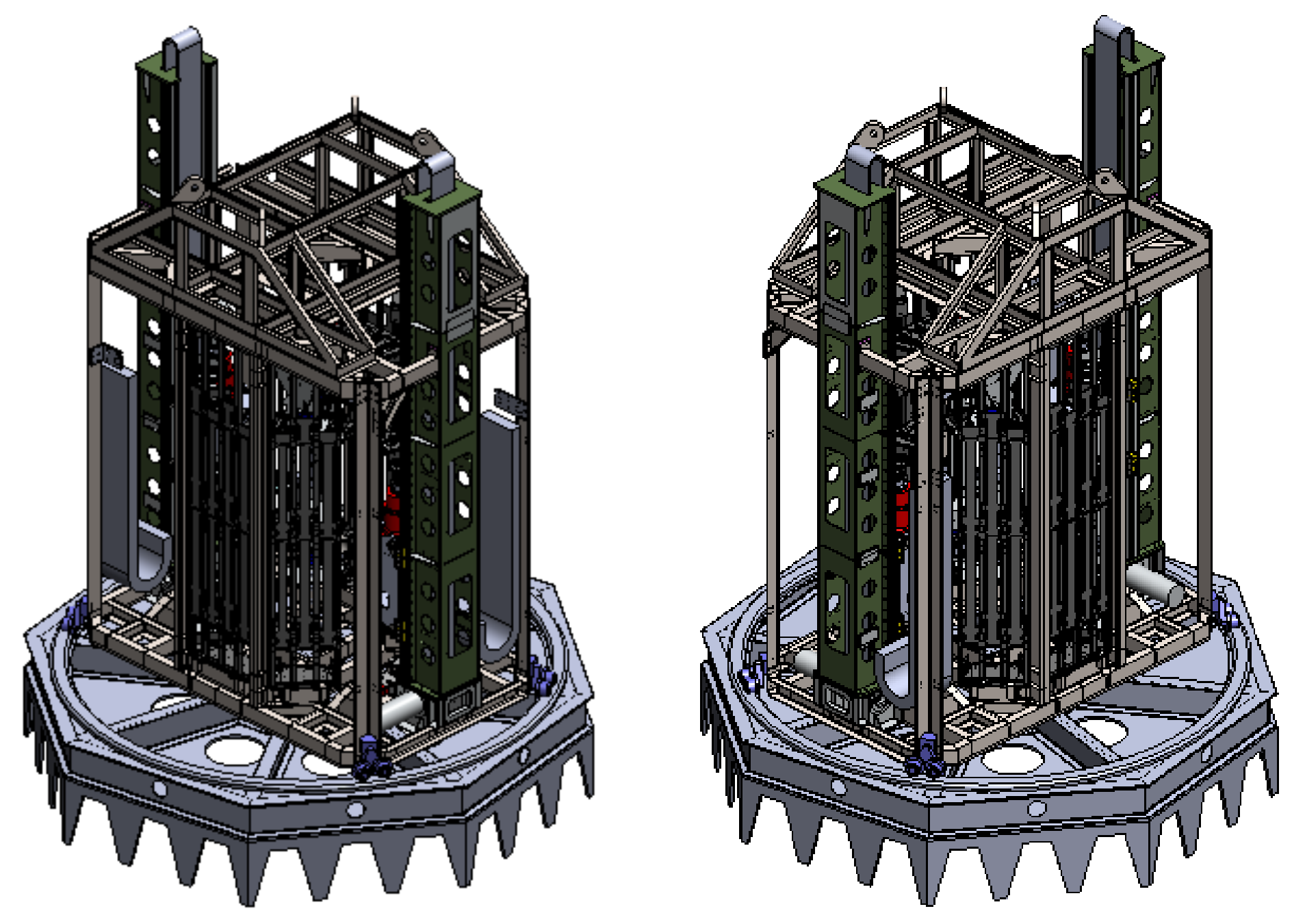


\section{Conceptual Design 3}
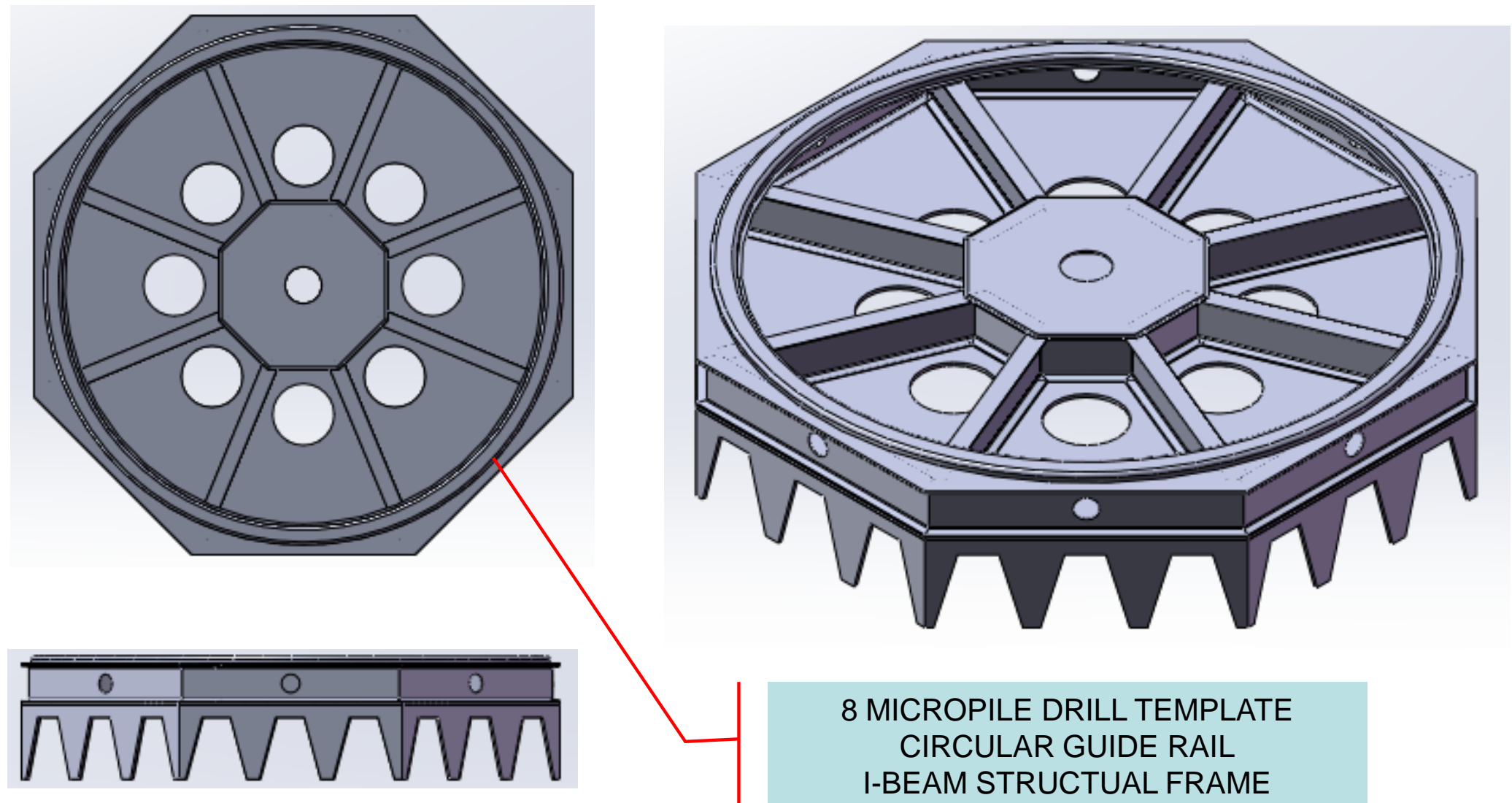

8 MICROPILE DRILL TEMPLATE CIRCULAR GUIDE RAIL I-BEAM STRUCTUAL FRAME JAGGED LANDING SKIRT SELF LEVELING MECHANISM 